Ineke Klinge and Claudia Wiesemann (Eds.)

\title{
Sex and Gender in Biomedicine
}

Theories, Methodologies, Results

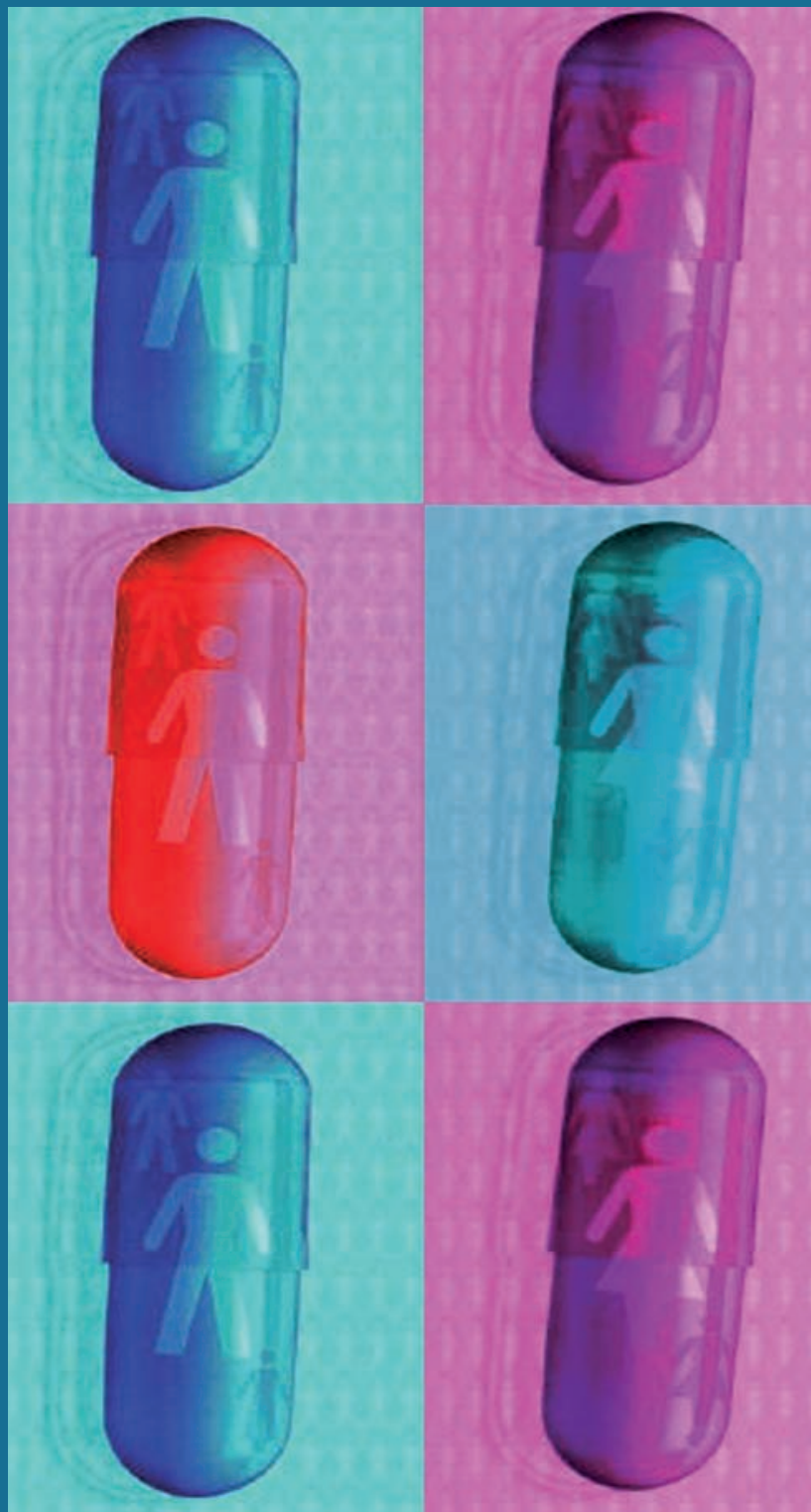

Universitätsverlag Göttingen 

Ineke Klinge and Claudia Wiesemann (Eds.)

Sex and Gender in Biomedicine

This work is licensed under the Creative Commons License 2.0 "by-nd", allowing you to download, distribute and print the document in a few copies for private or educational use, given that the document stays unchanged and the creator is mentioned.

You are not allowed to sell copies of the free version.

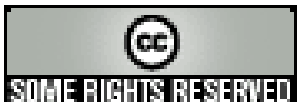


erschienen im Universitätsverlag Göttingen 2010 
Ineke Klinge and

Claudia Wiesemann (Eds.)

Sex and Gender in Biomedicine

Theories, Methodologies, Results

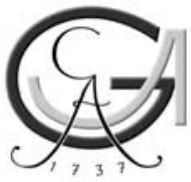

Universitätsverlag Göttingen 2010 


\section{Bibliographische Information der Deutschen Nationalbibliothek}

Die Deutsche Nationalbibliothek verzeichnet diese Publikation in der Deutschen Nationalbibliographie; detaillierte bibliographische Daten sind im Internet über $<$ http://dnb.ddb.de $>$ abrufbar.

\section{Address of the Editors}

Claudia Wiesemann

e-mail: cwiesem@gwdg.de

Ineke Klinge

e-mail: I.Klinge@hes.unimaas.nl

This work is protected by German Intellectual Property Right Law.

It is also available as an Open Access version through the publisher's homepage and the Online Catalogue of the State and University Library of Goettingen

(http://www.sub.uni-goettingen.de). Users of the free online version are invited to read, download and distribute it. Users may also print a small number for educational or private use. However they may not sell print versions of the online book.

Satz und Layout: Solveig Hansen

Umschlaggestaltung: Jutta Pabst

Titelabbildung: Arne Hansen

(C) 2010 Universitätsverlag Göttingen

http:/ / univerlag.uni-goettingen.de

ISBN: 978-3-941875-26-5 


\section{Table of contents}

Preface

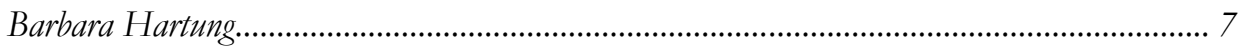

Preface

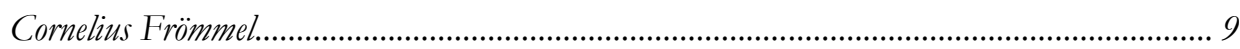

Editorial

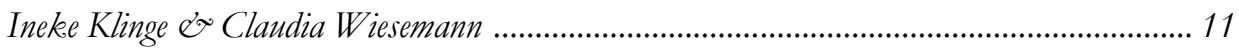

Sex and gender in biomedicine: promises for women and men

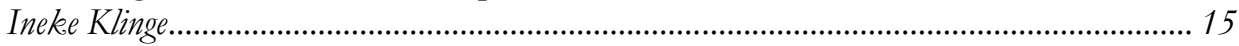

Gender issues in living organ donation: medical, social, and ethical aspects Silke Schicktanz, Mark Schweda \& Sabine Wöhlke.....

Sex, gender, and the brain - biological determinism versus socio-cultural constructivism

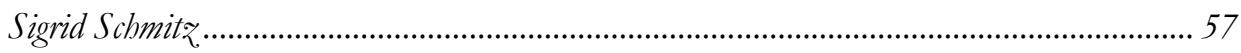

The brain between sex and gender - women and men from a neuroscientific perspective

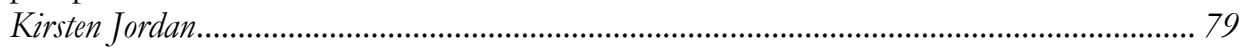

Sex and gender in addiction research and therapy

Verena Metz \& Gabriele Fischer.

Contributors 



\section{Preface}

Dr. Barbara Hartung

Ministry of Sciences and Culture

Lower Saxony, Germany

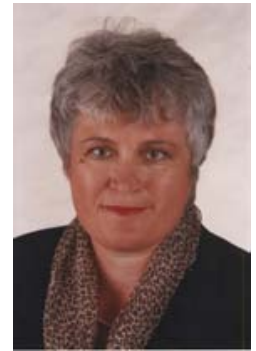

The German federal state of Lower Saxony has for a long time been supporting efforts to integrate gender into academic research. Following the recommendations of Reports from Research on Women: outlook for Sciences, Technology, and Medicine (1997), a Lower Saxonian research network for women and gender research was established and funded with the total sum of 7.5 Mio. DM over a time period of five years. In the year 2001, the Maria-Goeppert-Mayer-Programme for International Women and Gender Research was started: about 400,000 $€$ are provided annually to award visiting professorships or lectureships to high-ranking foreign scientists, but also to junior scientists. The target of the programme is to integrate the most recent findings of international research projects into research and teaching in Lower Saxony, Germany. So far, 113 professorships and 30 lectureships were awarded, half of which were assigned to foreign scientists. In 2008/2009, Dr. Ineke Klinge, Maastricht University, held a Maria-Goeppert-Mayer visiting professorship in Sex and Gender in Biomedicine at Göttingen University, Germany. I appreciate the fact that results and contributions of an accompanying lecture series organised by Prof. Claudia Wiesemann, Prof. Silke Schicktanz and Dr. Inken Köhler from Göttingen University Medicine within the frame of this professorship have been gathered in the volume at hand and thus made available to a broader public. This is an important contribution to support and promote further discussions on the integration of gender aspects in biomedicine. 



\section{Preface}

Prof. Dr. Cornelius Frömmel

Dean of Medical Faculty

University Medicine Göttingen, Germany

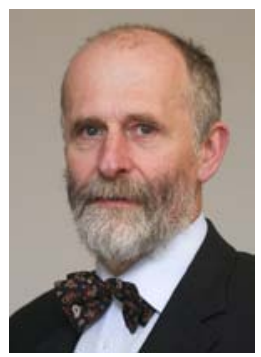

Gender Medicine is a relatively new term for a scientific domain that strives for integration of sex and gender aspects as recognised determinants of health and disease in biomedical research and clinical practice. To further advance this innovative field, the University Medicine Göttingen, together with the Ministry of Sciences and Culture of Lower Saxony, Germany, established a Maria-GoeppertMayer Guest Professorship in 2008/2009 entitled Sex and Gender in Biomedicine. This initiative was realised with the help of Prof. Claudia Wiesemann, Department of Ethics and History of Medicine, University Medicine Göttingen. We were honoured to host Dr. Ineke Klinge, Maastricht University, a renowned European expert in the field. Additionally, in 2008/2009 the UMG held a series of lectures on Gender Medicine, in which knowledgeable gender experts from different disciplines shared their latest research results. This introduction of gender medicine has been positively evaluated by researchers, clinicians and students and has thus provided a sound basis for further development. In doing so, the UMG joins other initiatives facilitated by the European Commission as well as universities in Germany, the Netherlands and Austria. The University Medicine Göttingen has committed itself to an embedding and furthering of these aspects in research, education and treatment. We thereby support European research policy making gender equality a criterion of scientific excellence. We are convinced that, in the future, this innovative research domain will appeal to a growing number of researchers and students and will result in a better health care for women and men. 



\title{
Editorial
}

\author{
Ineke Klinge \& Claudia Wiesemann
}

Gender Medicine has become a remarkable feature of international medical research, be it in publication or journal titles, lecture series or newly founded academic chairs as recently in Vienna. The growing use of the term Gender Medicine highlights that a scientific domain has evolved striving to integrate sex and gender aspects in biomedical research, clinical practice and public health. In Gender Medicine the recognition of sex and gender aspects moves beyond the political and social dimensions that drove feminism and gender mainstreaming but recognises that sex and gender are strong determinants of health, illness and disease, of diagnosis, therapy and salutogenesis. After years of pioneering by individual groups and university departments with a special interest in studying and addressing sex and gender issues in health and disease, we are now witnessing an ever stronger support by institutional bodies, research organisations and funding bodies as for example the European Commission.

In Germany, the Ministry of Science and Culture of Lower Saxony has made an important contribution to this development. Since 2001 they have been funding international guest professorships in their Maria-Goeppert-Mayer Programme for gender research. Within this programme, Claudia Wiesemann, Silke Schicktanz and Inken Köhler from Göttingen University Medicine were successful to attract a guest professorship on Gender Medicine for their university. This initiative was supported by the Dean of Faculty, Cornelius Frömmel, and co-financed by the Göttingen Medical School. 
During winter semester 2008/2009 Ineke Klinge from Maastricht University, The Netherlands, held this professorship at the Medical Faculty of the University of Göttingen titled Sex and Gender in Biomedicine. She taught the seminar Women, Men and Medicine. How it Matters to be a Man or Woman in Medicine for medical students and an interdisciplinary seminar Gender, Diversity and Images of Men and Women in Health Care Practices. Next to clinical lectures she initiated a practical workshop Scientific Excellence and 'Sexy Research'. A workshop on Sex and Gender in Biomedicine for students in Molecular Medicine and developed research contacts with various departments at Göttingen University Medicine. Her inaugural lecture is published in this book.

On the occasion of this guest professorship a series of lectures was organised in which knowledgeable experts shared the latest developments regarding sex and gender issues in their fields of expertise. In this book, we have collected some of the contributions to exemplify concepts, approaches, methods and results in the field.

In the first chapter, biomedical scientist and gender expert Ineke Klinge introduces the field of Gender Medicine. She starts off with an overview of critical reviews of traditional biomedicine made by the women-and-health movement, feminist biologists and gender scholars that led up to an innovative perspective that is now known as Gender Medicine. She next addresses the European Union policy for gender equality in research as a driving force for this new specialty and its accomplishments. Examples of newly gained insights in diseases like asthma, osteoporosis and depression are given. The author shows how this innovative approach can be fruitfully applied to all medical specialties. This is demonstrated by the fact that Gender Medicine today is firmly established in societies, institutes, journals and networks. In the long run this will lead to better knowledge on the gendered body and better health outcomes for women and men.

Bioethicists Silke Schicktanz, Sabine Woeblke, and Mark Schweda apply a methodology of sex and gender research to the field of organ transplantation. They examine the at first view appalling fact that women more often donate organs whereas men more often receive them. Their findings illustrate how fruitful it is to combine biological, epidemiological, ethical and cultural approaches to analyse the clinical outcome of this rapidly evolving and hotly disputed medical field. Drawing upon extensive quantitative and qualitative findings they arrive at an in-depth explanation of sex imbalances in organ donation. They also offer insights on the impact of gender roles in organ transplantation relevant for medical practices as well as for the bioethical discourse.

The emerging field of neuroscience offers another instructive example of how the gendered body can be addressed. Two papers by biologist Sigrid Schmitz and neuropsychologist Kirsten Jordan scrutinise recent neuroscientific findings from a gendered perspective and show how a gendered methodology not only helps avoid the pitfalls of sex and gender stereotypes but also leads to cutting-edge research results. 
Sigrid Schmitz, addresses sex, gender and brain research first from a methodological perspective using the tools described by Evelyn Fox Keller. The differing approaches of biological determinism and socio-cultural constructivism are elaborated in order to develop a more complex view on brain-behaviour interrelations against a gendered background. In particular, she scrutinises underlying concepts such as the 'laterality hypothesis'. In her recommendation for future research she refers to the developmental systems approach as adopted by Anne Fausto-Sterling for studying sex and gender interaction. Kirsten Jordan reviews the field of contemporary brain research. She discusses fetal and neonatal developments, anatomy and function of brain areas as measured with MRI techniques and the relative role of hormones, experience and environment in spatial and language skills in women and men. Most interestingly, the recall of stereotypes had a significant effect on the outcome of cognitive tests in the sexes.

Sound meta-analyses of current findings from a gendered perspective still are a major requirement in a multitude of clinical fields. This is exemplified by psychiatrist Gabriele Fischer and clinical psychologist Verena Metz with regard to addiction research. They describe the state of the art regarding the influence of sex and gender in addiction. They review research on legal and illegal substance addiction, and research on non-substance addiction, including recent addictions like gambling and internet, pinpointing to many neglected aspects with regard to sex and gender.

These examples from different biomedical fields demonstrate how innovative research and high-quality clinical practice can be achieved when sex and gender aspects are incorporated into biomedicine. A high level of critical deliberation and methodological scrutiny is necessary to escape the dangers of sex and gender stereotypes still present in so many recent debates.

This volume is the result of a fruitful and friendly cooperation of a number of persons. The editors Ineke Klinge and Claudia Wiesemann thank Silke Schicktanz and Inken Köhler for their encouraging support when implementing Gender Medicine at Göttingen University. Solveig Hansen good-humouredly and tirelessly assisted the editors in preparing the volume for publication. Alexander Weiss gave significant support in editing and formatting. Daniela Dreykluft served as an English proof-reader and helped translate some of the texts. We are also grateful for the generous financial support by the Ministry of Science and Culture of Lower Saxony, Germany, and the Göttingen University Medicine, Germany, that enabled us to do all this right from the start.

Göttingen, Germany, and Maastricht, The Netherlands

Autumn 2009

Ineke Klinge and Claudia Wiesemann 



\section{Sex and gender in biomedicine: promises for women and men. How incorporation of sex and gender in research will lead to a better health care}

Ineke Klinge

\section{Abstract}

In this paper I introduce the field of Gender Medicine: what does it represent, what are current activities and which outlook for the future does it offer? First a short historical overview will be given on how Gender Medicine came into being as a new research domain. Second comes the discipline of Gender Medicine today: what are current features and characteristics? In a third part I will highlight the EU gender equality policy for research as a driving force for Gender Medicine. Finally some examples of sex and gender sensitive knowledge and innovative research avenues are presented as gathered in successive EU projects that I was involved in.

\section{How Gender Medicine came into being as a new field of research and as biomedical discipline}

Gender studies involvement with life sciences and biomedical research has a longstanding tradition. The innovation of 'traditional' biomedicine started with the women's health movement and the feminist critique of science in the 1980s. 
Involvement with life sciences and biomedical research is visible in publications as early as 'Alice through the Microscope' by the Brighton Women and Science group in 1980 which focused on science and women's lives (1).

In that book a patriarchal science was unveiled that neglected or stereotyped women's bodies, health and lives. Soon after, pioneering feminist biologists like Lynda Birke and Anne Fausto-Sterling started academic critiques of biomedicine, addressing biology and medicine in the first place $(2,3)$. The strategies they employed were directed towards the biomedical method itself. Both authors could demonstrate that the scientific method was not as objective as it was believed to be; instead, effects of gender were visible in the production of biomedical knowledge. The claim that processes of gender had an influence on the production of biomedical knowledge at the same time opened up possibilities for change. Much knowledge that was regarded by feminists as 'biology is destiny', turned out to be far from determinist. If the influence of gender on biomedical knowledge production was taken account of, many myths about women and women's roles could become dismantled. Although it is a biological fact that only women can give birth to a child, in no way this is a blueprint for who (mother or father) should be charged with caretaking during the consecutive years. Londa Schiebinger has twice produced an overview of the feminist involvement with science in her books Has Feminism changed Science? and Gendered Innovations in Science and Engineering $(4,5)$. She described what had been accomplished in various fields including biomedicine.

Developments in biomedicine have been two-fold: a first change in research practices was a methodological one. In the USA the Office of Women's Health Research (OWHR) at the NIH strived for a change of the standard practice by which women as objects of research were excluded. A joint effort of academic feminists, congressional leaders, medical doctors at the NIH and the women's movement, resulted in legislation and in guidelines on inclusion of women and minorities in clinical research from 1994 onwards (6). More epistemological critiques focused on effects of gender in the production of biomedical knowledge. Those scholars pointed to gaps in knowledge, for example knowledge on urine incontinence in women (7). The critique also pointed to the interpretation of observations and research data, whereby men and processes in the male body were seen as normal and women and processes in the female body as deviant or pathological. An example of this are the 'atypical' symptoms of cardiovascular disease in women in contrast to the 'typical' symptoms in men; or the 'stable' hormone levels in men and the 'changing' hormone levels in women making them unreliable for positions with high responsibilities.

Other gender effects are language issues and metaphors. Ethological research for example speaks about 'the lion and his harem'. "Metaphors are not innocent devices used to spice up texts. Analogies and metaphors [...] function to construct as well as describe - they have both a hypothesis-creating and a proof-making function" as Londa Schiebinger $(1999,149)$ has framed it. The focus on activities of 
males limits researchers' ability to 'see' what lies outside the logic of the metaphor. ${ }^{1}$ A fourth effect is the reproduction of gender roles visible in biomedical textbooks. This reproduction has been demonstrated by Emily Martin in the description of reproductive processes of sperm meeting the egg (8). The meeting of egg and sperm is told as a romance between the active courageous Rambo Sperm and the passive egg, waiting like the Sleeping Beauty to be kissed by the prince. Gendering the egg as passive and the sperm as active, places them within a deep matrix of cultural and historical meanings as pointed to by Evelyn Fox Keller (1996) (9).

Since the 1980s extensive efforts by gender scholars and women-and-health researchers at various places have been made to 'correct' the observed gaps and biases. Together these efforts share the aim of what today has been brought together under the name of Gender Medicine. Gender Medicine as an innovation of biomedical research focuses on sex, gender and health, and addresses women's and men's health issues in research and clinical practice. The aim of this new research field is to develop a sex and gender sensitive research practice which will lead to an adequate knowledge base for clinical treatment and informed health policies. It has developed into a vast research area, a field of acknowledged interest and relevance to a rising number of researchers, clinicians and policy makers.

Influential textbooks have appeared in English and German (10-15). Next to that specialised journals have been launched. The journal Gender Medicine states as its mission: to focus on the impact of sex and gender on normal human physiology and on pathophysiology and clinical features of disease. ${ }^{2}$ Societies have been established such as the Organization for the Study of Sex Differences (OSSD), and the International Society of Gender in Medicine (IGM).

And there are specialised centers like the Berlin Institute of Gender in Medicine (GiM) and the Center for Gender Medicine at the Karolinska Institute, Stockholm; these centers have developed substantial research programmes, provide grants and implement teaching modules (elective and/or compulsory courses).

Gender Medicine as an innovation of biomedical and health research has ethical and social implications. Increasing the quality and quantity of evidence that sex and gender have on health outcomes and health care will add to a better targeting of medical care at an individual level. Socially, to ensure gender equity, sex and gender need to be considered in health care policy $(16,17)$. Gender Medicine is also about justice, about abolishing health inequities and about fostering the quality

\footnotetext{
${ }^{1}$ Schiebinger $(1999,152)$ further states that "Historical examples show how gender can become a silent organiser of scientific theories and practices, setting priorities and determining outcomes."

2 "Gender Medicine welcomes original reports from the entire spectrum of academic disciplines devoted to the study of the human condition as it relates to both biological sex and the socio-cultural concept of gender. The journal serves an international multidisciplinary audience in a mixture of academic and clinical practice settings. Therefore, the journal encourages scholars in disciplines such as anthropology, sociology, psychology, and other allied sciences to consider contributions to the journal”. (Aims and Scope of the Journal, www.GenderMedJournal.com)
} 
of research. The issue of justice can be illustrated by Article one of the Constitution of the Kingdom of the Netherlands which says: all people in the Netherlands should be treated equally in equal cases. Discrimination based on religion, political view, race, sex, or sexual orientation is not allowed. In other words, making a difference is not allowed. Intriguingly the non-discriminatory proposition put forward by Gender Medicine is: to treat persons equally in health care often comes down to making a difference!

\section{Gender Medicine today: current features and characteristics}

The most concise conclusion of the recent wealth of research into sex and gender in relation to health and disease is that it signals the end of the 'one size fits all era' in which the 'male norm' in biomedicine was not even questioned. Sex and the newly introduced concept of gender have now been recognised as determinants of health and disease (18-22). For a good understanding of the impact of both sex and gender it is necessary to introduce the conceptual distinction between the two (23-26).

Sex refers to biological differences between men and women such as chromosomes (XX or $\mathrm{XY}$ ), internal and external sex organs (ovaries, testes) and hormonal profiles (of estrogens and androgens). Biological sex differences are often viewed as dichotomous, either male or female, although biological variability is substantial (27).

Gender refers to the socially constructed roles and relations, personality traits, attitudes and behaviours and values that are ascribed to the two sexes in a differential manner. While sex is a biological fact that is the same in all cultures, the meaning of sex in terms of gender roles can be quite different across cultures. To illustrate this Susan Phillips uses the example of menopause: all women in the world will at a certain moment in time stop menstruating. The value attached to menopause and post-menopause, however, shows a large cross-cultural variation (28). The WHO further elaborates gender roles: they determine differences in opportunities and resources available to women and men and differences in their abilities to make decisions and exercise their human rights including those related to protecting health and seeking care in case of ill health.

As gender processes are at work on several levels, each with implications for health and disease, the following examples serve to illustrate the health impacts on the respective levels.

Gender effects at the individual level: male and female gender roles can influence health behaviours and as a consequence individual health. It is well known that men delay the seeking of help from a general practitioner because the stereotypical male gender role prescribes to be strong, not to show weakness and to 'tough it out' $(29,30)$. The presentation of health complaints by women may reflect their socialisation as females, and communication patterns between doctors 
and patients are influenced by gender stereotypes $(31,32)$. Gender role behaviour plays a role in compliance with a treatment (see the example of teenagers living with asthma and diabetes later on) and in risk perception, where men and women express different levels of concern about the same risks and attribute a different meaning to those risks. Obviously this applies to men's and women's perception and fear of disease (33).

An example of gender effects at the institutional level is the obstruction of women's access to higher education by influential medical professors in the first decades of the $20^{\text {th }}$ century who claimed that a woman should not spend her energy in intellectual labor but in producing babies (34). For a long time the labour division between men and women was characterised by the male breadwinner working outside the home and a housewife charged with care-taking duties inside the home. Of course a lot has changed since the 1950s but still today all statistics show that even when both partners have full time jobs, the majority of household work and care-taking is done by women. And finally: job segregation along the lines of sex can lead to differential exposure rates $\mathrm{f} / \mathrm{m}$ to different occupational hazards like toxic chemicals, different ergonomic demands, a different risk of accidents and different psychosocial stressors (35).

A third level of gender is the symbolic level: Metaphors used in biomedical textbooks have been demonstrated to reflect stereotypical gender images. I already mentioned how the romantic love between the active sperm and the passive egg has been criticised. To portray female biological processes like menstruation as 'failed production' and menopause as 'the breakdown of nervous control' has serious implications for how women experience these processes (8).

The scope of the impact of sex and gender can be illustrated by two more elaborated examples. The first is taken from a study by Williams and is meant to outline the impact of gender roles at an individual level (36). The example is about teenagers living with asthma or diabetes. It is an interesting example because much research linking health disadvantages with gender has focused on women, and has neglected the way how social constructions of masculinity affect individual health of men. The study found that the majority of teenage girls incorporated asthma or diabetes and the associated treatment regimens of injecting insulin or using inhalations into their social and personal identities. They talked about it with their friends and did not hesitate to inject themselves in the classroom. In doing so they showed a greater adaptability to living with asthma and diabetes compared to boys. Boys made every effort to keep both conditions outside their personal and social identities by passing. ${ }^{3}$ Signs of illness were seen by them as potentially stigmatizing. They played down the severity of the disease and skipped part of the treatment if that

\footnotetext{
${ }^{3}$ Passing refers to an individual assuming a new identity in order to escape the negative aspects of one identity and to access the privileges and status of another.
} 
fitted their school schedule better. It urged them to work hard to pass in public settings wherever possible, using specific strategies such as some extra running to get glucose levels down. It is obvious that such strategies are potentially harmful to their personal health.

And finally there is the groundbreaking example on sex, gender and coronary beart disease. In the 1990s, we saw a rising awareness about the relevance of sex differences and gender effects. It was the decade of the acknowledgement of sex differences beyond reproduction. Coronary heart disease (CHD) has become the first and most famous example where sex and gender aspects in research and treatment have been studied extensively. The example has become widely known and has led to considerable changes in treatment guidelines and postdoctoral education of medical doctors, for example in Germany and The Netherlands. In 1960 the American Heart Association could still organise a conference about women and heart disease under the title: "How can I help my husband to cope with cardiovascular disease" (37). The idea that women themselves were at risk for coronary heart disease was not at all an issue. Today we know that coronary heart disease is also the major killer in women. Extensive studies have produced data on sex differences in underlying biological processes and symptoms. The 2008 edition of Gender Medizin (11) lists 71 clinically relevant differences relating to heart disease covering the whole spectrum from epidemiology, diagnosis, treatment, and clinical symptoms.

That CHD was underdiagnosed in women by the medical profession was due to the gendered image of the disease: CHD was seen as a 'male' disease, a disease of stressed middle aged managers. The phenomenon that a disease is missed in the opposite sex because of the image as a 'male' or 'female' disease is called the 'Yentl syndrome' after a film from 1983. It means that a woman has to masquerade as a man in order to get the same medical attention (38).

Gender also plays a role in the way how symptoms are presented. Research has described a masculine communication style: that is a business-like presentation of complaints, focused on a solution. A feminine communication style is characterized by a presentation embedded in social and contextual aspects. A (male) doctor could easily miss a CHD diagnosis and instead prescribe tranquillizers to a middleaged woman.

Sex differences turned out to have a major impact on drug development of cholesterol lowering drugs (statines) and on preventive treatment with aspirin. For example, the American Heart Association recommended aspirin therapy to high risk adults in order to reduce the incidence of coronary heart disease, based on a number of trials in which only $20 \%$ of the subjects studied were women. However, recent sex-specific meta-analyses showed that aspirin therapy reduces the risk of a myocardial infarction in men only, whereas the risk of an ischemic stroke is lowered only in women (39). The recommendation should therefore only have applied to men and in fact was harmful to women, because the use of aspirin increases the risk of bleeding events. 
Regarding sex and gender we should keep in mind two things: first that the distinction between sex and gender is a conceptual one, necessary to avoid confusion in biomedical and health research. In actual life there is a continuous interaction between the two. And secondly that gender roles are not fixed, they change with time and culture.

So far the focus has been on innovations in biomedicine in terms of attention to sex and gender, yet another important insight relevant for biomedical and public health research is the interaction between sex, gender and other dimensions of difference like age, ethnicity, socio-economic status, sexual orientation (40). The WHO has formulated this as follows: gender roles and unequal gender relations interact with other social or economic variables (age, ethnicity, socio-economic status, sexual orientation) resulting in different and sometimes inequitable patters of exposure to health risk, and in different access to and utilisation of health information care and services. A first attempt to address diversity in clinical research has been made in The Netherlands by Wieringa and colleagues (41).

\section{EU gender equality policy for research}

Although the case of coronary heart disease has been an important milestone, the awareness of it seemed mostly located in fields like gender studies in medicine, which developed at ever more universities. Attention to sex and gender aspects did not seem part of mainstream biomedical research yet.

The year 2000 offered an opportunity to raise the awareness of the relevance of sex and gender issues in mainstream research. In that year the Gender Impact Assessment Studies were launched by the European Commission. The policy framework behind these studies was the EU gender equality policy, a policy enshrined in successive treaties of Amsterdam and Maastricht. Aim of these studies was the evaluation of the gender dimension in the development, management, and implementation of the Framework Programmes (FP).

The studies, which were executed by seven research teams, investigated the participation of women in research and analysed whether the research themes, methods, and issues prioritised in FP5 affect women and men differently. Conclusions and recommendations were intended for the preparation and implementation of the next Framework Programme, FP6.

We conducted the Gender Impact Assessment study of the Quality of Life and Management of Living Resources Programme that addressed the broad range of life sciences research including biomedical and health research (42). The term 'gender dimension of the research content' launched by the Commission is to be understood in biomedicine as consideration of both sex differences and gender effects. Again we emphasised the conceptual distinction to make our points.

The study has had a big impact. Taking account of sex and gender aspects had grown from a special interest topic to an issue of quality of European research. 
The recommendations of our study were firmly implemented in FP6 (2002-2006). New guidelines were introduced for applicants submitting proposals under two thematic priorities. ${ }^{4}$ They had to answer a set of specific questions regarding integration of the gender dimension. Integrated Projects and Networks of Excellence also had to write a Gender Action Plan (43, 44).

The FP 6 Work Programme for Life Sciences, Genomics and Biotechnology for Health stated it as follows (page 4-5):

Sex and gender aspects in research have a particular relevance to this Theme as risk. factors, biological mechanisms, causes, clinical manifestation, consequences and treatment of disease and disorders often differ between men and women. Therefore all activities within this thematic priority must take the possibility of such differences into account in their research protocols, methodologies and analysis of results.

Issuing (top-down) guidelines is one thing, but what would you have to do if you were at the laboratory bench, working with the usual technical possibilities of basic science, animal experiments, clinical testing? It was not difficult to imagine that researchers would face a number of challenges (conceptual, methodological, practical or ethical) to integrate sex and gender into their research and that they might need practical tools and relevant examples. A shortlist of problems put forward at the meeting of the Commission Network on Gender Aspects in Food Quality and Safety Research (GENDFOODSAFE) in 2004 was: 1) 'Why is integration of the gender dimension a good thing to do?' 2) 'What is the theoretical basis?' 3) 'We foresee methodological issues (confounding, effect modification)' 4) 'We foresee practical issues (the raising of female rats)' 5) 'How about financing larger studies?' 6) 'What are the ethical problems? (more persons exposed to testing)'

But also jokes were launched ridiculing the gender issue: 'what is the sex of your cells today?' However, in the meantime the important Institute of Medicine (IOM) report had been published (45). It pointed exactly to the level that was ridiculed: to sex differences at the basic cellular level: Even, or exactly, at these levels we may not presume men and women to be the same. Every cell has a sex. Whether a cell contains an XX or an XY chromosome may have an impact on everything from regulation of gene expression in a cell line to the efficacy or toxicity of a pharmaceutical in living human. "Sex, that is being male or female, is an important basic human variable that should be considered when designing and analysing studies in all areas and at all levels of biomedical and health related research" (IOM, 2001, p. 3) This was the trigger to formulate the GenderBasic project, which was funded by the EC in 2005. Aim of the project was to develop practical tools and relevant examples for the research community. The project consisted of various activities. ${ }^{5}$

\footnotetext{
${ }^{4}$ Thematic priority 1.1.1. Life sciences, Genomics and Biotechnology for Health, but the guidelines were also relevant to thematic priority 1.1.5 Food Quality and Safety.

${ }^{5}$ See www.GenderBasic.nl.
} 
First running FP6 projects were interviewed on problems or challenges encountered in executing the (compulsory) Gender Action Plan. Secondly, knowledgeable researchers at high-level life sciences research institutes (such as Inserm, Charité and Karolinska Institute) were interviewed on (possibly) existing institutional policies regarding integration of sex and gender aspects in research. This part of the project aimed at finding out how institutes outside the realm of EU research policy would practice integration of sex and gender. A major activity of the project was the commission of review articles on the various methodological aspects of integrating sex and gender in various types of biomedical and health research (basic, translational, clinical and public health). Next to that reviews were commissioned on bealth conditions that were in urgent need of addressing sex and gender aspects (asthma, metabolic syndrome, nutrigenomics, osteoporosis, anxiety disorders, work-related health). High-level scientists were invited to write these reviews offering a state-of-the-art and solutions for methodological challenges. Comments on these review articles were solicited from peers. Finally authors, referees and selected stakeholders met during a two-day expert meeting in January 2007 in Maastricht during which reviews and referee comments were discussed among the participants.

We hosted scientists from a wide range of backgrounds - basic and clinical researchers, epidemiologists, social scientists and gender experts - who displayed great enthusiasm, and a real exchange of views took place. For biomedically oriented researchers the examples on the relevance and explanatory power of gender were an eye-opener. Precisely the conceptual distinction of gender from biological sex was welcomed, since the majority had become 'socialised' by biomedicine to use the terms interchangeably, which leads to unwanted confusion, as is visible in much biomedical literature. Despite many efforts by important institutional actors, such as the US Institute of Medicine, WHO and Health Canada, to 'educate' basic and biomedical researchers on the distinction between sex and gender, this apparently had not become standard practice and we can only continue to spread the word $(46,47)$. After the expert meeting and production of the proceedings containing a systematic overview of the contents of the discussion, all review articles were rewritten for publication in the Journal Gender Medicine. The final result was a special volume GenderBasic: Promoting Integration of Sex and Gender Aspects in Biomedical and Health-related Research containing the ten reviews on the relevance of sex and gender ranging from new methodologies for the basic molecular level of gene polymorphisms to the field of health behaviours in public health and addressing six conditions of major relevance in healthcare. The achievements of GenderBasic were threefold: 1) It stimulated research into sex differences. 2) It stimulated research into the workings, mechanisms and effects of gender in particular for understanding masculinity and male gender roles and effects on individual health behaviour and 3) it stimulated research into the interaction of sex and gender $(48,49)$. 


\section{Innovative knowledge}

Gender Medicine as an innovation of biomedicine, a new way of doing research by taking account of sex and gender aspects promises a better understanding of health and disease, more evidence based and precise knowledge, more effective therapies, and better health outcomes for women and men. In what follows I will present some of the most telling examples from the GenderBasic project and related research. First, an example from pre-clinical animal research where sex and gender aspects only recently have attracted research interest. Holdcroft (2007) points, first of all, to the relevance of very small differences between the sexes that may, however, produce clinical treatment effects as a consequence of additive or synergistic effects and therefore have to be investigated (50). Several current obstacles prohibit discovering small differences; for example, estrogen effects are leveled out due to variability in the hormonal cycle among females, and in consequence, are lost. Therefore she called for a determination as accurately as possible of the ovarian cycle phase of female animals. She further argues that animal models are needed that are adequate for studying human disease: the current models cannot consider co-morbidity, age-related changes or use of contraceptives.

A second example comes from research on asthma, a chronic inflammatory airway disease. A well known fact is that asthma has a higher prevalence in boys than in girls before puberty and a higher prevalence in women than in men in adulthood (51). Asthma is a complex disease and the relative influence of genetic, hormonal, social and cultural factors remains to be studied. The review demonstrated that biological sex factors play a role in fetal lung development. It has been demonstrated that the lungs of the female foetus mature more rapidly than those of the male foetus and surfactant production in female foetuses also starts earlier compared to male foetuses. Taken together, the results imply that female newborns have increased airflow rates compared with male newborns and are less likely to develop respiratory distress syndrome. Hormonal changes and genetic susceptibility are likely to contribute to the change in prevalence around puberty. The study on therapy compliance that I mentioned earlier described how gender role behaviour prevents adolescent boys to use their asthma inhalation in the presence of their peers, in contrast to girls who build their illness into their social life, which enables them to comply with their treatment regime (36).

The review on osteoporosis offered a good example of how a 'female disease' has led to a considerable neglect and underdiagnosis of the disease in men $(52,53)$. As such it is the reverse of the Yentl syndrome described for coronary heart disease. How could this happen? In my $\mathrm{PhD}$ thesis Gender and Bones, I have described how osteoporosis became inserted in the menopause syndrome in a context of a highly medicalised menopause during the 1980 and 1990s (54). It happened in a time when hormone replacement therapy (HRT) seemed the universal solution for menopausal complaints, prevention of $\mathrm{CHD}$, prevention of osteoporosis, and even more diseases. Moreover, HRT was rather aggressively sold at the time by pharma- 
ceutical firms as a medicine for eternal youth and against the loss of femininity. Now almost two decades later and after the results of the WHI study, HRT is no longer first choice for preventing osteoporosis in women.

The conclusion of my thesis was that gendered values on the meaning of being a woman have had a big impact here. At the same time underlying scientific research could not reach a consensus about the primary pathophysiological principle of osteoporosis. This scientific debate lasted for more than 50 years. In the meantime HRT became immensely popular and was widely propagated. It was even sold as emancipation. The side effect was the neglect of osteoporosis in men; men do not have a menopause. Only in the late 1980s research on osteoporosis in men made a catch-up effort and mean scores ( $\mathrm{T}$ and $\mathrm{Z}$ scores) for bone density became established for men. Medication had been developed for women, but was also prescribed to men. ${ }^{6}$

And finally an example from mental health. Various strands of research have studied depression: men's health research, gender research, basic research. Men's health research has pointed to the masculine gender role. 'Big boys do not cry' is an example of how a young boy may be denied a masculine identity because he displays emotion (29). It is important to consider what this means for men and depression in practice: this socialisation affects men to recognise their own emotional difficulties, how they express them and how they seek help to cope with them. Caring for health is regarded a feminine issue. The prevalence data of women to men of 2:1 have been questioned; does this figure reflect social reality?

Community samples show different figures and there are many mental health problems in men (alcoholism, suicide). According to this strand of research an explanation can be found in the male gender role. The men's health research agenda contains more hypotheses on gender role effects and suggestions for improvement of health information targeted at men (55).

Gender research has pointed to the fact that epidemiological data have not been questioned because of gender images of women as the weaker sex and therefore easily susceptible for depression (56). Gender research has pointed to the involvement of physical aspects of hormonal dynamics, the duration and intensity of stress factors and the overburdening of HPA axis. It also pointed to psychological and social aspects like the socialisation of women, learned helplessness and economic dependence. Gender research also raised the hypothesis that the diagnosis according to the DSM IV could be biased as the dominant symptoms investigated seemed to reflect feminine behaviour patterns, leading to underrecognition of symptoms mentioned by men. Symptoms mentioned by women are feeling gloomy, crying spells, negative self image, guilt, indecisiveness (reflecting female socialisation). Symptoms mentioned by men are restlessness, fatigue, loss of energy, loss of concentration, disturbed sleep (aspects that are limiting their working life). Besides, when women in the doctor-patient communication tend to talk easily, they

${ }^{6}$ Personal communication by Professor Alan White, GenderBasic expert meeting 2007, Maastricht. 
will disclose more symptoms compared to men. Moreover relevant differences between men and women were found in response to treatment and the development of medication for depression. Finally the possibility was launched that depression in men is another disease.

Basic research studies underlying biological processes such as adaptation to stress. By studying the role of the neuropeptide urocortin in rats, a basic neurobiology group at the department of Cellular Animal Physiology at Radboud University, Nijmegen, The Netherlands this summer came up with the hypothesis that depression in men might biologically be another thing than depression in women (57). And that perhaps because of male/female differences in the relationship between the two systems involved in adaptation, different drugs should be developed for women and men.

This example of depression illustrates how useful it can be to approach depression from several perspectives and that much is to be gained by multidisciplinary collaboration.

\section{On the relationship between feminism and the biological body: uneasy companions?}

'What lies beneath' can serve as catchphrase for a discussion on the neglect of biology in feminist theory on the body. I borrowed this subtitle from the movie by Robert Zemeckis (2000) because it fits the contents of an intriguing issue: the relationship between gender research and biology. I will not go into details of this discussion, but give my evaluation of the lack of address of 'what lies beneath' in much feminist theory. The early feminist disgust of biology because of the abuse made of biology to legitimise social gender roles (biology is destiny) is understandable. But it implied that biology was left to the traditional disciplinary approaches and that was not a good thing to do.

In 2002 Kuhlmann and Babitsch wrote an article on the neglect of attention for biological processes in the work of feminist theoreticians but also in much work of women and health researchers (58). The first group writes about the body but does not address biological materialities, the second group invests in studying socioeconomic determinants of health. The feminist pioneers Birke and FaustoSterling which I introduced in the beginning agree with this lack of attention to biology that Kuhlmann and Babitsch identified. Birke (1999, 2) boldly states in her book Feminism and the biological body that "feminist theory is only skin deep" and calls for interactive models of causality (59). For Fausto-Sterling biology cannot be neglected, she found a new approach in the so-called developmental systems approach: the challenge is to develop an interactive model of how genes and environment come together in the production of human capabilities (60).

In doing so we can learn to understand how biology and environment work together in producing strong bones, relevant to osteoporosis research (61). Analy- 
sis from a gender perspective of different types and intensity of exercise in boys and girls can give clues to differences in bone strength. We can learn to see how genetically determined differences between men and women but also among women, together with environmental factors like gender and lifestyle determine the outcome of dietary advice in the case of obesitas (62). It emphasises once more the relevance of studying the sex-gender interaction and to acknowledge how embodiment merges nature and culture.

\section{Outlook for future research}

Gender Medicine stimulates new ways of doing research: that is to consider sex and gender at all levels of research, from basic research into gene polymorphisms to health behaviour in public health. New research questions have been put forward that do not focus on differences per se but on the development of differences. For example: I see it as a challenge to combine my interest in biology and biomedicine - in the investigation of 'what lies beneath' - with insights from gender research. An innovative research agenda resulted from the GenderBasic project and new research collaborations have been developed.

The recommendations of the GenderBasic project that ended in 2008, were directed at various institutional actors including universities. What could universities do to promote, facilitate and ensure the integration of sex and gender in research contents, processes and methodologies through institutional arrangements? We recommended that universities should push for gender mainstreaming, should create chairs in Gender Medicine, and should ensure the uptake of the new insights into biomedical and health sciences education. A good practice in this respect, as implemented at various universities in Europe, is to start with a lecture series (Ringvorlesung), as an awareness-raising activity. Those lectures, directed at the whole faculty, are delivered by knowledgeable experts in the field and illustrate the relevance and latest research data of Gender Medicine for the different disciplinary medical fields. Such a lecture series often results in a publication, a textbook, that next can serve as educational material for implementation of Gender Medicine in (bio)medical curricula.

On a European level, efforts to bring together the various but scattered educational initiatives of a number of universities have resulted in a project funded by the Erasmus Life Long Learning Programme to develop a European module in Gender Medicine. The module will have a flexible format and can be implemented in various curricula (medical, health sciences, and molecular medicine) and will also be offered as post-initial training for health professionals. The consortium consists of seven Universities in Europe, and the project (two years duration) will start in October 2009. All these efforts will hopefully contribute to disseminate information on Gender Medicine to clinicians, researchers, patients as well as the wider public and policymakers. 


\section{References}

1. Curran L, Brighton Women \& Science Group: Alice through the microscope. London: Virago; 1980.

2. Birke L, Vines G: Beyond nature versus nurture: process and biology in the development of gender. Women's Studies International Forum 10; 1987; 555570.

3. Fausto-Sterling A: Myths of gender. New York: Basic Books; 1985.

4. Schiebinger L: Has Feminism changed Science? Cambridge \& London: Harvard University Press; 1999.

5. Schiebinger L: Gendered innovations in science and engineering. Stanford, California: Stanford University Press; 2008.

6. NIH: Guidelines on the inclusion of women and minorities as subjects in clinical research. NIH Guide. Washington: NIH; 1994.

7. Lagro-Janssen T: Developments in the field of women's studies medicine. European Journal of Women's Studies 6; 1999; 487-500.

8. Martin E: The egg and the sperm: how science has constructed a romance based in stereotypical male-female roles. Signs: Journal of Women in Culture and Society 16; 1991; 485-501.

9. Fox Keller E: Reflections on gender and science. Yale: University Press; 1996.

10. Legato MJ: Principles of gender-specific medicine. San Diego, California: Elsevier Academic press; 2004.

11. Rieder A, Lohff B: Gender Medizin. Geschlechtsspezifische Aspekte für die klinische Praxis. Wien: Springer; 2008.

12. Hochleitner M: Gender Medicine. Ringvorlesung an der Medizinischen Universitaet Innsbruck. Wien: Facultas; 2008.

13. Regitz-Zagrosek V, Fuchs J: Geschlechterforschung in der Medizin. Frankfurt am Main: Peter Lang; 2006.

14. Hurrelmann K, Kolip P: Geschlecht, Gesundheit und Krankheit. Männer und Frauen im Vergleich. Bern: Huber; 2002.

15. Lagro-Janssen T, Noordenbos G: Sekseverschillen in ziekte en gezondheid. Nijmegen: SUN; 1997. 
16. Annandale E, Hunt K: Gender inequalities in health: research at the crossroads. In: Annandale E, Hunt K (eds): Gender Inequalities in Health; Buckingham Philadelphia: Open University Press; 2000; 1-35.

17. Doyal L: Gender equity in health: debates and dilemmas. Social Science \& Medicine 51(6); 2000; 931-939.

18. Bird CE, Rieker PP: Gender matters: an integrated model for understanding men's and women's health. Social Science and Medicine 48(6); 1999; 745-755.

19. Doyal L: Sex, gender, and health: the need for a new approach. British Medical Journal 323(7320); 2001; 1061.

20. Krieger N: Genders, sexes, and health: what are the connections-and why does it matter? International Journal of Epidemiology 32(4); 2003; 652-657.

21. Phillips SP: Defining and measuring gender: A social determinant of health whose time has come. International Journal for Equity in Health 4(1); 2005; 11.

22. Pinn VW: Sex and Gender Factors in Medical Studies Implications for Health and Clinical Practice. American Medical Association; 2003; 397-400.

23. Health Canada: Health Canada's Gender-based Analysis Policy: Women's Health Bureau; 2000.

24. Klinge I, Bosch M: Transforming research methodologies in EU life sciences and biomedicine: gender-sensitive ways of doing research. European Journal of Women's Studies 12(3); 2005; 377-395.

25. WHO-Europe: Mainstreaming gender equity in health: Madrid Statement. WHO Europe: Kopenhagen; 2001.

26. Wizemann TM, Pardue ML. Exploring the biological contributions to human health: does sex matter? Executive summary of the Institute of Medicine report. Journal of Women's Health \& Gender-based Medicine 10(5); 2001; 433-439.

27. Fausto-Sterling A: Sexing the body: gender politics and the construction of sexuality. New York: Basic Books; 2000.

28. Health Canada: Gender \& health collaborative curriculum project. www.gender andhealth.ca $<15$ December 2008>

29. Branney P, White A: Big boys don't cry: depression and men. Advances in Psychiatric Treatment 14(4); 2008; 256-262.

30. White A: How men respond to illness. Men's Health Journal 1(1); 2001; 18-19. 
31. Meeuwesen L, Bensing J, van den Brink-Muinen A: Communicating fatigue in general practice and the role of gender. Patient Educ Couns 48(3); 2002; 233 242.

32. Roter DL, Hall JA, Aoki Y: Physician gender effects in medical communication. A meta-analytic review. JAMA 288(6); 2002; 756-764.

33. Gustafson PE: Gender differences in risk perception: Theoretical and methodological perspectives. Risk Analysis 18(6); 1998; 805-811.

34. Bosch M: Women in science: a Dutch case? Science in Context 5(4); 2002; 484-527.

35. Messing K, Mager Stellman J: Sex, gender and women's occupational health: The importance of considering mechanism. Environmental Research 101(2); 2006; 149-162.

36. Williams C: Doing health, doing gender: teenagers, diabetes and asthma. Social Science and Medicine 50(3); 2000; 387-396.

37. Weber T, Auer J, Berent R, Lassnig E, Eber B: Kardiologie. In: Rieder A, Lohff B (eds): Gender Medizin. Geschlechtsspezifische Aspekte für die klinische Praxis. Wien \& New York: Springer; 2008; 343-387.

38. Healy B: The Yentl syndrome. The New England journal of medicine 325(4); 1991; 274-276.

39. Berger JS, Roncaglioni MC, Avanzini F, Pangrazzi I, Tognoni G, Brown DL: Aspirin for the Primary Prevention of Cardiovascular Events in Women and Men. A Sex-Specific Meta-analysis of Randomized Controlled Trials. JAMA 295(3); 2006; 306-313.

40. Schulz AJ, Mullings L: Gender, race, class \& health. Intersectional approaches. San Francisco: John Wiley \& Sons; 2006.

41. Wieringa N, Reijneveld M, Stronks K: Diversity from an epidemiological perspective: looking for underlying causes and changing merits. In: Wieringa NF, Hardon AF, Stronks K, M'charek AA (eds): Diversity among patients in medical practice: challenges and implications for clinical research. Amsterdam: Universiteit van Amsterdam; 2005; 13-46.

42. Klinge I, Bosch M: Gender in Research. Gender impact assessment of the specific programmes of the fifth Framework Programme. Quality of life and management of living resources (EUR 20017). Brussels: European Commission; 2001.

43. European Commission: Vademecum: gender mainstreaming in the $6^{\text {th }}$ framework programme - reference guide for scientific officers/project officers. Brussels: European Commission; 2003. 
44. European Commission: Gender action plan in integrated projects and networks of excellence. Compendium of best practices. Brussels: Research DirectorateGenerale; 2004.

45. Institute of Medicine: Exploring the biological contributions to human health: Does sex matter? Washington DC; 2001. www.nap.edu/books/0309072816 /html <08 September 2009>

46. Fishman JR, Wick JG, Koenig BA: The use of 'sex' and 'gender' to define and characterize meaningful differences between men and women. In: National Institutes of Health (ed.): Agenda for research on women's health for the $21^{\text {st }}$ century. Washington DC: Department of Health and Human Services; 1999.

47. Lorber J: Sex matters and gender matters. www.bmj.com/cgi/eletters/323/ 7312/541 <16 April 2009>

48. Klinge I: Bringing gender expertise to biomedical and health-related research. Gender Medicine 4 (Supplement B); 2007; 59-63.

49. Klinge I: Gender perspectives in European research. Pharmacological Research 58(3-4); 2008; 183-189.

50. Holdcroft A: Integrating the dimensions of sex and gender into basic life sciences research: methodologic and ethical issues. Gender Medicine 4 (Supplement 2); 2007; 64-74.

51. Postma DS: Gender Differences in Asthma Development and Progression. Gender Medicine 4 (Supplement B); 2007; 133-146.

52. Geusens P, Dinant G: Integrating a Gender Dimension into Osteoporosis and Fracture Risk Research. Gender Medicine 4 (Supplement B); 2007; 147-161.

53. White, AK: Osteoporosis and the problem of candidacy. Commentary. GM2. Geriatric Medicine: Midlife and beyond 38 (Supplement 03); 2008; 5.

54. Klinge I: Gender and bones: the production of osteoporosis 1941-1996. Utrecht: PhD Thesis, Utrecht University; 1998.

55. Oliffe JL, Phillips M: Men, depression and masculinities: A review and recommendations. Journal of Men's Health (3); 2008; 194-202.

56. Noordenbos G: Worden mannen over het hoofd gezien? Sekseverschillen in de diagnostiek en behandeling van depressie. Tijdschrift voor Genderstudies 10; 2007; 16-28.

57. Kozicz T: On the role of urocortin 1 in the non-preganglionic EdingerWestphal nucleus in stress adaptation. General and Comparative Endocrinology 153(1-3) 2007; 235-240. 
58. Kuhlmann E, Babitsch B: Bodies, health, gender - bridging feminist theories and women's health. Women's Studies International Forum 25(4); 2002; 433 442.

59. Birke L: Feminism and the biological body. Edinburgh: University Press; 1999.

60. Fausto-Sterling A: The problem with sex/gender and nature/nurture. In: Williams SJ, Birke L, Bendelow CA (eds): Debating Biology: Sociological Reflections on Medicine, Health and Society. London: Routledge; 2003; 123 132.

61. Fausto-Sterling A: The bare bones of sex: Part 1 - sex and gender. Signs: Journal of Women in Culture and Society 30(2); 2005; 1491-1527.

62. Ordovas JM: Gender, a significant factor in the cross talk between genes, environment, and health. Gender Medicine 4 (Supplement B); 2007; 111-122. 


\title{
Gender issues in living organ donation: medical, social, and ethical aspects
}

\author{
Silke Schicktanz, Mark Schweda \& Sabine Wöhlke
}

\section{Abstract}

The gender-disparity hypothesis for living kidney transplantation has been discussed for more than 20 years. It states that women donate kidneys more frequently than men, but fewver women than men receive organs. Our investigation aims at a) the quantitative verification of the genderdisparity-hypothesis in four European countries and b) the qualitative and ethical analysis of possible causes. Our quantitative analysis is based upon data for Germany, the Netherlands, Belgium and Austria provided by Eurotransplant for a five year period (2003-2007). On the recipient side, the higher number of men could be explained by statistically taking into account the sex-ratio for end stage renal disease. On the donor side, there is a significant difference between expected and observed numbers of women serving as donors in all four countries. Parents as living donors are the most important group to explain the deviation. Fathers donate to their children significantly less often and mothers more often than one would expect according to epidemiological data. To explore reasons bebind these behavioural differences, we conducted and analysed focus group discussions in Austria, Germany and the Netherlands to gather information about attitudes and moral positions. Following the assumptions of the two-moralities debate, we found differences between men and women in their argumentation concerning (1) the formal structure of decision making and judgment (2), the role of the family for moral argumentation, and (3) the assessment of public institutions such as the state, the market and the medical system. Our findings indicate that gender related roles (and expectations) have a great impact on framing moral issues in organ transplantation while general moral attitudes are rather similar between men and women. We finally discuss consequences for clinical practice as well as for further research. 


\section{Introduction: is there a gender aspect in organ donation?}

Organ donation has complex medical, social, and ethical aspects. In this paper, we address sex and gender issues in organ transplantation, precisely, differences between men and women donating or receiving an organ. In many Western countries, about twice as many women as men donate a kidney. This fact, however, is still often neglected in medical and ethical overviews of organ transplantation. For the purpose of this paper, we focus on living organ donation, particularly on kidney transplantation: first, most evidence is available with regard to living organ donation (LOD). Though one can also observe a difference in sex of donors in post-mortem transplantation, this is yet not well investigated. ${ }^{1}$ Second, in most countries, only the number of living kidney transplantations (LKD) is high enough to detect sex and gender related differences while living liver and lung transplantations are still too rare for gaining evidence with respect to an imbalance in the sexes. First, we will present statistical findings substantiating significant differences in the men/women ratio on the donor and on the recipient side; secondly, we will consider social and psycho-moral aspects of organ donation which interact with medical practice. Against this background, we will, thirdly, present socio-empirical data from focus group discussions with male and female potential donors exploring socio-cultural and moral factors for gender differences in donation. Finally, we discuss why and how gender issues should be addressed in the clinical setting.

\section{Quantitative socio-demographical and medical data}

A variety of quantitative differences between men and women on several levels can be found in LKD. First and foremost, if we compare absolute numbers and sex proportion between donors and recipients we constantly observe a deviation from the normal population sex ratio (49\% male vs. 51\% female). (See table 1). However, it is necessary to analyse each side separately. On the recipient side, we statistically observe over time steady and over country rather stable differences - on average $37-41 \%$ are female patients and 59-63\% male without high variations between different countries. (See table 1, first column, for an overview see also (2)) On the donor side, we observe differences in the sex ratio in various countries, too (see table 1, second column), but in this case there are much higher variations between different countries. In Germany, for instance, $61 \%$ of all living donors are female whereas only 39\% are male. In Switzerland, the disparity is even more pro-

\footnotetext{
${ }^{1}$ Interestingly, in post-mortem kidney transplantation, the ratio is reversed: In Germany, $46 \%$ of all donors are female and 54\% male. However, this difference is neither well understood nor sufficiently investigated, yet. Recent German surveys show that there are no significant differences between men and women concerning the motivation of post-mortem donation and the holding of organ donor cards (1).
} 
nounced: $65 \%$ of living organ donors are female while only $35 \%$ are male (3). In the USA, Kayler et al. (4) as well as recent UNOS (5) data show the same trend. In contrast, in Great Britain (6) and Norway (7) the sex ratio of donors is less pronounced but has still not reached sex equality with regard to donors or recipients. Iran seems to be a special case. Here, the sex ratio on the donor side is reversed: more men than women are donors. This reversed effect on the donor side is explained by special legal and economic frameworks. In Iran (8) donors in living unrelated donation get paid by the state as well as by the family of the recipient. The same trend was reported in recent studies showing that in the case of (illegal) commercialisation of organ donation (e.g. in Latin America and East-Asia), men sell their organs much more often than women (9). Also, German men are more willing to donate when offered a hypothetical financial incentive (10).

Table 1: Comparison of the total numbers of living kidney donations with respect to sex ratio in various countries with established living kidney donor programmes.

\begin{tabular}{|c|c|c|c|c|}
\hline Country & $\begin{array}{c}\mathbf{f}: \mathbf{m} \\
\text { recipient }\end{array}$ & $\begin{array}{c}\mathbf{f}: \mathbf{m} \\
\text { donors }\end{array}$ & $\begin{array}{c}\text { LKD in } \% \text { of } \\
\text { total kidney } \\
\text { transplantation }\end{array}$ & Source \\
\hline Germany & $39: 61 \%$ & $61: 39 \%$ & $20 \%$ & $\begin{array}{c}\text { Eurotransplant } \\
(2003-2007)(11)\end{array}$ \\
\hline USA & $39: 61 \%$ & $59: 41 \%$ & $44 \%$ & UNOS (2009) (5) \\
\hline Switzerland & $36: 64 \%$ & $65: 35 \%$ & $18 \%$ & $(1993-2003)(3)$ \\
\hline UK & $41: 59 \%$ & $53: 47 \%$ & $39 \%$ & $\begin{array}{c}\text { UK Transplant } \\
(2007-2008)(6)\end{array}$ \\
\hline Norway & $37: 63 \%$ & $58: 42 \%$ & $40 \%$ & $(1985-2002)(5)$ \\
\hline Iran & $37: 63 \%$ & $22: 78 \%$ & $95 \%$ & $(8)$ \\
\hline
\end{tabular}

Comparing four European countries, all of them members of Eurotransplant ${ }^{2}$, we found an interesting pattern of ratio of men-women on the donor as well as on the recipient side. (See graph 1a and $1 \mathrm{~b}$ ). To this purpose, we analysed statistical data available for Germany, Netherlands, Belgium, and Austria for a period of time between 2003 and 2007. In these countries the lumped sum of a 5-years period was large enough for substantial statistical analysis of LKD (in Austria N=232; in Bel-

${ }^{2}$ Eurotransplant is an international institution located in Leiden, The Netherlands, in charge of waiting lists and organ allocation for the following countries: Germany, Austria, The Netherlands, Belgium, Luxemburg, and Slovenia. 
gium $\mathrm{N}=150$; in Germany $\mathrm{N}=2507$; and in the Netherlands $\mathrm{N}=1360$ ). In an analogous study to Kayler et al. (4) we considered the sex ratio of each country's population as well as the sex differences in end stage renal disease (ESRD) for the statistical analysis (mean comparison test with Unixstat). ESRD is the main reason for kidney transplantation, the epidemiology of ESRD shows a statistically highly relevant deviation between men and women. ((4), For details on the calculation see also (2)). Out of 100 cases of ESRD 61.8 are men and 38.2 are women. This sex difference in ESRD was taken into account when calculating the potential number of recipients of kidney transplantations.

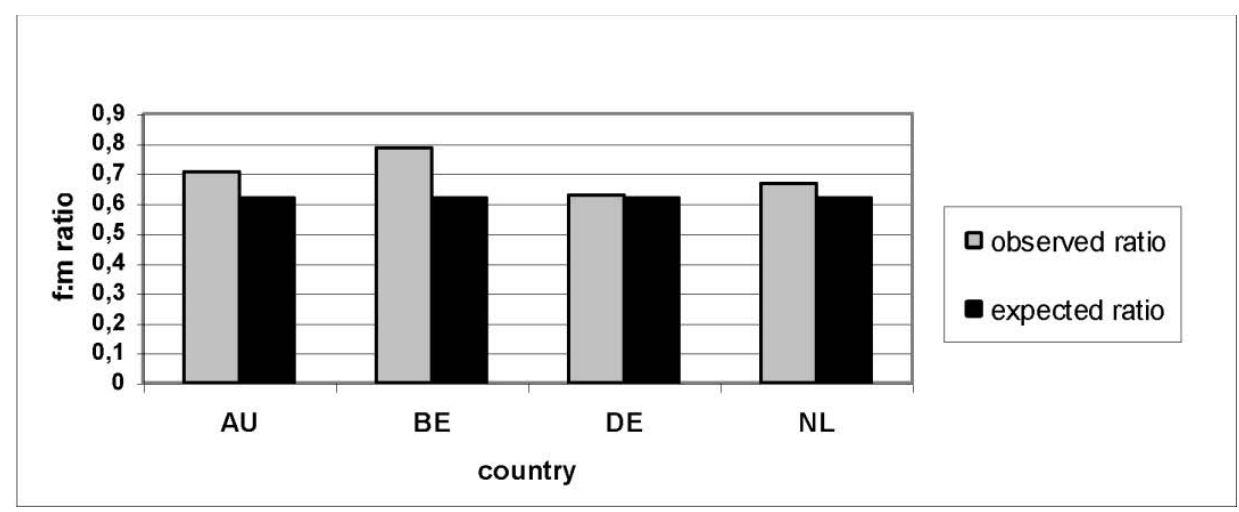

Graph 1a: Women/men ratio in relation to observed and expected recipients' numbers in living kidney transplantation in Austria (AU), Belgium (BE), Germany (DE) and the Netherlands (NL) Data provided by Eurotransplant 2003-2007 (N=4249). The slight differences between observed and expected sex ratio in all four countries are statistically non-significant.

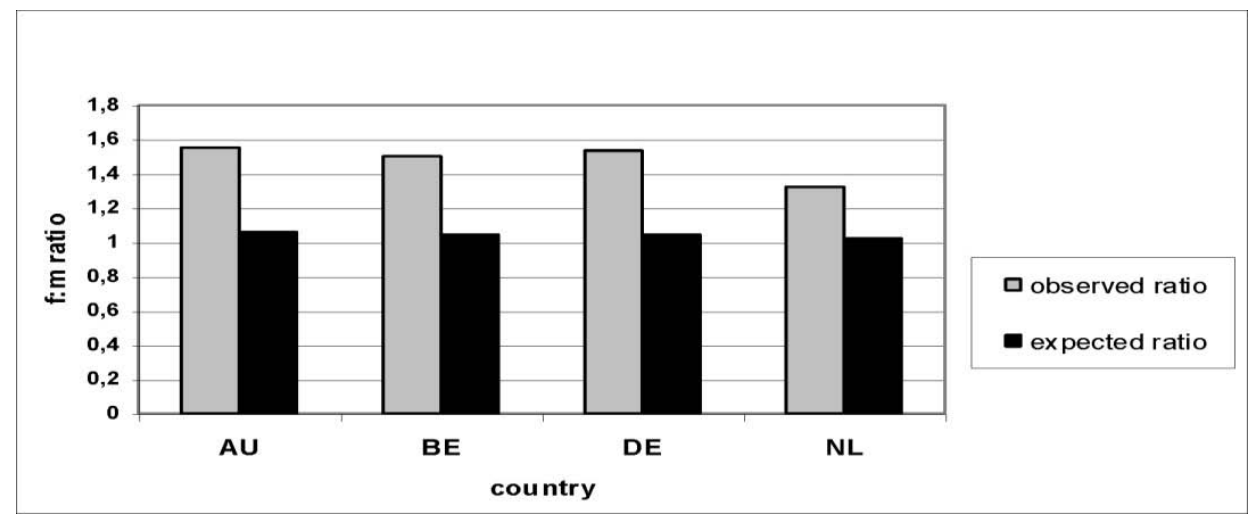

Graph 1b: Women/men ratio in relation to observed and expected donors' numbers in living kidney transplantation in Austria [AU: $p<0.005]$, Belgium [BE: $p<0.05$,] Germany [DE: $p<0.00005]$, The Netherlands [NL: $p<0.00005]$ (data provided by Eurotransplant for 2003-2007) (N=4249)). The deviation between observed and expected sex ratio in all four countries are statistically significant. 
In graph $1 \mathrm{a}$ and $1 \mathrm{~b}$ we have summarised the results of a comparison of observed and expected ratio of female and male recipients and donors in four countries. On the recipient side a statistical analysis (Chi-square test, $\mathrm{N}=4249$ for all four countries) did not reveal statistically significant differences, while on the donor side there are significant differences between observed and expected female-male ratio in all four countries. Our results are mainly in line with findings for other countries (e.g. $(12,14))$ showing that the gender 'effect' on the donor and recipient side has different reasons. Thus, they raise different concerns. In our study, the differences between men and women on the recipient side, in line with the study of Oien et al. (7) for Norway, can be explained by epidemiological facts (concerning ESRD and population ratio). However, the high impact of epidemiology in kidney diseases points to medical, genetic, and even social factors lying behind that sex ratio of kidney diseases. In contrast, studies such as Kayler et al. $(4,13)$ for the USA or Thiel et al. (3) for Switzerland show that even on the recipient side there are statistically significant differences between observed and expected sex-ratio which cannot be explained by epidemiological factors alone. Furthermore, significant differences on the donor side, as demonstrated in Kayler et al., Thiel et al. and our findings cannot be explained by incidence of diseases in the sexes. In these cases, social, economical, and even cultural effects have to be presumed.

For a deeper understanding of these results, we investigated the male/female relation in specific subgroups of the donor-recipient relationship. We differentiated between biologically related (parents, siblings) and biologically non-related donorrecipient-relations (spouses). (See table 2$).^{3}$

Table 2: Percentage of each of three major subgroups of donor-recipient relation with regard to the total numbers of living kidney transplantations performed per country (data provided by Eurotransplant 2003-2007).

\begin{tabular}{|c|c|c|c|}
\hline Country & Spouses in \% & Parents in \% & Siblings in $\%$ \\
\hline Austria & 24 & 36 & 22 \\
\hline Belgium & 23 & 36 & 29 \\
\hline Germany & 34 & 36 & 17 \\
\hline Netherlands & 24 & 25 & 22 \\
\hline
\end{tabular}

\footnotetext{
${ }^{3}$ In our analysis we did not investigate other subgroups such as grandparents, cousins, friends, anonymous donors, or homosexual couples as the numbers in each subgroup were too small.
} 
Concerning the sub-group of spouses, we did not find any statistically significant differences between expected and observed numbers of wife-to-husband- or husband-to-wife-transplantations in the four European countries. In the sub-group of siblings, we observed a trend in Germany that sisters donate more often than brothers (2; the effect is weaker over a 5-year-period: $\mathrm{p}=0.91995)$. In the other three countries, we did not find any statistically significant discrepancies of observed and expected donations between sisters and brothers. However, in the subgroup of parents, the effect is very strong: here we observe that in three of four countries mothers statistically donate significantly more often than fathers. (See table 3).

Table 3: Observed and expected numbers of mothers and fathers as donors in living kidney transplantation in four European countries. Mothers donate significantly more often than fathers in Belgium, Germany, The Netherlands, but not in Austria (data provided by Eurotransplant 2003-2007 ( $\mathrm{N}=4249) \quad(* \mathrm{p}<0.05$; $* * \mathrm{p}<0.005 * * * \mathrm{p}<0.0005)$.

\begin{tabular}{|c|c|c|c|c|}
\hline Country & $\begin{array}{c}\text { Mothers } \\
\text { observed }\end{array}$ & $\begin{array}{c}\text { Fathers } \\
\text { observed }\end{array}$ & $\begin{array}{c}\text { Mothers } \\
\text { expected }\end{array}$ & \% of excess \\
\hline Austria & 49 & 34 & 41,5 & $\begin{array}{c}18 \% \\
(\mathrm{p}=0.9003)\end{array}$ \\
\hline Belgium & 36 & 19 & 27,5 & $\begin{array}{c}26 \% \\
(\mathrm{p}=0.97811)^{* *}\end{array}$ \\
\hline Germany & 578 & 335 & 456,5 & $\begin{array}{c}31 \% \\
(\mathrm{p}=1)^{* * *}\end{array}$ \\
\hline Netherlands & 201 & 142 & 171,5 & $\begin{array}{c}17 \% \\
(\mathrm{p}=0.99856) * *\end{array}$ \\
\hline
\end{tabular}

To summarise, the general difference between female and male donors results from the imbalance between mothers and fathers. However, the statistical analysis does not provide plausible explanations for this difference in behaviour of male and female donors. With respect to the recipient side, the major explanation for the sex differences most probably results from the epidemiological fact that men suffer from renal diseases more often than women and thus more often are in need of an organ transplantation. Our findings do not support claims that organs in these countries are withheld from potential female recipients. However, there are some limitations of quantitative statistics: first, some numbers are low, and high sample size is needed to reach significance. Second, variation in documentation (e.g. data on relationship between donor and recipient are not always sufficiently available) in different countries hampers statistical analysis (that is why we mainly concentrate on data from the four Eurotransplant countries). 
Furthermore, quantitative data do not provide any insight in motives, moral attitudes or social reasons. Thus, there is a need for complementation by further qualitative social research and ethical analysis.

\section{Theoretical background: explanatory hypotheses}

Taking into account these findings, one can state that the typical living organ donor is a woman (35-49-year-old (14)), whereas the typical recipient is a male (of no specific age). Since this so-called 'gender disparity' has been known for more than 20 years (15) various explanations have been offered (16). As the empirical part shows, it is necessary - from a theoretical as well as an ethical perspective - to distinguish two aspects: the first refers to the side of the organ recipients: According to our analysis of the four European countries, epidemiological factors of ESRD (see above) can explain sex difference. (See also (7)). Hence, it is not plausible to assume an ethical problem of unjust allocation. Both men and women receive organs according to their medical needs (and not because of social or economical reasons). However, in some countries (such as Switzerland and some U.S. American transplantation centres, see below) the difference cannot be sufficiently explained by epidemiological factors. Here the following kind of questions should be clarified: are women actually discriminated regarding access to medical care, e.g., organ transplantation (17), or are there motivational differences in the gender that lead to a rejection of this type of medical treatment? Some authors speculate that there may be a gender difference in the acceptance of 'aggressive' biomedical treatments, and female patients may more often renounce the opportunity of having an organ transplanted (18-20). A second set of explanations focuses on the side of the donors. In those cases where evidence shows that women more often than men donate an organ - as our own data indicate - it is necessary to ask whether there are social, moral-psychological or cultural reasons for that. Socio-economic factors, too, might play a role: As there is a health risk for the donor, men might be less often donors for other family members as they are often the socio-economic safeguards of the family (3). Finally, gender differences in moral attitudes and moral thinking might also play a role in decisions about living or post-mortem donation (16).

\subsection{Differences in the willingness to donate organs?}

There are two main conflicting approaches to explain the difference between women and men in organ donation. On one side, these differences in behaviour and attitude are explained because of differences in moral judgments and rational reasoning. Thus, one might claim that women donate more often than men because of their moral attitude and willingness to help their beloved ones (16). This autonomy-based position considers that human agents are autonomous and rational which is a common assumption in liberal moral philosophy. On the other 
side, there are feminist and socio-ethical concerns assuming that differences in behaviour and attitude are due to asymmetries in social power, e.g., that they result from the internalisation of role expectations. In our case, this would mean that women donate more often because of social pressure (9).

In this paper, we start from the assumption of the concept of autonomy - a concept which belongs to the foundations of recent legal and ethical debates on organ transplantation. Thus, we follow Biller-Andorno's hypothesis (16), that gender differences in organ donation can be explained by gender differences in moral psychology: If the right to an 'autonomous decision' exists - why do we observe significant difference between (some) men and women?

The idea that differences between men and women in living organ donation reflect male and female specificities on the level of moral thinking and moral attitudes relates to the debate about the 'two moralities'. The controversy initially evolved around Lawrence Kohlberg's theory of moral development (see (21)) which has remained an influential theory in moral psychology until today. Kohlberg conceptualised a theoretical stage model to describe the cognitive evolution of moral reasoning and judgment on the level of the individual. According to this model, there are six stages which mark different levels of rationality and cognitive advancement in moral reasoning. These stages range from a pre-conventional level where moral questions are considered in terms of obedience and punishment to a 'postconventional' level of abstract and impartial reasoning about rights and duties on the basis of universal principles of autonomy and justice.

Carol Gilligan criticised Kohlberg's research for lacking sensitivity to differences between men and women (22). As his theory seems to presume and privilege specific meta-ethical and moral philosophical conceptions of morality and was empirically examined with a sample of male participants, Gilligan argued that the stage model Kohlberg constructs is biased, neglecting the moral perspectives of women and degrading their view to a deviation from an inherently male norm. On the basis of her own research, she claimed that women's experiences are expressed in 'a different voice', thus postulating a primarily female moral point of view which is distinct from - but of the same value as - the one of men. She described this point of view as a 'morality of care' which is based on emotional bonds and which is primarily concerned with caring and responsibilities in interpersonal relationships - as opposed to the male 'morality of justice' based on impartial reasoning and abstract universal principles.

The 'two moralities'-debate has had a considerable influence on feminist ethics and gender studies in general (23-25) and has triggered highly controversial metaethical, ethical, and sociological (26) discussions about the hierarchy of ethical principles, the formal manner of moral argumentation and the role of social 'perspectivism' in moral argumentation. Some of these issues are obviously of particular interest for medicine and medical ethics, too. Since caring traditionally is a constitutive element of the professional self-understanding and practice in medicine and nursing, it has been questioned whether the justice orientation can provide a 
suitable framework for ethical reasoning in the medical domain at all. Moreover, using the justice-care dichotomy as a starting point, several empirical studies have investigated patterns of moral attitudes and reasoning in the medical context, e.g. between physicians and nurses or among medical students (see (27), (28)). However, up to now the explanatory power of the two-moralities hypothesis has not been examined for the differences between men and women in organ donation.

If gender differences in moral psychology play such an important role in the context of organ donation, this would have rather far reaching consequences: first of all, the attitude and behaviour of women would have to be acknowledged appropriately. If, however, this hypothesis has to be rejected, one would have to pay attention and scrutiny to the alternative idea, that social pressure or problematic stereotypes resulting from traditional role models play a role (see above). Then, it would be important to critically review the decision making processes to clarify whether decisions can really be regarded as voluntary. And finally, the fact that in living organ donation the person deciding is always a man or a woman would have to be acknowledged appropriately as a factor in bioethical and social science debates as well as in medical practice itself (29).

\section{Qualitative socio-empirical research: background and methods}

Against the background of the above mentioned 'two moralities'-debate, we analysed empirical material from focus group discussions in three European countries. We made use of Gilligan's distinction between a 'morality of justice' and a 'morality of care', in order to explore gender-related aspects in moral attitudes towards donating and accepting organs. We do not imply taking sides with one of the moral psychological or philosophical positions involved in the debate. Our main research question was whether there are basic differences in moral argumentation of men and women when discussing organ transplantation. This refers to the formal level of framing moral problems in terms of justice (rights, duties, and fair allocation) or of care (feeling responsible for relationships and close relatives, avoiding to hurt somebody), as well as to the level of social, cultural, and economic settings mentioned by women and men when discussing organ transplantation, especially concerning the family context and the role of public institutions.

\subsection{Composition of sample and method of data collection and analysis}

Our research is based on the exploration of European citizens' views of and attitudes to organ donation and their motivational backgrounds. In order to capture the richness and depth of cultural implications, connotations and contexts of public attitudes, quantitative research needs to be accompanied by and complemented with qualitative methods. In qualitative socio-empirical research, focus groups, i.e., 
moderated group discussions with 8-10 participants, are a convenient and established tool (30) or investigating common sense beliefs on a general level (31). Our analysis is based on the transcripts of three group discussions at a time in Germany, The Netherlands and Austria. ${ }^{4}$ As mentioned above, they are member states of Eurotransplant that vary in their numbers of post-mortal and living donations. (See table 4). A cross-national comparison might help to identify culturally invariant arguments.

Table 4: Organ donation rates as mean value per year between Austria, Germany, and the Netherlands (data provided by Eurotransplant 2003-2007).

\begin{tabular}{|c|c|c|c|}
\hline Country & $\begin{array}{c}\text { Donor per } \\
\text { Mio citizens } \\
\text { (PPM) }\end{array}$ & $\begin{array}{c}\text { Total post- } \\
\text { mortem } \\
\text { donation }\end{array}$ & $\begin{array}{c}\text { Total living } \\
\text { kidney donation }\end{array}$ \\
\hline Austria & 23.5 & 192 & 51 \\
\hline Germany & 15.7 & 1298 & 537 \\
\hline Netherlands & 13.5 & 265 & 304 \\
\hline
\end{tabular}

In each country, four focus groups with 8-10 participants were formed, but for the present study we analysed in detail one of each country, which was performed with lay persons on organ transplantation issues. They were recruited with different strategies to allow for a widespread coverage of socio-demographic criteria. The overall number of response was 85 in Germany, 70 in Austria and 71 in The Netherlands. In all three countries, more women than men responded (Germany 1:2 male:female; Austria 1:2 male:female; The Netherlands 2:3 male:female). The participants were classified as 'lay people' insofar as they had stated that neither they themselves nor their relatives had had any concrete experience with organ transplantation before. We did not choose patients here because we were interested in public moral attitudes of men and women with regard to their willingness to organ donation. Thus, a hypothetical scenario seemed more appropriate since it allows

\footnotetext{
4 The Austrian focus groups were recruited, organised and conducted by the Department of Social Studies of Science at the University of Vienna. The Dutch focus groups were recruited, organised and conducted by the Department of Philosophy at the University of Utrecht. The German focus group was recruited, organised and conducted by the Research Group Bioethics and Science Communication at the Max-Delbrueck-Center for Molecular Medicine Berlin-Buch. All focus groups were recruited, organised and conducted in the beginning of 2005, following the guidelines for setting and content of the EU Project 'Challenges of Biomedicine', Contract No. SAS6-CT-2003-510238. For further details see: http:/ /www. univie.ac.at/virusss/cobpublication. <20 September 2009>
} 
for a more open discussion and avoids justifications with regard to personal experience. However, in ongoing studies, we also investigate the attitudes of patients and affected persons (see discussion part).

Groups were composed with respect to age, educational level, and religion. Men and women were evenly distributed. Overall, for this present study, 27 European citizens took part, 13 men and 14 women, which is a sufficient number for an explorative qualitative study. In each group, the participants' age was balanced, it ranged from 18 to $>60$. In all countries, the group discussions were moderated by two facilitators and followed the same semi-structured questionnaire. The questionnaire contained six open questions about attitudes towards and opinions about post-mortem and living organ transplantation, surrogate decisions in the case of a brain-dead relative and public policy.

All transcripts were anonymised and translated into English, using individual speaker codes (nationality/sex). The participants' responses were analysed separately for men and women. First we followed a procedure based on Grounded Theory (32) in which interpretative concepts are developed inductively. Our qualitative content analysis of the concepts (33) concentrated on common arguments (e.g. pro/contra-arguments) and topics (e.g. decision process, role of body concepts, physicians, information etc.) that recurred during discussion. On this level, we found no country-specific topics.

\section{Qualitative socio-empirical research: results about gender differences and similarities}

In each group, the participants expressed a wide range of opinions regarding organ transplantation in general: while some of the participants were quite positive towards organ donation and biomedical progress, others expressed rather critical views. Overall, gender issues were not in the focus of any of the groups. When explicitly asked whether gender mattered, members of all three groups expressed the strong opinion that gender differences are not relevant for moral, social, or scientific questions about organ transplantation.

Our empirical analysis thematically focuses on three main aspects: in light of the controversial discussion about the two-moralities, the section 1) starts with the more formal aspects of reasoning, i.e. the construction and structure of moral judgements. With regard to hypotheses about differing gender roles in families and relationships, the section 2) explores the role of the family and of close social relationships in arguments in the context of organ donation. It is a merit of gender studies to induce critical reflection on political, cultural, and social influences on concepts of self-identity, attitudes, and morality with regard to gender. 
Therefore, our analysis was extended to participants' attitudes towards public, political, and social institutions and how they were 'gendered'. Against this background, the section 3) examines the roles of the market, the state, or the system of experts as systemic factors of modern science and medicine.

\subsection{Differences in the understanding and style of moral argument}

Although a majority of participants, regardless of their sex, held that donating organs is a morally meritorious and laudable act, many speakers, men as well as women, expressed the view that, at least with respect to living donation, there can be no general moral responsibility or duty to donate. This attitude is often based on the moral principle of personal autonomy. Autonomy is widely acknowledged as the basis of the right to bodily self-determination, that is, the exclusive authority to make decisions concerning one's own body without third persons interfering.

Throughout all group discussions, autonomy constituted the central normative touchstone for evaluation of organ donation. The principle of autonomy was frequently mentioned by both male and female participants. However, occasionally there seem to be gender differences in the way of referring to self-determination. Men usually took the normative validity and weight of the principle as a selfevident and an incontrovertible fact that hardly needed any further justification. Some female speakers, however, referred to autonomy in a more pronounced, at times even defensive manner. One had the impression that they felt the need to defend their autonomy against contravening expectations of relatives or society. There seemed to be an implicit awareness of a specific societal status as a woman, especially in the family context, and, in consequence, of a discrepancy between a general recognition of autonomy and particular gendered family roles and responsibilities.

Apart from the references to autonomy, a second position was often expressed: that organ donation is not a moral obligation. It conceives of organ donation as a highly individual matter of personal conscience and subjective feelings. Interestingly, especially female participants often followed this line of argument. On closer inspection, this position did not provide a basis for a general right to refuse donation. It did not involve the normative conviction that there is no effective moral principle from which such a judgement could be derived. Instead, it rather expressed some form of scepticism as to whether general moral principles can be applied to individual cases and do justice to the particular situation, at all. Morality is rather perceived as a matter of subjective feelings and attitudes which cannot be generalised with respect to other persons or cases.

In summary, a majority of participants agreed that there is no general moral duty to donate organs, although there were different background assumptions supporting this position. The majority of participants of both sexes endorsed an autonomy-based approach and postulated a strong right to refuse donation, albeit some female speakers showed a somewhat defensive position. Some female spea- 
kers put forward an altogether different position. For them, the moral conflicts involved in organ donation did not allow for any general judgements. Rather, they were perceived as a matter of individual feelings and irreducibly private weltanschaunng which might vary from person to person and from case to case. This attitude endorses a preference for the model of living donation instead of postmortal within the family circle because it provides an adequate framework for the settlement of moral conflicts among the affected persons themselves.

\subsection{It's a family affair: individual actors and close social relationships}

To understand gender aspects in organ donation, it is necessary to pay attention to relationships and gender role expectations. Therefore, we investigated whether relationships or gender played a role when our participants discussed to whom they would be willing to donate and from whom they would be willing to receive organs. In this part of the analysis, we focused on three aspects derived from the general discussion of gender disparities in organ donation: firstly, we examined whether men and women hold different views of the family. The roles ascribed to family members constituted a second aspect: who did they think would be a suitable donor/recipient, and which reasons did they give for this with regard to family relationships, social responsibility, or role expectations? Thirdly, we analysed whether health risks related to organ transplantation were considered an important topic as this is a major ethical argument against living donation.

Men as well as women talked about 'family' as a point of reference for sociomoral obligations. For most of them, the family still consists of the members of the traditional 'nuclear family' comprising mother, father, and child. Other relatives like sisters, brothers, aunts, uncles, cousins etc. are rarely mentioned as 'family'. Taking into account the modern pluralism of ways of life, it could have been expected that close friendships would be mentioned as well, because friends have become more important in social networks and sometimes even replace close family ties. However, no statement referred to this aspect.

At the beginning of the discussions, the facilitators introduced a short vignettecase concerning a brain dead woman for whom the parents have to make a decision pro or contra post-mortem donation. Uncertainty how to decide in this case was frequently expressed. Men as well as women affirmed the need to donate for their own children, but were uncertain with regard to a donation for a less closely related person. Many women used responsibility within the family context as an argument pro donation. Genetic relatedness was used as argument for better transplantation results on the part of the recipient because of genetic matching in immunology, but also for special interest in intra-familial donations. For example, some women referred to socio-biologistic argumentation involving heredity: by donating an organ to a still procreative family member, they saw the chance to ensure genetic continuance of the family line. Other women argued on an emotional interpersonal level, stressing how they would feel guilty in a given situation. 
These women also mentioned duties, but these were based on the idea of reciprocal exchange within a family. These statements indicate that men and women interpret moral obligations in the light of different role patterns. It is notable, however, that a number of men and women felt increasingly less obliged to fulfill the traditional gender expectations.

In summary, men and women based their arguments on different role patterns. Men showed a understanding of responsibility governed by general principles, while women tended to base their arguments on individual responsibility linked to concrete social roles and persons. In the context of living organ donation, women more frequently used responsibility for the survival of the family as an argument pro donation, saw themselves as being under an 'enormous pressure' to donate, and expressed fear of being guilty of failure to render assistance.

It is notable that the use of the word 'responsibility' in the relevant parts of the discussion was often equivocal. We identified two different, albeit interconnected, concepts of responsibility in the controversy. The first one can be labelled causal responsibility. It refers to authorship, that is, the (wilful) causation of certain events. In this sense, somebody is responsible for something if he (wilfully) caused it by his course of actions. The second concept of responsibility, more often referred to by female participants, means being in charge of someone or something, which usually involves an obligation to further the flourishing of the respective person or thing and prevent it from harm. In this sense, someone is responsible for someone or something if he/she has duties against him/her/it, for example a duty to involve one's partner in a discussion on organ donation, as in this case.

These two understandings of responsibility have implications for its range: while causal responsibility is perceived as naturally linking the responsible person and the act, the question for what or whom someone is in charge is determined in social networks and institutional settings like families or work places. Thus, the concept of responsibility as 'being in charge' seems to lead to a 'community-based' model which makes morally relevant distinctions related to degrees of social closeness, e.g. the nuclear family, the wider circle of family, friends, and strangers.

Men more frequently discussed the topic of risks of living organ donation on an abstract level. Women, on the other hand, rather put the focus on the dangers for their own body. However, with regard to the most common argument in this context, namely that one would not accept a living donation from a family member in order to avert risks for that person, no gender difference could be determined. Both men and women used this type of argument. A great number of male participants would prefer a post-mortem organ, so as in general not to harm a living person. Women more frequently discussed the particular risk for individual family members and how to avoid this by means of a post-mortem organ.

On the whole, the qualitative analysis shows that the family still remains a fundamental consideration in the assessment of organ transplantation. But it was also observed that no consistent image of the family prevailed - most probably a result of present-day diversified ways of life. Nevertheless, in thought experiments, par- 
ticipants often came back to the image of the nuclear family. Women more frequently than men argued from a position of care and responsibility for others. Men, on the other hand, more often used arguments of duties towards the family. However, before stating that this is clear evidence for a morality of care specific to women and a morality of justice dominant among men, it is necessary to have a closer look at the analysis of arguments regarding the social and public sphere.

\subsection{Public institutions and the socio-cultural context}

In this section, we pay attention to the socio-cultural context of organ transplantation, such as 'the state' or 'the expert-system'. As in the section on the family, participants often draw upon personal biographical experience (e.g. with hospitals or with legal authorities) whenever they referred to these social institutions. However, the socio-cultural embedding is different to the familial embedding insofar as it is experienced as supra-individual and as collectively shared, while the family is seen as an individually shaped social structure.

Participants did not see organ donation as a case of individual decision-making or 'something only between me and my physician'. Instead, three public institutions were mentioned, but with interesting differences between men and women concerning frequency and framing: the market, the state, and the medical system (the experts). All three were linked to specific questions of justice - and are not seen as independent from each other.

Men quite often referred to 'the market'. They criticised the illegal organ market, which was considered a global phenomenon. Even those who were convinced that the illegal organ trade takes place 'somewhere else', e.g., in India or Eastern Europe, used the illegal-market-argument as a justification to be sceptical about organ donation. The main moral problem of this market seemed to be injustice in allocating organs for transplantation, as, compared to the poor, the rich can get an organ more easily. In consequence, organ transplantation was considered as justified only if just allocation and equal access was guaranteed.

Generally, female focus group participants hardly ever referred to 'the market' or 'the state' or 'the legal situation'. Instead, they focussed on the expert system in medicine as public institution which was seen as prominent in decision-making contexts. Physicians or scientists were criticised to 'transcend limits' (expanding moral and legal limits by cloning, human experiments etc.) and for not respecting the wishes of the patients or the public.

Many men expressed distrust in experts and the medical system, but this did not undermine their belief in the value and objectivity of 'independent' studies. Several men acknowledged that even experts sometimes disagree and that they may have different opinions on different subjects. In a discussion about brain death, one male participant referred to empirical studies to support his rejection of the brain death criterion. These were not put forward as general, fundamental arguments against science. It was rather seen as a question of which experts someone 
believes in. Sometimes, the pragmatic view was expressed that science and medicine can be seen as valuable means to reach specific goals. This pragmatic attitude could often be observed when doubts about the scientific basis of the brain death criterion were expressed by members of the group.

\section{Discussion: the importance of gender roles for organ donation}

Given the small sample in our qualitative study, we do not attempt to make representative statements, but see our research as an important explorative contribution to a better understanding of differences in health related decisions between men and women. Hence, we discuss the socio-empirical findings in the light of our statistical analysis, showing on the one hand that in various countries, motivation and/or social pressure play a major role for explaining the gender difference on the donor side while on the other hand, medical and epidemiological aspects play a major role for explaining the gender difference on the recipient side.

Taking the idea that differences in the willingness to donate are based on differences in reasoning and morality as a starting point, we found that in the focus groups, men tend to show a preference for an abstract approach to organ donation resting on general principles that cover society as a whole and allow for clear conclusions to be derived from every case. While focussing on individual autonomy they emphasise the right to deny donation and the need to prevent harm for oneself. They prefer systemic solutions on the level of social institutions such as the state or the market. Many women, on the other hand, rather argue from within the context of particular social units and relationships such as the family and strive to assess and judge each case individually. From this perspective, moral conflicts often do not allow for any general judgements or systemic solutions, but are rather perceived as a matter of feelings and individual experience. This attitude goes along with a preference for living donation in the family context, which is also a basic legal condition in all three countries.

However, these findings do not affirm any of the basic outlines of the twomoralities debate, due to the following reasons:

Recent moral philosophical considerations show that there is no general antagonism between the central concepts of justice and care as suggested by Lawrence Kohlberg (34). In a differentiated perspective, justice appears as only one dimension of rights and duties, as a concept especially reserved for social, public institutions, while in the private sphere, there are also rights and duties towards family members. The category of care can be divided into care for oneself and care for others. This can help to understand why in our focus groups, men as well as women argued in terms of rights and care for the family. Insofar as differences were observed, they were rather due to the situative and contextual framework. This means that they reflected particular social contexts such as the family or the 
public sphere as well as personal experiences of participants in different ways. Especially two findings are critical to the liberal, autonomy centered idea that men and women show different moral attitudes to organ donation because of different ways of moral reasoning: first, only women mentioned the fear of being under an 'enormous pressure' in such decisions. This is a serious hint that women in general may experience these feelings more often than men. This might question the liberal rational perspective on decision making processes in organ donation.

Second, there is a clear gender-related difference in how social institutions such as the market, the state and the expert system are referred to: in the case of women the private domain of family life and personal contact to physicians prevails whereas in the case of men it is the market, science as such, politics, and law. It is commonly held that throughout the history of Western social thought and Western institutions and practices, the public and the private have been considered separate gendered spheres $(35,36)$. The incidence of 'gendered' institution when discussing organ transplantation strengthen that not the biological sex, but socially constructed and internalised gender roles are at stake (24). These gender roles are acquired, exercised and evaluated either.

Moral attitudes that refer to one's own body (e.g. in the case of illness or death), the care about the next-of-kin, and negative duties towards society (such as the right not to donate organs to society) seem to be connected to gender roles rather than to the sex of a person. Traditional role expectations such as caring for others (mothers' or daughters' roles) or earning money and being independent (fathers' or sons' roles) are well-discussed motives in health and socially related behaviour (3740).

However, the expression of potential pressures and fears (as during focusgroup discussions) is also a sign of a transformation of these social roles which leads to a diversification of moral positions, claims and expectations, and in consequence also to conflicts between traditional role models and principles such as personal autonomy. Men-women differences in the setting of a focus group can also be understood as a way of 'doing gender' (41), that is, of a person's performative act of presenting gender in behaviour and statements. While 'gender roles' emphasise the external ascription, 'doing gender' emphasises the subjective action. Any critical reflection on gender issues has to confront the problem that there exists a (theoretical as well as empirical) confusion of external and internal perspectives (as two sides of one coin) on what is actually related to gender/sex or to the socially constructed/natural.

Second, it is necessary to take into account moral psychological research which investigates the potential gender difference in handling moral dilemmas. NunnerWinkler suggests that it is not the biological sex but rather gender-related experiences and different ways of 'being affected' by a situation that account for gender differences. For example, men and women show different moral attitudes towards abortion or military service due to the fact that these affect both sexes in a different way: the issue of abortion is closer to the experience of women while military 
service is closer to the perspective of men (42). Following this line, we ask whether men and women are 'affected' differently by organ donation. Different forms of being affected lead to different forms of problem framing, competence and expertise (43). With 'being affected' we refer to a status classifying a person in relation to a state of affairs (e.g. being ill). This status is based on external ascriptions as well as on subjective self-ascriptions. As previous studies have shown, being directly, indirectly or hypothetically affected is related to moral, epistemic and cultural differences $(43,44)$, (e.g. the experience of being a patient with a chronic kidney failure who wants a new organ differs remarkably from being a healthy person who fears serious health risks of a living organ donation or hesitates to opt for a donation programme because of religious or cultural reservations towards brain death). From an ethical perspective, however, it is always important to take both perspectives into account.

We assume that in this context, different gender roles constitute different forms of 'being affected': on the one hand, the fact that women usually assume the role of caring for cbildren may explain why mothers donate significantly more often than fathers (see above), while fathers, although most probably emotionally affected by a child's disease as well, do not have the social experience to care for them. On the other hand, the gender role of the 'bread earner' might rather motivate men to provide their organs for transplantation when organ procurement is framed as a form of money earning (as is the case in Iran) while in altruistic transplantation systems, the 'bread earner' is spared because of health risks for the donor and unclear insurance situations.

\section{Outlook: bioethical and medical relevance of gender disparity in organ transplantation}

Our findings have practical implications for the clinical setting and for future research. First, from a psychological and educational point of view, it is necessary to raise more awareness for gender-related roles in the education of care givers, physicians, and psychologists who are involved in informing and recruiting potential donors. Physicians and psychologists still have an important gate keeper function when it comes to detecting coercion or power relations. Increasing their sensitivity to gender roles and expectations will allow for an identification of potential intra-familial conflicts and help to avoid wrong expectations about gratefulness and family bonds. $(43,44)$ Public campaigns for organ donation by national and international institutions and companies are dominated by the rhetoric of 'help for life', 'sharing life', 'gift of life', 'altruistic act' and 'Samaritan donation'. 
The impact of this rhetoric as well as of visual language ${ }^{5}$ should be critically investigated. At the moment, it often implicitly reinforces a gendered perspective on organ transplantation, mainly addressing those who are more sensitive to care for the family and care for the suffering.

Second, from an etbical point of view, it is necessary to critically reflect on the way bioethical theory and medical practice focus on the principle of autonomy and informed consent. Although autonomy undoubtedly is of central importance in the medical context, an exclusive focus on this concept or a too narrow understanding of its meaning runs the risk of blinding out power structures and role expectations which prompt decisions even in those cases when informed consent is obtained. Thus, in the spirit of empowerment of patients and in order to ensure a morally acceptable decision-making process, it is important to enable persons to become aware of and reflect on their gender roles. This is not to say that individual decisions are automatically invalid as soon as they are motivated by certain social contexts or gender roles. However, a truly autonomous, authentic, and therefore stable donor decision will probably be achieved more easily if a person is aware of their role behaviour and of gender role expectations and has a chance to deliberately accept or refuse them.

Third, from a medical point of view, there is a particular interest to increase the numbers of organs donated by men (see also (47) A recently published long-term study (48) has confirmed that kidneys from female donors have a higher risk of failure than those from male donors, irrespective of the sex of recipients. The authors also found that female recipients have a lower rate of graft failure. Within the medical focus, the recipient side should not be forgotten. As we have discussed in the first part of our paper, epidemiology explains why more men receive organs than women in four Eurotransplant countries. However, the reasons for this gender disparity in the epidemiology of renal disease are still under investigation. As a meta-study (49) shows, there are various complex physiological, genetic, and social factors involved but not well understood, yet. In polycystic kidney disease, membranous nephropathy, immunoglobulin A nephropathy, and 'chronic renal disease of unknown aetiology', diseases in men progress at a faster rate to end stage renal failure than in women. In type 1 diabetes mellitus males are more likely to manifest signs of renal disease, such as proteinuria. Factors responsible for this sex disparity include diet, anatomy and physiology of glomerulus, and the effects of sex hormones.

Finally, from a methodological point of view, our findings can help to inform future empirical approaches to the phenomenon of sex and gender disparity in organ donation, particularly, to avoid the pitfalls of re-affirming gender stereotypes (e.g., in questionnaires). In this study, we investigated motives and attitudes of potential

\footnotetext{
${ }^{5}$ Many advertisements for organ donation show only children or families. The American brochure 'sharing life' produced by Astellas company and provided by several websites shows only women when presenting the idea of 'potential living donors' (see http://www.transplantexperience.com/pdf /PDTP-0044_LvngKidneyBook-m7.pdf <10 September 2009>
} 
Silke Schicktanz, Mark Schweda \& Sabine Wöhlke

donors or recipients in a hypothetical transplantation scenario. More research on 'doing gender' is necessary in real-life scenarios, because emotions, time pressure and social bonds might have a stronger impact than in the reflective situation of a discursive setting. Further follow-up studies not only with patients, but also with their relatives are urgently needed. Moreover, it is also important to examine gender differences in post-mortem donation - a phenomenon not discussed at all, so far.

\section{Acknowledgements}

We would like to thank Eurotransplant for providing basic data and especially Jochem Rieger, Madgeburg, who did the statistical analysis. Furthermore, we would like to thank all participants of the focus groups for sharing their thoughts with us. We are also grateful to various colleagues who commented on an earlier version of the paper: Kristin Zeiler, Linköping, Nikola Biller-Andorno, Zürich, Ineke Klinge, Maastricht, and Claudia Wiesemann, Göttingen.

\section{Disclosure Statement}

No competing financial interests exist.

\section{References}

1. Heuer M, Hertel S, Remmer N, Wirges U, PhilippT, Gerken G, Paul A, Kaiser GM: Organspendebereitschaft: Auswertung einer Umfrage zu Gesundheitsthemen. Deutsche medizinische Wochenschrift 134(18); 2009; 923-926.

2. Schicktanz S, Rieger JW, Lüttenberg B: Geschlechterunterschiede bei der Lebendnierentransplantation: Ein Vergleich bei globalen, mitteleuropäischen und deutschen Daten und deren ethische Relevanz. Transplantationsmedizin 18; 2006; 83-90.

3. Thiel GT, Nolte C, Tsinalis D: Gender imbalance in living kidney donation in Switzerland. Transplantation Proceedings 37; 2005; 592-594.

4. Kayler LK, Rasmussen CS, Dykstra DM, Ojo AO, Port FK, Wolfe RA, Merion RM: Gender imbalance and outcomes in living donor renal transplantation in the United States. American Journal of Transplantation 3; 2003; 452-458. 
5. http://www.ustransplant.org/annual_reports/ <22 October 2009>

6. https://www.uktransplant.org.uk/ukt/statistics/transplant_activity_report/cur rent_activity_r eports/ukt/transp lant_activity_uk_2007-2008.pdf <21 October 2009>

7. Oien CM, Reisaeter AV, Leivestad T, Pfeffer P, Fauchald P, Os I: Gender imbalance among donors in living kidney transplantation: the Norwegian experience. Nephrology, Dialysis, Transplantation 8; 2005; 783-789.

8. Ghods AJ, Savaj S: Iranian model of paid and regulated living-unrelated kidney donation. Clinical Journal of the American Society of Nephrology 1; 2006; 1136-1145.

9. Sheper-Hughes $\mathrm{N}$ : The tyranny of the gift: sacrificial violence in living donor transplants. American Journal of Transplant 7; 2007; 1-15.

10. Decker O, Beutel M, Winter M, Brähler E: Sex Sells? Geschlechterunterschiede und Anreizmodelle in der Organspende. Transplantationsmedizin 20; 2008; $38-53$.

11. http://www.eurotransplant.nl/?id=statistics $<18$ November 2009>

12. Jindal RM, Ryan JJ, Sajjad I, Murthy MH, Baines LS: Kidney transplantation and gender disparity. American Journal of Nephrology 25; 2005; 474-483.

13. Kayler LK, Meier-Kriesche HU, Punch JD, Campbell DAJ, Leichtman AB, Magee JC, Rudich SM, Arenas JD, Merion RM: Gender imbalance in living donor renal transplantation. Transplantation 73(2); 2002; 248-252.

14. Harper AM, Rosendale JD, McBride MA, Cherikh WS, Ellison MD: The UNOS OPTN waiting list and donor registry. Clinical Transplantation 1998; 73-90.

15. Kjellstrand CM: Age, sex, and race inequality in renal transplantation. Archives of Internal Medicine 148; 1988; 1305-1309.

16. Biller-Andorno N: Gender imbalance in living organ donation. Medicine, Health Care and Philosophy 5; 2002; 199-204.

17. Jaglal SB, Goel V, David NC: Sex differences in the use of invasive coro-nary procedures in Ontario. The Canadian Journal of Cardiology 10; 1994; 239-244.

18. Sanner M: 'Transplant recipients' - conceptions of three key phenomena in transplantation: the organ donation, the organ donor, and the organ transplant. Clinical Transplantation 17; 2003; 391-400.

19. Truog RD: The ethics of organ donation by living donors. The New England Journal of Medicine 353(5); 2005; 444-446. 
20. Ingelfinger JR: Risks and benefits to the living donor. The New England Journal of Medicine 353(5); 2005; 447-449.

21. Kohlberg L, Levine C, Hewer A: Moral stages: A current formulation and a response to critics. New York: Karger; 1983.

22. Gilligan C: In a different voice. Psychological theory and women's development. Cambridge, Mass. et al.: Harvard University Press; 1994.

23. Hagemann-White C: The societal context of women's role in family relationships and responsibilities. In: Garms-Homolova V, Hoerning EM, Schaeffer D (eds.): Intergenerational relationships. Lewiston, NY: Hofgrefe; 1984; 133-142.

24. Pauer-Studer H: Identity, commitment and morality. Journal of Economic Methodology 13(3); 2006; 349-369.

25. Haraway D: Simians, cyborgs and women. The reinvention of nature. London: FAB; 1991.

26. Jaffee S, Hyde JS: Gender differences in moral orientation: A meta-analysis. Psychological Bulletin 126; 2000; 703-726.

27. Rickard M, Kuhse H, Singer P: Caring and justice: A study of two approaches to health care ethics. Nursing Ethics 3(3); 1996; 212-223.

28. Robertson DW: Ethical theory, ethnography, and differences between doctors and nurses in approaches to patient care. Journal of Medical Ethics 22(5); 1996; 292-299.

29. Conradi E, Biller-Andorno N, Boos M, Sommer C, Wiesemann C: Gender in medical ethics: Re-examining the conceptual basis of empirical research. Medicine, Health Care and Philosophy 6; 2003; 51-58.

30. Morgan DL: Focus groups as qualitative research. Thousand Oaks: Sage; 1997.

31. Bohnsack R: Rekonstruktive Sozialforschung - Einführung in Methodologie und Praxis qualitativer Forschung. Opladen: Leske + Budrich; 2004.

32. Strauss AL, Corbin JM: Basics of qualitative research. Grounded theory procedures and techniques. Newbury Park: Sage; 1990.

33. Mayring P: Qualitative content analysis. Forum Qualitative Sozialforschung $1(2) ; 2000$.

34. Döbert R, Juranek N: Do concepts matter? The impact of a justice framing on responses to a moral dilemmas - A research note in morality in context. In: Edelstein W, Nunner-Winkler G (eds): Morality in context. Amsterdam: Elsevier; 2005; 225-244. 
35. Elshtain JB: Public man, private woman: women in social and political thought. $2^{\text {nd }}$, revised edition: Princeton University Press; 1993.

36. Held V: The ethics of care. Personal, political, and global. New York: Oxford University Press; 2006.

37. Goffman E: Gender advertisements. New York et al.: Harper; 1987.

38. Hilton BA, Starzomski RC: Family decision making about living related kidney donation. American Nephrology Nursing Journal 21(6); 1994; 346-354.

39. Sanner MA: Giving and taking- to whom from whom? People's attitudes toward transplantation of organs and tissue from different sources. Clinical Transplantation 12; 1998; 530-537.

40. Fellner CH, Marshall JR: Kidney Donors. In: Macaulay J, Berkowitz L (eds): Altruism and helping behavior. New York/London: Academic University Press; 1970; 269-281.

41. West C, Zimmerman DH: Doing gender. Gender \& Society 1; 1987; 125-151.

42. Nunner-Winkler G, Nikele M: Moralische Differenzen oder geteilte Werte? Empirische Befunde zur Gleichheits-Differenz-Debatte. In: Heintz B (ed.): Geschlechtersoziologie. Opladen: Westdeutscher Verlag; 2001; 108-135.

43. Schicktanz S, Schweda M, Franzen M: 'In a completely different light'? - The role of being affected for epistemic perspectives and moral attitudes of patients, relatives and lay people. Medicine, Health Care and Philosophy 11; 2008; 57-72.

44. Raz A, Schicktanz S: Diversity and uniformity in genetic responsibility: moral attitudes of patients, relatives and lay people in Germany and Israel. Medicine, Health Care and Philosophy; 2009; DOI 10.1007/s11019-11009-19215-x.

45. Surman OS, Fukunishi I, Allen T, Hertl M: Live organ donation: Social context, clinical encounter, and the psychology of communication. Psychosomatics 46(1); 2005; 1-6.

46. Weber K, Martin MM: Gender and consent to organ donation. The Journal of Social Psychology 146(2); 2006; 247-249.

47. Sanfey H: Gender-specific issues in liver and kidney failure: A Review. Journal of Women's Health 14(7); 2005; 617-626.

48. Gratwohl AG, Döhler B, Stern M, Opelz G: H-Y as a minor histocompatibility antigen in kidney transplantation: a retrospective cohort study. Lancet 372; 2008; 49-53.

49. Silbiger S, Neugarten, J: Gender and human chronic renal disease. Gender Medicine 5(Suppl. A); 2008; 3-10. 



\title{
Sex, gender, and the brain - biological determinism versus socio-cultural constructivism
}

\author{
Sigrid Schmitr.
}

\section{Abstract}

This paper outlines the field of brain research devoted to the question of sex differences in brain structure and function with implications for buman bebaviour and cognition. Based on the analytical approaches of gender and science studies, the findings, the methodological influences, the theories and interpretations in this field of research are critically reviewed. Taking account of the inconsistent findings on this issue, the differing approaches of biological determinism and socio-cultural constructivism are elaborated in order to develop a differentiated view on brain-behaviour interrelations against a gendered background. The constructive approach reveals a challenging view on the nature-nurture-debate and points to gender constructions in the brain formed by a specific psychosocial and cultural background.

\section{Introduction}

The question of sex differences ${ }^{1}$ in the human brain is being controversially discussed since mid 19th century and has not lost its discursive power until today, neither in the scientific debate (1-4) nor in popular science literature (5-7), to name only a few examples. One reason for this ongoing debate is the aim not only

\footnotetext{
${ }^{1}$ I use the term sex differences because studies in brain research are predominantly based on a concept of binary biological sexes, female and male, although some papers use the term gender in their title.
} 
to detect distinct differences between female and male brains, but also to explain how their brain structures and functions determine thinking, behaviour, cognitive skills, attitudes, and perceptions about the world, and even sexual orientation. Meanwhile, modern brain imaging technologies ${ }^{2}$ give new insights into the living brain that should lead to an improved understanding of the brain's structure and function in relation to cognitive processes.

The concern of this paper is to critically review the current state of brain research on sex differences, to reassess which findings remain contradictory and to challenge the interpretations derived from these findings. The sex/gender distinction $^{3}$ is of particular importance in this context in order to challenge the view that behaviour, cognition and action can be explained by biological sex determination (concerning genes, hormones, the brain structures and functions) to full extent. In contrast, by using the term gender we can also challenge the idea that experiences in a socio-cultural context not only influence the individual's behaviour and identity, but, moreover, that those gendered learning processes gain influence on the formation of biological processes and bodily development.

In this paper I elaborate analytical approaches of gender research ${ }^{4}$ that can help to assess the validity of brain research results and to gain a profound understanding of the mutual interactions between biology and culture within the scopeof sex, gender, brain and behaviour. I start this analysis by disclosing some presumptions that underlie sex difference research in the neuroscientific field (section 3). I then pick out three fields from current brain research on sex differences (language, space, and the corpus callosum) to apply the analytical framework of gender research for a critical analysis (section 4). In doing so, it is helpful to differentiate between two perspectives, Keller called science of gender and gender in science (8). The first perspective, science of gender, focuses on the empirical inquiry within scientific research and critically reflects the relations between theories, methods, findings and their interpretations. This analytical approach not only uncovers research results that support or contradict each other, it also challenges the ways in which these findings are elaborated and presented with certain methods of research.

\footnotetext{
${ }^{2}$ The radiological method of Magnetic Resonance Imaging (MRI) uses nuclear magnetic components (e.g., of hydrogen atoms) that react in a scanner to radio-frequency waves and generate a tissue specific signal. The signals are then computed into grey-level characteristics to visualise and separate brain structures in a digital image. Further processing is conducted to colour the brain structures or to develop three-dimensional brain models. Functional Magnetic Resonance Imaging (fMRI) refers to the same principle but measures the magnetic changes of oxygenised/deoxygenised blood flow related to activation pattern in certain brain areas. Positron Emission Tomography (PET), in contrast, uses radio-actively-labeled oxygen or glucose that accumulates in nerve cell networks during information processing to detect and visualise active brain areas.

${ }^{3}$ For a detailed explanation of the sex/gender distinction, see the paper of I. Klinge in this book.

${ }^{4}$ Gender research covers analytical approaches that not only refer to the biological formation of the sexes but also include the investigation of societal influences and constructions, both, on the formation of gender roles, gendered behaviour and gendered identities, and on the processes of scientific work itself.
} 
Thereby, omissions and distortions can be debunked, for example concerning the selection of test subjects (women, men, age groups, ethnicities, etc.), test procedures or the conduction of data analyses. Within this approach, the brain imaging technology can be taken under review as well, because these methods of image construction represent a whole array of decisions on aspects that are included or omitted in the course of the imaging procedure.

The second perspective of gender in science takes a more meta-analytical level and examines how socio-cultural gender aspects are incorporated in the epistemological and methodological framework of brain research. It challenges the view of seemingly neutral and objective outcomes of scientific research by disclosing the influences of social processes and beliefs on scientific activity, on its presumptions, goals, research programs and presentations. Some of these influences can already be shown with respect to the three fields of research in section 4 .

However, it is not the goal of gender research to discredit the use of brain research for gender debates in general, but rather to raise awareness of the sociocultural embeddedness which cannot be avoided in any scientific endeavour. Therefore, to further elaborate the gendering processes in science it is also crucial to question the theoretical concepts that underlie the interpretation of the findings derived from neuroscientific analyses, i.e., determinist concepts vs. plasticity concepts (section 5). Determinist concepts attach more importance to genetic and hormonal causes for explaining brain processing and cognitive action. They assume that the biology of the brain and the way the brain works are more or less predefined. In contrast, plasticity concepts conceive the development of brain structures and brain functions more as a result of individual experience. Instead of being predefined, behaviour, cognition and the processing of information transform the nerve networks in the brain. This nature-nurture controversy is strongly intersected with the question of sex and gender in the brain. Against this background, I discuss how we can then speak of a gendered instead of a sexed brain, combining biological and socio-cultural interactions into a concept of embodiment (section 6). Last but not least, I stress the influence of brain research on the public debate and propose some challenges for the neurosciences to contribute to these debates in a responsible manner.

\section{Regarding the brains of women and men}

When dealing with structures and functional processes in the brain in relation to the construction of sex/gender differences, I will focus on studies that analyse the cortex. This brain part encompasses all those united cell structures and nerve networks that take part in the information processing of cognitive action such as thought and problem solving.

A brief summary will shed some light on the prevailing concepts about the make-up and function of the cortex. The adult human cortex contains ten to 
twenty billion nerve cells, each of them interconnected up to 10.000 other nerve cells via synapses. Thus, the cortex is an extremely dense network where information is transferred via electrical and chemical impulses. The constitution of the cortex network is not purely accidental. Certain areas are largely responsible for the processing of certain information, for example the occipital lobe for visual information, areas in the temporal lobe for auditory perception, areas in front of the temporal central sulcus for motor regulation and those behind the central sulcus for the compilation of the somato-sensory functions. Besides these specialisations of certain areas for the sensory information, the cortex is also instrumental in more complex processing of information. The more the pronounced visual, auditory and somato-sensory impulses are bound (multi-modal information processing), the more networks interact. The frontal lobe, in particular the pre-frontal cortex, takes a central role in the generation of associations and decision processes.

Repeated processing of information patterns seems to stabilise the subnetworks of the cortex. As a result, these sub-networks 'recognise' similar information faster, which is a basic requirement for learning. An important issue in brain research is how unequivocally the aforementioned networks are determined a priori or to what extent the networks are moulded in the course of each person's development and learning experiences. The latter question in particular refers to the concept of brain plasticity which I am going to discuss in relation to gender issues later on.

With respect to analyses of sex differences in brain research, differently activated networks in particular cortex areas (function) as well as differences in the size of the related cortex areas or the density of their nerve cell connections (structure) are investigated during various cognitive tasks. The following core-questions are current research topics in the majority of studies: Do structures and functions of the brain differ according to various groupings - not only by sex but also by ethnicity, disease, or social classification? Do these differences determine cognition and behaviour? At first glance, these questions stand to reason. At second glance, it becomes clear that a whole array of presumptions underlie these methodological approaches. First, a binary grouping with an unambiguous dividing line must be determined, e.g., between women and men. Second, it has to be postulated that both groups on each side of the line show clear behavioural differences. This means that all analyses take for granted a stable binary two-sex concept. Third, it must be presupposed that the biological material of the brain shows demarcated differences in its structure and function that are just as clear. Fourth, these differences in the structure of the cortex or in its activation networks must be measurable. Fifth, it must be assumed that there is a direct relation between differences in the brain and differences in behaviour. All of these postulates are not put into question, but they are nevertheless the prerequisites to put sex (and other) differences in the central scope of research, and to accentuate the brain as the crucial entity to explain the causes of these differences leaving other explanations uncon- 
sidered. ${ }^{5}$ In addition, one has to question whether particular studies base their interpretation of results on deterministic concepts or on the brain plasticity approach and how these relations to particular theories influence the interpretation of the findings.

\section{Methods - findings - contradictions}

I will single out three research fields to shed some light upon the methods, findings and interpretations of results in current brain research with particular focus on brain imaging analyses. The debate regarding the different use of both hemispheres of the cortex by women and men during cognitive problem solving is salient in this issue. The laterality hypothesis that many research groups adhere to assumes that female brains use both hemispheres more prominently to solve cognitive tasks (symmetry, bi-laterality), whereas male brains are assumed to make stronger use of either one or the other hemisphere, according to the task specificity (asymmetry, laterality).

\subsection{Research field 1: brain - sex - language}

One main field of brain analyses exploring sex differences comprises functional imaging studies (mostly fMRI or PET studies) on language processing. The brain is 'scanned' while the test subject receives a language task via a screen or head phones. For example, $\mathrm{s} /$ he has to match word pairs or to recognise a rhyme and has to push a button every time two words belong to the same category or if they rhyme. After the termination of the task and after a complete series of computational processes, activated areas of the brain are finally made visible and illustrated in colour.

However, this seemingly standardised procedure comprises a high degree of methodical variations, concerning the amounts of subjects per task group in various ages with differing socio-cultural backgrounds, diverse sets of language subtasks, a broad array of computational and mathematical algorithms for image construction, and differing methodological and statistical procedures in data analysis (2).

A number of brain imaging studies have presented results that refer to sex differences in brain activation during language processing tasks; here I refer only to some of them (12-16). In contrast, other studies found no sex difference; again I name only some examples (17-21).

\footnotetext{
${ }^{5}$ Other analyses of gender research have outlined how these ascriptions have been developed in historical and socio-cultural contexts. However, their treatment would exceed the scope of this chapter; for a more in-depth analysis, especially concerning the history of intelligence research, see Bleier (1984), Hagner (2006), Schmitz (2008) (9-11).
} 
Instead of reviewing all these contradictory findings here (for a detailed overview see $(2,3,22,23)$, I take two empirical studies to exemplify the approach of critical gender research scrutinizing the methods, findings, presentations and interpretations of the papers.

The study by Shaywitz et al. (16) was published in 1995 in Nature and has been cited widely for the last ten years in almost all publications that refer to sex differences in language processing. In popular science reports in particular, it is presented as scientific evidence for the bilateral language processing in women in contrast to the left-side (lateral) activation in men. However, the detailed analysis of the study has warranted a series of critical assessments. Altogether, 19 men and 19 women conducted various language tasks involving orthographic and semantic decisions, and the recognition of rhymes. Differences in the subjects' performance were not to be found in any of the tasks. During the cognitive task solution, activations in particular networks in the right and left cortex, the so-called Broca areas, were measured with fMRI technology. Only for the identification of rhymes did the 19 men use the left sided Broca area more than their right counterpart, whereas, in general, the female subjects showed a stronger bilateral activation during rhyme recognition. These mean differences were presented in the paper as images of the female and the male brain with coloured Broca areas in both or the left hemisphere, respectively. Additionally, the laterality indices were shown in a table as means of the two pre-categorised sex groups. However, when looking at the individual results in detail (15), the symmetry in activation of both Broca areas occurred only in eleven of the nineteen women. While the general mean differences are stressed in the publications, there are no statements regarding the eight women that did not prove a clear symmetrical activation in rhyme recognition. In spite of this quite ambiguous result, the abstract of the Shaywitz publication (16) summarises: "Our data provide clear evidence for a sex difference in the functional organisation of the brain for language [...]", and already the second half of this sentence: "[...] and indicate that these variations exist at the level of phonological processing", is usually lost in the popular science reception that followed up.

Julie Frost and her team (18) wanted to repeat the findings of the Shaywitz study to confront the fact that the number of subjects was too low to allow general conclusions and that the selection of the examined regions of the brain was limited. The group conducted a study comparable to the method of the Shaywitz research group with 100 subjects (50 women and 50 men), who had to solve a wordpair task, and completely analysed the scanning results for all cortical brain regions. But instead of proving the results of the former study, their statistical analysis found no differences in the laterality of activation, neither in the Broca area nor in other cortex regions. It is interesting that these authors chose a unique way to present their results in brain images on page 203 of their study: in four series, images of the concerned brain regions are shown, each series comprising five slices in line with coloured brain regions of average activation in 50 subjects. In the two upper series the results represent two groups of subjects chosen by chance, the two lower 
series show data of 50 women and 50 men (corresponding to the accepted sex categorisation). Already by visual comparison, these brain images do not show any differences, neither between the subjects chosen by coincidence nor between the sex groups. The presentation of statistical results then confirms this first impression. ${ }^{6}$ To that effect, the research group interpreted their results: the similarity between women and men in this study was larger than the differences between them.

In conclusion, both studies pursued similar research questions, but revealed contradictory results using differing procedures of data analysis and presentation of findings. Both papers used particular settings of images in order to stress their interpretation of the findings. Thus, it turns out to be highly controversial to generalise findings from one study and to argue for sex differences between the female and the male group as seemingly homogeneous categories. This aspect was also elaborated in a meta-analysis by Sommer and colleagues (22), who compared the entirety of the fMRI studies regarding language, sex and the brain from 1995 to 2004, with a total of 14 studies with 422 women and 377 men, including the Shaywitz and Frost studies. They found no comprehensive sex differences in the laterality of language processing. Likewise, the meta-analysis could not determine a consistent relation to the defined task type (for example, differences in rhyme recognition but not in word-pair tasks). Strikingly, those studies that did present differences consistently used a low number of research subjects, whereas no differences could be determined in studies with larger groups of participants. The latter should appear in case of a population effect. In conclusion, Sommer et al. traced the marginal occurrence of differences in small groups back to a statistical random effect because with a high number of studies statistical artefacts occur automatically.

Against this background of contradictory research findings another aspect has to be considered in critical analysis. The Shaywitz publication and similar studies that presented sex differences are more likely to be published and cited in scientific and popular literature, especially when they support the prevalent laterality hypothesis, in contrast to the Frost study or other publications that found no differences. A 'non-difference' finding that indicates sex analogousness seems to be less interesting, even when it is more valid because of a higher number of subjects. This 'publication bias' (2) uncovers the underlying presumption of the search for differences between the binary sex categories that I have outlined in the beginning. It leads to a distortion of knowledge by emphasising differences more than similarities (1) resulting in a tenacious power influencing the popular debate on gender constructions via popular science (25).

Last but not least, within this context of the impact of neuroscientific knowledge presentation on the socio-cultural gender discourse, the power of brain images is of particular interest. The Shaywitz research group was the first that tested

${ }^{6}$ For a detailed analysis of the Frost-Study see Schmitz/Schinzel (24). 
for sex differences in the field of language processing with the 'new' methods of brain imaging. Corresponding images with red or yellow activation areas in the brain attain an enormous persuasive power by now because they communicate the impression of being able to visualise where and how the brain is working at a specific point in time. Confronted with these images we cannot prevent ourselves from thinking that the brain blinks red or yellow even though these colour markings are only the result of calculations of an activated magnetic status in the brain. Thus, the imaging technologies of brain research have reached an increasingly ostensive validity of the presented findings.

What cannot be seen in the image is the long and drawn-out process for its construction. For a start, brain images are not direct copies of the inside of the brain because images are constructed with the assistance of several IT-supported calculations, algorithms and models, computer graphic methods and statistical evaluation paradigms. The visually impressive illustration of the end result, the digital brain image, can be misleading: a long chain of steps for its interpretation is necessary to filter out the results from the measured data. Analyses of science and technology studies (STS) have addressed the multitude of decisions that are made by research groups during the course of the construction process from scanner to image: what will be included in the image and what is left out, what will be accentuated and what remains in the background (26). For example, not all brain activation is considered in the evaluation during an fMRI procedure. Only those values that exceed a prior determined threshold are included. These values that exceed the threshold are used to separate task-oriented activations from background noises of the brain that are always present. The threshold is determined by the scientific community within certain limits. Kaiser et al. computed various threshold specifications, all within the scientifically accepted scope, on the same data of 22 women and 22 men derived in a task of language processing. The first statistical procedure revealed no difference concerning the mean activations in the Broca area between women and men. Both groups showed a left-sided activation. Using a lower threshold (more activations are included in the evaluation that results in the images), the men's brains - in contradiction to the laterality hypothesis - showed a bilateral activation in comparison to a more pronounced left-sided activation in the women's brains (27). For the first time, it was shown how dependent the results of brain imaging studies are on the methods and calculations used by the experimenters. This dependency on methodology is gaining importance because various research groups use different methods in image construction and data analyse and there is hardly a study that is perfectly comparable to another. The difficulty to compare results of brain imaging is an enormous problem also within neuroscientific debates (28). For this reason, comprehensive statements generalising across tasks, methods, and sexes referring to studies of this kind must be seen with a critical eye. 


\subsection{Research field 2: brain - sex - space}

The second field of research concerns sex, the brain and spatial ability or orientation skills. Again, analyses comprise a wide range of tasks from mental rotation (the ability to align a geometrical figure mentally to determine concurrences with a set of given figures) via navigation skills to the development of spatial maps with particular spatial cues such as landmarks or directions. Here, I will focus on the latter aspects of navigation and orientation skills for a critical analysis.

Sex difference research stresses that men possess a better ability in processing characteristics of direction in contrast to women's advantage of remembering and positioning landmarks (29). In this context, there is a broad debate on the causalities for these differences (30). Evolutionary argumentations start from the hypothesis that the male hunter developed large scale directional and configurational skills in prehistoric age, whereas the female gatherer improved landmark skills in particular. These biological theories go together with hormonal theories arguing that higher testosterone levels favour spatial performance in men. On the other hand, environmental factors are stressed to explain the influence of social and learning experience on the development of spatial and orientation strategies. Successful strategies for navigation and knowledge acquisition of directions, configurational cues and landmarks are learned in childhood and youth. Accordingly, the individual variability in spatial strategies is often higher than differences between the female and male subjects. To a certain extent, however, girls and boys in western societies still have different experiences in outdoor navigation. Boys are allowed to discover their environment on their own more than girls, and in line with these experiences feelings of security and insecurity conjoin which influence the choices made about one's own strategy by the same token (31). Gendered experiences then act secondarily upon spatial orientation as they influence which strategies are developed and implemented in one's own behavioural repertoire. One could argue that due to these socio-cultural influences the term gender difference research would characterise this field of research in a better way. However, as the following brain imaging studies refer to binary sex groups without further differentiating female or male participants along their experience or socio-cultural background I will continue to name these issues as what they are: sex difference research. I discuss the topic of a possible gendered brain in detail in section 6 .

Brain research has started to analyse the processing of navigational and landmark cues during orientation behaviour with the help of brain imaging technologies. Eleanor Maguire and her research team concluded from fMRI analyses that the right hippocampus (a structure in the inner part of the brain) and the right parietal cortex seem to be mainly responsible for the recognition of navigational cues, whereas the parahippocampus, a structure next to the hippocampus, seems to be mainly responsible for object localisation (32). 
Concerning differences between women and men, this concept should lead to the hypothesis that men's right hippocampus would be more activated in conjunction with their preferred strategy in finding direction, and with women, the parahippocampus would be more activated in conjunction with their preferred landmark strategy. Grön and colleagues (33) combined the navigation in a virtual maze with the measuring of brain activation in a study with twelve women and twelve men. The results are quite astonishing, but the interpretation is even more astounding. In general, the men showed a more intense activation in the left hippocampus and in the right parahippocampus, while the women used the right parietal cortex and the right frontal cortex more intensively. It is all the more remarkable that the authors cite this as proof for women's preferred landmark processing. They claim that women 'keep a lookout' for landmarks to support their navigation (although they did not show a higher activity in the parahippocampus), while the left-side hippocampus activation of the men represents the use of complex geometrical tools for spatial navigation (although navigation processing, according to Maguire, is attributed to the right hippocampus). In spite of these inconsistencies, this study has been cited prominently as proof for ascertaining the differences between women's and men's brains and their performance in spatial orientation. Recently, Blanch and colleagues (34) disagreed with these conclusions. They did not confirm differences between twelve females and thirteen males concerning the activation of particular brain areas while learning routes from a map.

Thus, the state of research on sex, brain and cognitive processing in spatial orientation also shows contradictory results, and the investigation of certain areas of the brain during the processing of landmarks (assumed as female specialisation) in contrast to the acquisition of directional cues (hypothesised as male priority) presents substantial discrepancies. Neither in behaviour nor in the performances can a clear dichotomy be substantiated; the activation networks in the cortex vary highly for each individual. Additionally, the results are again dependent on each study's methods and measuring contexts. For example, Blanch et al. (34) criticised the method of the study by Grön et al. (33) as it had used uncorrected significance levels for detecting sex differences in brain activity patterns.

However, while the potential or non-existent sex differences are discussed within the brain sciences, popular science repeats the determination of male and female brains regarding orientation skills in an uncritical manner. Most popular science articles or books state with reference to allegedly 'non-ambiguous proof from brain sciences' that men have better spatial orientation than women, and some do this without quoting citations from scientific literature at all (7).

\subsection{Research field 3: sex and the corpus callosum}

Brain research is concerned not only with the location of activated areas in congruence with cognitive problem solving but also with the size, volume or connectedness of the underlying brain structures. There is a long tradition in determining sex 
differences in brain size or volume, or in size, volume or density of particular brain areas, respectively $(35,9,11)$. When both hemispheres of the cortex work together in processing information, they must exchange this information. This transfer occurs primarily through a fibre bundle that connects related cortical areas in the two hemispheres, the corpus callosum. Regarding the laterality hypothesis, the corpus callosum is another protagonist for the investigation of sex differences following the hypothesis: if women use both hemispheres more, their corpus callosum or parts of it should be larger than men's who mostly use one hemisphere at a time, the underlying premise being that a larger corpus callosum would contain more connecting fibres for the transfer of information.

The corpus callosum's straight road to success in sex difference debate began with the publication of DeLacoste-Utamsing and Halloway (1982), who measured its size in the brains of five women and nine men post-mortem (36). They stated differences in the shape of the back part of the corpus callosum, the so-called splenium: the women's splenia being larger and more bulbously shaped than those of the men. This publication triggered a wealth of successive studies. To make a long story short: for every study that has presented differences in a part of the corpus callosum, there are others that did not find differences or even presented opposite results. For example, Witelson (1989) published results that indicated that the women's isthmus, another part of the corpus callosum, was more pronounced than that of men (37), whereas other studies stated the reverse, that men had even more fibres running through their isthmus than women (38). In summary, a metaanalysis on a set of 49 studies with more than 1000 subjects generated no regularised sex differences concerning the size of the corpus callosum, even when results have been corrected for relative cortical size differences between the sexes (39). In the totality of the studies concerning the corpus callosum, it has been shown that the variability within the groups of women or men is often larger than the differences between them. Thus, the critical analysis of the findings concerning sex and the corpus callosum shows the same pattern of ambiguous results as the other research fields. And, as for the field of language research, this meta-analysis also showed a 'publication bias', as studies stating differences for the corpus callosum were cited more prominently than those negating difference (39).

Again, the contradicting results strongly ask for a critical analysis of the methodical variations in the research field. First, one has to question how the corpus callosum (CC) can be measured at all. Fausto-Sterling (40) provided a detailed analysis of the methodological influences on the measurement of the corpus callosum. She identified the rather diverse ways of handling the research objects in the laboratory or during an fMRI analysis and named these processes "Taming the Wild CC" on page 119 of her book. For example, this brain structure can only be relatively well demarcated in the cross-section exactly between both hemispheres because the fibres branch out extensively into both sides of the cortex. Thus, the measurement of parts of the corpus callosum, for example the isthmus or the splenium, is limited to the midline area. Here, subareas are demarcated differently by 
different research groups, with varying calculation procedures and resulting in differing separations in five to seven callosal parts. Furthermore, the size of such an area can be calculated with varying mathematic models (e.g., a square or a rhombus) and sex differences can be increased or decreased, according to the interpretation model based on the same data (41). Consequently, a comparison between the results or a generalisation of studies has to be handled with caution.

Additionally, a whole set of factors influences the size of the corpus callosum, one being the subject's age or handedness (37). Hence, the reputation of the corpus callosum as a marker of sex differences is on the decline in the scientific arena due to criticism by gender research. As Wallentin (3) states in his recent review on page 4: "the alleged sex-related corpus callosum size difference is a myth". Nonetheless, and similar to the other research fields, sex differences related to the corpus callosum are still cited in popular science with reference to the women's more pronounced connection explaining their higher connectedness between the hemispheres during cognitive procedures.

\subsection{Summary}

These analyses of brain research's methodological and empirical background in three issues uncovered its strong focus on sex difference research. Even though there are very contradictory results, scientific and, even more, popular scientific publications predominantly cite studies to determine the differences between women and men (25). Methodological variations have been outlined that influence the assessment of findings and challenge the transfer of results between studies or the drawing of simplified generalisations over the sex categories. With the help of the analytical approaches under the first perspective of science of gender (see introduction) methodological flaws in empirical studies can be uncovered. This can help to raise awareness within the scientific community on how the empirical setup, the techniques of data acquaintance and analysis, or the use of statistical procedures influence research findings. More and more, this type of reflective analysis is found in publications in high ranked neuroscience journals $(2,3,22,23)$.

Brain imaging methodology puts its emphasis on the localisation of demarcated brain areas, whose specific function is to be attributed to certain tasks. No question, brain imaging has turned out to be an important technique to improve knowledge of brain processes. However, science and technology studies (STS) demystify the uncritical acceptance of these images as neutral or objective facts as they illustrate how decision processes in a scientific community during image construction are influenced by external factors: by background theories, research questions and aims, technological prerequisites, economic and political aspects, as well as by popular perceptions of gender $(26,42-44)$. Uncovering these influences on scientific work is part of the second perspective of gender in science. 
These are some approaches to critically reflect on the debate on the gendered brain. Another step of gender research is to question the theoretical underpinnings of the empirical 'evidence' and challenge the interpretation of findings. Up to here, cognitive processing has been viewed based only on its biological sources. However, there are other theories that take into account influences of our experiences and social interactions on the acquisition of certain ways of cognition and behaviour as well as on the structural and functional development of the brain.

\section{Theories and interpretations: from a determined to a constructed brain}

The brain shows plasticity according to individual experience. Adults who are socalled early bilinguals, i.e., who have learned two languages up to the age of four, show similarly activated areas in the frontal cortex when asked to conduct speech production tasks (like reporting their daily activities) in one or the other language. Adult late bilinguals, however, who have acquired a second or third language later in life, show slightly differing cortical activation patterns during similar language tasks (27, 45). Maguire's research group (2000) reported results from an MRIanalysis of 16 London taxi drivers compared to 50 non taxi driving males. Taxi drivers with a long lasting navigation practice and orientation experience had a larger hippocampus than untrained/unskilled controls; and the hippocampal size correlated with the duration of the individual's driving experience (46). Studies done with adult key board players yielded the result that those who had received training experience with both hands from early age on (before the age of six) had a high symmetry in handedness as well as a larger corpus callosum (comparing those parts that connect motor cortex areas) than those musicians that had not been trained ambidextrously (47, 48). Recently, Draganski (2004) and colleagues showed that training in juggling for untrained students enhanced neuronal networks in cortical motor areas within three months (49).

With due methodological precaution and without over-generalising these findings, it can be hypothesised that not only behaviour, action and learning strategies are acquired by training, but that brain structures and patterns of activation change too, according to relevant experiences. The concept of brain plasticity, the idea that brain development is responsive to environmental influences $(50,51)$, was already developed in the 1970s. It was shown that rats and mice maturating in an environment with many stimuli had a larger cortex with more neuronal connections. For humans, interpretations made from studies on brain dysfunctions and their rehabilitation had a great impact upon the development of the brain plasticity concept. For example, up to the age of six, the visual area in the back of the cortex is highly shapeable. If one eye is hardly or never used, such as in the case of strabismus, processing areas of the other eye in the visual cortex can take over this function. These processes can be influenced by training in childhood. Conversely, the 
principle of brain plasticity is used in medical rehabilitation, for example after brain injury of a particular brain region. If rehabilitation starts early, other cortex areas can take over functions that have become limited as a result of the brain injury (e.g., language skills).

The dynamics of the central nervous circuits' adaptability were soon discussed as the basis for learning processes (52). According to this approach, repeated input of information pattern stabilise the associated cortical networks. A broad field of neuroscientific research is presently engaged in analysing such processes on the cellular level. Researchers investigate the way in which synchronous activation of neurons sensitise and strengthen the synaptic connection (synaptogenesis) whereas they are reduced due to missing input or to a-synchronic activation. Recently it is discussed how even new nerve cells are formed during increased information processing in learning contexts (neurogenesis), particularly in the hippocampus (53, 54).

The effects of individual experience on the brain seem to be specific with respect to time and space. Even before birth, the growing network of nerve cells, their dendrites and their synapses are modulated via outer stimuli (e.g., light, music). After birth the brain is especially dynamic and adaptable in certain phases of development. For humans at birth, only the networks in the centred brain regions (brain stem, midbrain, and diencephalon) seem to be stabilised to a great extent. The cortex and the networks of the limbic system (that is involved in the mediation between motivational, emotional and cognitive processing) are closely linked and they 'mature' more slowly and remain especially plastic in the midst of experience up to adolescence, holding a lifelong degree of plastic potential.

Based on plasticity concepts it turns out that neuronal and synaptic plasticity are not only prerequisites for learning, but that learning seems to be a prerequisite for the cortex's functional development in general.

In lieu of these approaches the biological structure and function of the brain turns out to be highly interwoven in a constructive process between nature and nurture, and the question of determined sex or constructed gender differences in the brain can now be discussed from a more differentiated background.

\section{Enculturation of the brain: from a sexed to a gendered brain}

Based on the concept of brain plasticity, there are various possibilities of interpretation concerning the findings of the three research fields analysed above: 1) Different experiences can result in different structures and functions of the cortex (inter-individual variability). 2) Similar experiences can be displayed in similar cortical networks (group specific homogeneity). 3) The brain plasticity of the cortex seems to remain highly dynamic up into puberty and seems to keep some plastic potential throughout the whole life. Every individual's brain seems to be subject to permanent change. 
Given these possibilities, further interpretations concerning the diversity and homogeneity of the brains of men and women can be put forward. Women are not all that identical, and neither are men. Different women have different experiences and develop different learning strategies just as men do. The high variability of research findings concerning the brain and the overlapping results in men and women can be related to this argument. On the other hand, gender roles and stereotypes until today prescribe similar experiences and behaviours for girls and women in their disassociation from boys and men in various fields of socialisation (as has been described for environmental exploration). Individual experiences and behaviours are more or less 'gendered' in the western society (55). To which extent brain structures and functions mirror 'gendered' experiences is presently still hypothetical because there is a lack of corresponding empirical studies. However, the aforementioned examples of plasticity give some hints in the direction of a gendered brain.

Brain research studies, especially those that use imaging methods, are almost always carried out on adults. Thus, each brain finding - visualised in brain images is, without exception, only a snap-shot of a current state in the individual development and does not allow for direct evidence about the quantity or quality of biological determination. Neither does it give direct evidence for the incorporation of societal and learning influences on the brain's structure and function. The question of cause and effect cannot be answered referring to the brain image alone.

Nevertheless, although brain plasticity research now encompasses a broad array of the neurosciences and is discussed in the popular sphere as well, the brain remains to stand for the cause of biological determination for human behaviour, including gendered ascriptions. How can the sex difference-based interpretations and their acceptance by society be explained? These uni-linear explanations seem to extract their power of persuasion primarily from their simplicity. The succeeding popular and prototypical argumentations state: the differences supposedly exist, they have been developed in evolution and are unchangeable, each sex has its advantages and when society accepts those different gender roles and allocations, there will be fewer problems in communication and social organisation (7). Secondly, the modern brain images are of persuasive power. When structures and activation networks for certain cognition or apperception processes are 'discovered' for one in contrast to the other gender group, when they are imaged with a convincing illustration, then a causal explanation based on deterministic and natural entrenchment in pursuing group differences is not far-off. The images recount a genealogy, a story of beginnings, in which biological matter is depicted as essence, that leads to culture, behaviour, thought, etc. $(56,57)$. In this alliance of localisation methods and brain research findings, uni-linear biological explanations are often taken into societal debate without critical reflection. Yet this is only possible as long as the numerous methodological variations and decisions of brain analyses, some of which have been mentioned above, are not made transparent. For reasons of precaution, many neuroscientists back out of this issue, claiming 
that they have no responsibilities for the use of their results (58). Nevertheless, their results are used in many cases to confirm sex differences as a naturally determined category and to confirm the normalisations of gender that are based upon it. It should at least be stipulated that the research disciplines themselves take care for making all concepts and possible recommendations accessible to public debate.

With respect to the plasticity concept it is possible to discuss the inter-relation between the brain and experience, and between nature and nurture on a more general level. Amongst other researchers, Fausto-Sterling (2000) attempted to understand the constitution of the individual body, its structures and functions in a network of social and cultural experience (40). The body is not only attributed gender significations, it is formed in its materiality by gender affected experiences and the perception of one's own body and in turn, the body itself reciprocally influences cognition and behaviour. With this concept of embodiment we can make a connection between socio-cultural constructions and the constitutions of corporealities of gender, without making tendentious deductions regarding cause and effect. Fausto-Sterling stresses that bodies are not the constitution of a gender preexisting reality. Body and culture, sex and gender are indivisibly intertwined, they influence each other in a network of constant reciprocal changing processes. The gendered brain, then, is also open for continuous change, individually and societal.

And even the question of how much of the brain is caused by biology and how much is caused by experience is not the intriguing one any more. It would be much more thought-provoking to explore how the network of interplaying factors develops and functions in mutual interaction.

\section{References}

1. Cahill L: Why sex matters for neuroscience. Nature Reviews Neuroscience 7; 2006; 477-484.

2. Kaiser A, Haller S, Schmitz S, Nitsch C: On sex/gender related similarities and differences in fMRI language research. Brain Research Reviews 61; 2009; doi:10.1016/j.brainresrev.2009.03.005 <14 September 2009>

3. Wallentin M: Putative sex differences in verbal abilities and language cortex: a critical review. Brain and Language 108; 2009; 175-183.

4. Hines M: Brain Gender. Oxford: Oxford Univ. Press; 2004.

5. Blum D: Sex on the brain: the biological differences between men and women. New York: Penguin; 1997.

6. Moir A, Jessel D: Brain sex. The real difference between men and women. New York: Dell Publ; 1992. 
7. Pease A, Pease B: Why Men Don't Listen and Women Can't Read Maps. London: Orion Publ. Group; 2001.

8. Keller EF: Origin, history, and politics of the subject called 'gender and science' - a first person account. In: Jasanoff S, Markle GE, Petersen JC, Pinch T (eds): Handbook of Science and Technology Studies. Thousand Oaks: Sage; 1995; 80-94.

9. Bleier R: The brain and human 'nature'. In: Bleier R: Science and Gender. New York: Pergamon; 1984; 49-79.

10. Hagner M: Genius, gender, and elite in the history of the neurosciences. In: Karafyllis NC, Ulshöfer G (eds): Sexualized Brains. Scientific modeling of emotional intelligence from a cultural perspective. Cambridge, Mass.: MIT Press; 2008; 53-68.

11. Schmitz S: Hirnbilder im Wandel? Kritische Gedanken zum ,sexed brain'. In: Mauss B, Petersen B (eds): Das Geschlecht der Biologie. Talheim: Talheimer Verlag; 2006, 61-92.

12. Chen C, Xue G, Dong Q, Jin Z, Li T, Xue F, Zhao L, Guo Y: Sex determines the neurofunctional predictors of visual word learning. Neuropsychologia 45(4); 2007; 741-747.

13. Clements A, Rimrodt S, Abel J, Blankner J, Mostofsky S, Pekar J, Denckla M, Cutting, L: Sex differences in cerebral laterality of language and visuospatial processing. Brain and Language 98(2); 2006; 150-158.

14. Dong Q, Mei L, Xue G, Chen C, Li, T, Xue F, Huang S. Sex dependent neurofunctional predictors of longterm maintenance of visual word learning. Neuroscience Letters 430; 2008; 87-91.

15. Pugh K, Shaywitz B, Shaywitz S, Constable RT, Skudlarski P, Fulbright R, Bronen R, Shankweiler D, Katz L, Fletcher J, Gore J: Cerebral organization of component processes in reading. Brain 119; 1996; 1221-1238.

16. Shaywitz B, Shaywitz S, Pugh, K, Constable RT, Skudlarski P, Fulbright RK, Bronen RA, Fletcher JM, Shankweiler DP, Katz L, Gore JE: Sex differences in the functional organization of the brain for language. Nature 373; 1995; 607609.

17. Binder JR, Rao SM, Hammeke TA, Frost, JA, Bandettini PA, Jesmanowicz A: Lateralized human brain language systems demonstrated by task subtraction functional magnetic resonance imaging. Archive Neurology 52; 1995; 593-601.

18. Frost JA, Binder JR, Springer JA, Hammeke TA, Bellgowan PS F, Rao SM, Cox RW: Language processing is strongly left lateralized in both sexes. Evidence from functional MRI. Brain 122; 1999; 199-208. 
19. Haut K, Barch D: Sex influences on material-sensitive functional lateralization in working and episodic memory: men and women are not all that different. Neuroimage 32(1); 2006; 411-422.

20. Plante E, Schmithorst V, Holland S, Byars A: Sex differences in the activation of language cortex during childhood. Neuropsychologia 44(7); 2005; 1210 1221.

21. Weiss E, Siedentopf C, Hofer A, Deisenhammer E, Hoptman M, Kremser C, Golaszewski S, Felber S, Fleischhacker W, Delazer M: Brain activation pattern during a verbal fluency test in healthy male and female volunteers: a functional magnetic resonance imaging study. Neuroscience Letters 352; 2003; 191-194.

22. Sommer IEC, Aleman A, Bouma A, Kahn RS: Do women really have more bilateral language representation than men? A meta-analysis of functional imaging studies. Brain 127; 2004; 1845- 1852.

23. Sommer, IEC, Aleman A, Somers M, Boks K, Kahn R: Sex differences in handedness, asymmetry of the planum temporale and functional language lateralization. Brain Research 127; 2008; 1845-1852.

24. Schmitz S, Schinzel B. GERDA: A brain research information system for reviewing and deconstructing gender differences. In: Pasero U, Gottburgsen A (eds): Wie natürlich ist Geschlecht? Gender und die Konstruktion von Natur und Technik. Wiesbaden: Westdeutscher Verlag; 2002; 126-139.

25. Cahill L. His brain, her brain. Scientific American 5(5); 2005; 22-29.

26. Beaulieu A: Images are not the (only) truth: brain mapping, visual knowledge, and iconoclasm. Science, Technology \& Human Values 27(1); 2002; 53-86.

27. Kaiser A, Kuenzli E, Zappatore D, Nitsch C: On females' lateral and males' bilateral activation during language production: A fMRI study. International Journal of Psychophysiology 63(2); 2007; 192-198.

28. Schmitz S: Neurowissenschaftliche Informationssysteme. Chancen und Grenzen in Datenmanagement und Wissensrepräsentation. In: Schinzel B (ed.): Interdisziplinäre Informatik. Neue Möglichkeiten und Probleme für die Darstellung und Integration komplexer Strukturen in verschiedenen Feldern der Neurologie. Freiburger Universitätsblätter 153. Freiburg: Universität Freiburg; 2001; 51-65.

29. Kimura D: Sex differences in the brain. Scientific American 267; 1992; 118125.

30. Coluccia E, Louse G: Gender differences in spatial orientation: A review. Journal of Environmental Psychology 24; 2004; 329-340. 
31. Schmitz S: Gender-related strategies in environmental development: Effects of anxiety on wayfinding in and representation of a three-dimensional maze. Journal of Environmental Psychology 17; 1997; 215-228.

32. Maguire EM, Frackowiak RSJ, Frith CD: Recalling routes around London: Activation of the right hippocampus in taxi drivers. The Journal of Neuroscience 17(18); 1997; 7103-7110.

33. Grön G, Wunderlich AP, Spitzer M, Tomczak R, Riepe MW: Brain activation during human navigation: gender-different neural networks as substrate of performance. Nature Neuroscience 3(4); 2000; 404-408.

34. Blanch RJ, Brennan D, Condon B, Santosh C, Hadley D: Are there genderspecific neural substrates of route learning from different perspectives? Cerebral Cortex 14; 2004; 1207-1213.

35. Gould SJ: Women's brain. In: Gould SJ: The Panda's Thumb. New York: Norton; 1980; 152-159.

36. DeLacoste-Utamsing C, Holloway R: Sexual dimorphism in the human Corpus Callosum. Science 216; 1982; 1431-1432.

37. Witelson S: Hand and sex differences in the isthmus and genus of the human corpus callosum. A postmortem morphological study. Brain 112; 1989; 799835.

38. Aboitiz F, Scheibel A, Fisher R, Zaidel E: Individual differences in brain asymmetries and fiber composition in the human corpus callosum. Brain Research 598; 1992; 154-161.

39. Bishop KM, Wahlstein D: Sex differences in the human Corpus Callosum: Myth or reality? Neuroscience \& Biobehavioral Reviews 21(5); 1997; 581-601.

40. Fausto-Sterling A: Sexing the body. Gender politics and the construction of sexuality. New York: Basic Books; 2000.

41. Allen LS, Richey MF, Chai YM, Gorski RA: Sex differences in the Corpus Callosum of the living human being. The Journal of Neurosciences 11(4); 1991; 933-942.

42. Beaulieu A: Voxels in the brain: neuroscience, informatics and changing notions of objectivity. Social Studies of Science 31; 2001; 635-680.

43. Burri RV: Doing images. Zur Praxis medizinischer Bilder. Bielefeld: transcript; 2008.

44. Joyce K: Appealing images: magnetic resonance imaging and the production of authoritative knowledge. Social Studies of Sciences 35(3); 2005; 437-462. 
45. Wattendorf E, Westermann B, Zappatore D, Franceschini R, Lüdi G, Radü EW, Nitsch, C: Different languages activate different subfields in Broca's area. NeuroImage 13(6); 2001; 624.

46. Maguire EM, Gadian DG, Johnsrude IS, Good CD, Ashburner J, Frackowiak RSJ, Frith CD: Navigation-related structural change in the hippocampi of taxi drivers. Proceedings of the National Academy of Science 97(6); 2000; 1-6.

47. Jäncke L, Schlaug G, Steinmetz H: Hand skill asymmetry in professional musicians. Brain and Cognition 34; 1997; 424-432.

48. Schlaug G, Jäncke L, Huang Y, Staiger J, Steinmetz H: Increased corpus callosum size in musicians. Neuropsychologia 33; 1995; 1047-1055.

49. Draganski B, Gaser C, Busch V, Schuierer G, Bogdahn U, May A:

Neuroplasticity: Changes in grey matter induced by training. Nature 427; 2004; 311-312.

50. Boniface S, Ziemann U: Plasticity in the Human Nervous System. Cambridge: Cambridge University Press; 2003.

51. Kolb B, Whishaw IQ: Brain plasticity and behavior. Annual Review of Psychology 49; 1998; 43-64.

52. Kandel ER, Hawkins RD: Neuronal plasticity and learning. In: Broadwell RD (ed.): Neuroscience, memory, and language. Decade of the Brain, vol 1. Washington D.C.: Library of Congress; 1995; 45-58.

53. Gould E, Beylin A, Tanapat P, Reeves A, Shors TJ: Learning enhances adult neurogenesis in the hippocampal formation. Nature Neurosciences 2(3); 1999; 260-265.

54. Rakic P: Neurogenesis in adult primate neocortex: An evaluation of the evidence. Nature Review Neuroscience 3; 2002; 65-71.

55. Kimmel MS: The gendered society. Oxford: Oxford Univ. Press; 2007.

56. Nikoleyczik K: Normkörper: ,Geschlecht' und ,Rasse‘ in biomedizinischen Bildern. In: Schmitz S, Schinzel B (eds): Grenzgänge. Genderforschung in Informatik und Naturwissenschaften. Königstein: Helmer; 2004; 133-148.

57. Schmitz S: Körperlichkeit in Zeiten der Virtualität. In: Schmitz S, Schinzel B (eds): Grenzgänge. Genderforschung in Informatik und Naturwissenschaften. Königstein: Helmer; 2004; 118-132.

58. Vidal C: Brain, Sex and Ideology. Diogenes 52(4); 2005; 127-133. 




\title{
The brain between sex and gender - women and men from a neuroscientific perspective
}

\author{
Kirsten Jordan
}

\section{Abstract}

This article offers an overview on sex and gender differences in the brain from a current neuroscientific perspective. I will ask to what extent brain and behaviour are biologically determined with regard to sex differences, and which social and environmental factors have modulating effects. First, I describe the perinatal sexual differentiation of the brain modulated by sex hormones, followed by an analysis of similarities and differences in brain anatomy between adult women and men. Furthermore, it is questioned to what extent women and men also differ with regard to their cognitive and emotional brain functions. Then, the modulability of these functions by biological and environmental factors is discussed. Due to the fact that stereotypes on differences between men and women are popular, current research results are finally introduced showing the influence of stereotypical conceptions on cognitive performance and the underlying brain functions.

\section{Introduction}

Sex and gender differences in the brain belong to the most fascinating research topics of modern neuroscience. In 1903, the provocative book 'On the Physiological Feeble-Mindedness of Women' by neurologist Dr. Paul Julius Moebius (1) had sold out eight print runs within a very short time. Today, the book market is virtually flooded with books such as 'Why Men Don't Listen and Women Can't Read Maps' $(2,3)$. These books try to substantiate popular stereotypes on a seemingly 
scientific basis. There is, however, also literature which, using the latest findings from psychology and brain research, demonstrates to the lay reader that this unbalanced view on sex and gender simply cannot be maintained (e. g. 4-6).

This article draws upon the results of these books. From a current neuroscientific perspective, the article examines to what extent our brain and behaviour are biologically determined with regard to sex differences, and which social and environmental factors have modulating effects. First, the perinatal sexual differentiation of the brain modulated by sex hormones is described, which is followed by similarities and differences in brain anatomy between adult women and men. Furthermore, it is questioned to what extent women and men also differ with regard to their cognitive and emotional brain functions. Subsequently, the modulability of these functions by biological and environmental factors is discussed. Due to the fact, that the above-mentioned stereotypes on differences between women and men are widespread, current research results are introduced at the end, examining the influence of these stereotypical conceptions on cognitive performance and the underlying brain functions.

\section{Sexual differentiation of the brain}

The prenatal and early postnatal phases of brain development and their modulation by sex hormones are extremely interesting in view of the sex differences in the brain to be discussed. Already in 1947, the French scientist Alfred Jost became interested in how sex hormones influence the sexual differentiation of the brain and behaviour and performed initial examinations using rabbits (7). It is known today that sex hormones, on one hand, influence neuronal processes by adhering to intracellular receptors that modulate the gene expression as transcription factors. On the other hand, they are able to change the activity of ligand-controlled ion channels using fast so-called nongenomic mechanisms to influence neuronal processes. On the basis of their studies on prenatal effects of testosterone, Phoenix et al. coined the concepts still prevalent today of the organising and activating effects of sex hormones (8). Organising effects of sex hormones result in permanent structural changes in the brain, which can manifest in sex-specific behaviour. In contrast, activating effects of sex hormones modulate the functional interaction within an already existing neuronal structure. Activating as opposed to organising effects of sex hormones lead to rather subtle changes of neuronal connections, the production and release of neurotransmitters, or the sensitivity of receptors $(9,10)$. In research on the sexual differentiation of the brain, especially those brain regions are well-examined which are related to sexual behaviour. Interestingly these brain regions also show the most distinct sexual dimorphisms. Melissa Hines defines three mutually non-exclusive theories: the classic and the gradual theory, as well as the theory of active feminisation $(11,12)$. According to the classic theory, androgens (e. g., testosterone) cause the masculinisation of the brain, whereas their ab- 
sence is rather associated with neuronal feminisation. Hence, a passive feminization is assumed in this model, according to which hormonal stimulation is unnecessary for the development of female neuronal structures. In contrast, the active feminisation postulates that also hormones of the ovaries (e. g., estradiol) are significant for the active feminisation of neuronal circuits and behaviour. The socalled gradual theory assumes that sex hormones themselves do not influence the behaviour of the sexes, but the variability within one sex. Thus, women who had been exposed to high androgen concentrations during the prenatal phase are said to have better spatial abilities than women who had been exposed to low androgen concentrations. Indeed, a current meta-analysis shows that girls with congenital adrenal hyperplasia, i. e., girls who had been exposed to an increased androgen secretion during the prenatal phase as a result of a genetic defect, have improved spatial abilities in which men on average perform better than women (see figure 1) $(13,14)$.
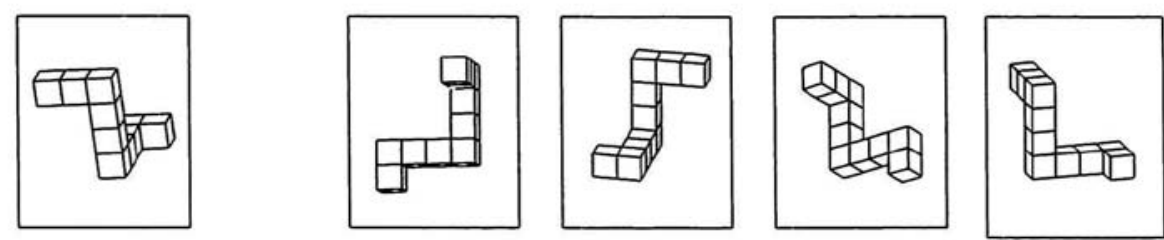

Figure 1. Characteristic spatial task in which men tend to perform better than women. Two of the four comparison objects on the right side can be transferred into the original object on the left (task from the Mental Rotation Test (14)).

The classic theory, also known as aromatisation hypothesis, has influenced the research on sexual differentiation most sustainably, therefore it will be introduced here in detail. According to this theory, testosterone is produced during the first weeks of the prenatal development in the genetically male organism. This process is activated by a gene region on the $\mathrm{Y}$ chromosome of the father known as the sex determining region of the $\mathrm{Y}$ chromosome (SRY). Interestingly, until this point in time, the gonads have developed such that either male or female gonads may form. The activation of the SRY gene region results in the production of the testisdetermining factor (TDF), which in turn furthers the differentiation of gonads into male gonads, the testes. These begin to produce testosterone, which to a large extent is then aromatised in the brain into estradiol. Mainly by genomic mechanisms, estradiol induces structural changes in certain brain regions particularly associated with sexual behaviour, e. g., by generating proteins to build up new synapses or by modulating neurite growth and apoptotic processes. According to existing models based on experimental animal studies, estradiol induces the expression of the gene for the enzyme cyclooxygenase-2 (COX-2), e. g., in the sexually dimorphic nucleus (SDN) of the preoptic hypothalamic region. This nucleus is decisively involved in controlling male sexual behaviour. Via various steps, the action of estradiol results in an increased generation of dendritic 
spines in neurons. Thus the SDN of male rats contains in a total of more than twice the amount of dendritic spines and more heavily branched astrocytes compared to female rats (15).

In addition to these classic, well-known mechanisms of sexual brain differentiation by estradiol, it is known in primates and also in humans that testosterone itself adheres to the corresponding androgen receptors (AR) and activates similar processes (16). In their review, Zuloaga et al. come to the conclusion that in most sexually dimorphic brain structures, testosterone also acts via ARs. The posterodorsal medial nucleus of the amygdala in male rats, e. g., is about 1.5 times larger than in female rats. This nucleus receives olfactorial and pheromonal signals and is important for male sexual arousal. The castration of adult male animals or the testosterone treatment of female animals lead to corresponding changes in size of this nucleus. Hippocampal structures also show a sexual dimorphism, which, however, apparently varies across the different species. In some mouse strains, the gyrus dentatus of males is larger than that of females, whereas in rats, this brain region differs in morphology but not in size between males and females (16). Moreover, the expression of certain genes on the sex chromosomes themselves results in the sexual differentiation of the brain. Thus, male fetal mesencephal neuronal cell cultures produce more dopaminergic neurons than female. Interestingly this was found if the male fetal mesencephalic neuronal cells were removed before the gonads were in the position of producing testosterone $(17,18)$.

Hence, in animal research, some clear evidence exists on a prenatal and postnatal sexual brain differentiation, especially evoked by the sex hormones estradiol and testosterone, but also by sex chromosomes. These processes lead to verifiable structural changes in different brain regions. In psychological and neuroscientific research, it is now of interest to what extent these findings can be transferred to humans and which sex differences in human brain anatomy based on such processes can be found.

\section{Sex differences in brain anatomy}

While sexual differences in brain anatomy in animals are relatively clearly described, many inconsistent research results still exist in view to humans. However, fact is that even when taking body height into account, the brain of men is still approximately 10 to $15 \%$ larger than that of women. This involves a higher quantity of neurons, a thicker brain cortex, and a correspondingly larger cortical volume (see Table 1) (19-21). Other authors, however, find a higher cortical thickness and a higher regional concentration of gray matter in the cortex of women compared to men, relative to brain size $(22,23)$. Lueders et al. also describe a higher gyrification of female brains, particularly of frontal and parietal cortex areas. This higher gyrification could partly compensate the brain size difference between women and men (24). According to Goldstein et al., sex differences can be found especially in 
those brain regions of which it is known from animal experiments that they are exposed to high concentration of sex hormones during the prenatal phase (25). Concerning the cerebellum, however, a difference in size between the sexes does not seem to exist (26).

Table 1: Selected global differences in brain anatomy between women and men $(19,20) * \mathrm{p}<0.05$

\begin{tabular}{|c|c|c|c|}
\hline Parameters & Men & Women & Ratio \\
\hline Cortex volume & $242-358 \mathrm{~cm}^{3}$ & $197-331 \mathrm{~cm}^{3}$ & men $>$ women* \\
\hline $\begin{array}{c}\text { Cortex } \\
\text { thickness }\end{array}$ & $2.72 \pm 0.24 \mathrm{~mm}$ & $2.61 \pm 0.21 \mathrm{~mm}$ & men $>$ women* \\
\hline $\begin{array}{c}\text { Quantity of } \\
\text { cortical neurons }\end{array}$ & $22.8 \pm 3.9 \mathrm{bn}$ & $19.3 \pm 3.3 \mathrm{bn}$ & men $>$ women* \\
\hline $\begin{array}{c}\text { Cerebellum } \\
\text { Packing density of } \\
\text { neurons }\end{array}$ & \multicolumn{3}{|c|}{ no difference } \\
\hline
\end{tabular}

For the interpretation of behavioural sex differences, especially regional differences are of interest in addition to global brain anatomy parameters. Brain regions which control sexual behaviour, such as the preoptic region in the hypothalamus described in the first section, show the corresponding sex differences also in humans. Thus, the nuclei located there, in humans known as interstitial nuclei of the anterior hypothalamus (INAH 1-4), are significantly larger in men than in women (27). For many years now, various sex differences have been described for the corpus callosum (CC), the connection between the cerebral hemispheres. It is discussed that the posterior part of the CC, i. e., the splenium or isthmus, is larger in women than in men or has a different form (28-30). Especially in popular scientific media, this is willingly treated as proof of a lower lateralisation of the female brain and a differing cognitive performance (31). The sex differences in the CC are, however, still very controversial. Zilles emphasises that the absolute area of the CC is nearly identical in women and men, so that only a relative size difference exists due to the smaller size of the female brain $(20,32)$. Dorion et al. point out that the different methods used to measure the size of the CC may also contribute to the inconsistent data currently available (33). In a meta-analysis on 49 studies, Bishop et al. find no sex differences independent of whether or not the data regarding brain size had been adjusted (31). Using a large group of subjects $(n=200)$, a study has recently examined the relation between the size of the $\mathrm{CC}$ and the data on brain asymmetry, which has been in the focus of research for a long time (34). Welcome and colleagues found no relation between sex, handedness and the size 
of the CC. But they found a relation between the asymmetry in behavioural performance and different subgroups of subjects classified according to handedness (34). Thus, individual differences in the CC in connection with handedness and behavioural asymmetry are possibly far more distinctive than mere sex differences.

The amygdala, a group of nuclei in the limbic system, is not only associated with the processing of emotional reactions, but also with the consolidation of memory contents related to emotions. It is also a well-examined brain structure with regard to sex differences (35). The data available here is rather inconsistent as well (21). Goldstein et al. describe a larger volume of the amygdala in men, whereas other authors find no sex differences at all (25). Both the amygdala and the hippocampus, one of the well-known learning and memory areas in the brain, belong to brain regions with a high quantity of sex hormone receptors (36). In this context early animal experiment studies have already shown that the density of dendritic spines in the pyramidal cells of the corpus ammonis region (CA1) changes across the menstrual cycle of rats (37). Based on these results sex differences in the hippocampus could be expected. Studies on humans regarding the size of the hippocampus, however, are rather contradictory. Both a larger hippocampus in women and no sex differences at all are described (21).

Sex differences are also discussed concerning other brain regions such as the planum temporale, the inferior frontal gyrus, or the occipital lobe, particularly with regard to brain asymmetries. Thus, for the region of the human occipital cortex (hOc5), associated with movement and space perception, a higher asymmetry in men than in women is described by Amunts et al. (38). The authors conclude that the better spatial cognitive performance of men is related to a better processing of visual-spatial information in these brain regions (38). Referring to language tasks, Hammers et al. assume that the partly better performance of women could be related to a larger volume in the inferior frontal gyrus (39). Other authors find no sex differences with regard to brain asymmetries in the various regions relevant to language $(40,41)$.

Thus, the brains of women and men are different both at the global and at the regional level. These differences, however, are often relatively small and not always to be found. As described, this holds also true for the relation between various properties of the brain structure and cognitive as well as emotional abilities. It is, however, noticeable that either the described differences all lead in one direction, but never in different directions, or no differences are found at all. Hence, the described differences in brain anatomy between women and men could indeed be very small and therefore hard to find in some designs, but yet existing. Thorough meta-analyses, which combine the results of studies according to selected criteria, could possibly bring more clarification. As Welcome and colleagues show, individual differences could also play a bigger part than sex differences (34). 


\section{Sex differences in brain functions}

Different brain structures could result in different brain functions and a different mental performance. Stable differences in favour of men are found for the abovementioned rotation of mental representations of three-dimensional objects known as mental rotation. Figure 1 shows a characteristic task of the well known Mental Rotations Test (14). Imaging examinations demonstrate first of all that both women and men use brain regions that are characteristic for spatial cognitive tasks, especially parietal, frontal and temporal regions, and that these networks are very much alike (see also figure 2). Several regional, partly quite variable differences are then often associated with different problem solving strategies of both sexes. One hypothesis explains that women and men use different problem solving strategies, and women obviously use less favourable ones (among others 42). In women relative to men, more activity is described, e. g., in right inferior frontal, bilateral inferior temporal and parietal brain regions, as well as in the left ventral premotor cortex. The authors of these examinations assume that in mental rotation tasks, women rather than men apply serial deductive, verbal analytic or also imitation strategies. According to these studies, higher hemodynamic responses in men compared to women are found in right parietal, left motor, parieto-occipital brain regions, and in the lingual gyrus, all associated with rather visual and holistic strategies (43-45). Despite the variability of several regional differences, these results nevertheless show that the different problem solving strategies in women and men assumed on the basis of behavioural studies can also be represented at the neuronal level. It also seems to be the case that sex differences are found in regions rather unspecific for the task, such as the inferior frontal gyrus, inferior temporal gyrus, and primary motor cortex, and not so much in the core regions of spatial cognitive tasks, i. e., the inferior and superior parietal cortex, including the intraparietal sulcus (46). The structural sex differences in the brain already mentioned as well as different sex hormone concentrations can certainly contribute to functional sex differences in the brain. The latter is discussed in the following section.

Sex differences in verbal and language performance are less distinct than those of spatial thinking. Women tend to show a better language performance, e. g., of verbal memory. The few imaging examinations, however, are still contradictory. Ragland et al. showed in a PET study in 2001 that a better verbal episodic memory performance of women, particularly during the free recall of studied words, is associated with a higher cerebral blood flow in middle temporal brain regions (47). In a verbal working memory task, higher hemodynamic responses were recorded in prefrontal areas in women than in men, although their performance was comparable (48). Women and men also showed a similar performance in a numeric working memory task, where Bell et al., however, found a higher activation in parietal and occipital brain regions in men (49). Sex differences are not only described in verbal memory but also in language production tasks, especially word fluency tasks, although not undisputed. The results of the imaging examinations, however, are 
not clear at all, either. Thus, sex differences are described, e. g., with a higher bilaterality of the activation patterns both in women and men (49,50). Other authors find no differences in the neuronal activation pattern of women and men (51). A more recent study demonstrates that, although sex differences were found at the group level, they disappeared at the individual level (52). In two meta-analyses, Sommer et al. find no lateralisation differences in brain functions between women and men in various language tasks $(53,54)$. In a current meta-analysis Wallentin shows that sex differences are described in studies using a small number of subjects (approx. 31 subjects) rather than in studies using a large number (approx. 76 subjects) (41).

These examples show that it has not yet been demonstrated to what extent sex differences in behavioural tasks can be represented in imaging studies. This may, among other things, result from the fact that the differences in behavioural performance in language tasks are not so clear as in spatial cognitive tasks. Then again, the mentioned meta-analyses possibly show no sex differences, because the various studies are too much distinct from each other in a multitude of diverse parameters. Thus, several language tasks and designs are used. In addition the cognitive performance is not always surveyed or no differences are found. On the other hand numerous studies on cortical plasticity document that changes in behavioural performance before and after training are represented at the neuronal level (55). Moreover, some of the existing contradictions could be clarified, if further influence factors on cognitive performance and brain functions such as current sex hormone concentrations or factors such as experience and individual strategies were more taken into consideration in the imaging studies (see also the following section).

Women are more emotional than men. This statement is willingly used time and again to explain sex and gender differences in everyday life. This shibboleth has also been discussed in neuroscientific literature for a long time. Interestingly women and men are not only different in their every-day emotional experience, but also with regard to the prevalence of certain psychic affective disorders such as depressions (56). As quite a few imaging examinations on sex differences in emotional perception and experience exist, I would like to refer to the high-quality and discerning review by Anne Schienle (57). In her review, Schienle comes to the conclusion that the context regarding the perception, experience and recall of emotions is apparently similar to that of cognitive abilities. The conformities and similarities on both the behavioural and the neuronal level are considerably higher than the differences between the sexes (57). Several studies show local differences in the neuronal activation networks, which, however, offer an unsystematic view. Many examinations find, e. g., a different activation in the amygdala, the group of nuclei particularly associated with the perception and experience of anxiety. Although several studies repeatedly refer to a different processing of emotional stimuli in women and men (58), no sex differences are found in meta-analyses with regard to the role of the amygdala during the perception of emotions (59). The amygdala is a 
brain region with a particularly high quantity of sex hormone receptors $(25,36)$. Goldstein et al. conclude from their examinations that sex differences in the brain are found especially in regions that contained many sex hormone receptors during the prenatal phase and were therefore exposed to their influence (25). So, taking the corresponding sex hormone level of the subjects into account, similar to the examinations of cognitive abilities, could clarify some of the contradictions among the results of various studies (see also the following section). Furthermore, Schienle points out that methodical problems during the performance and evaluation of these studies could lead to inconsistencies as well. These involve the lack of direct statistical comparisons between the groups, the examination of persons of only one sex in a study, a too liberal statistical performance (e. g., the very liberal interpretation of effects that had not been statistically corrected for multiple comparisons), or not observing/recording other influence factors such as age, personality, and learning experience (57).

Men and women are different not only on the structural but also on the functional level of their brain. Even if the statements are still contradictory in detail, it has become clear that small but not negligible sex differences exist with regard to the neuronal networks related to spatial cognitive, linguistic and emotional functions.

\section{Modulation of sex differences}

The preceding sections showed how sexual brain differentiation takes place and to what extent differences in brain structure and function are measurable. It has become clear that the similarities between women and men outweigh the differences, and that the differences found are still very inconsistent both on the structural and functional brain level. In addition to the already mentioned methodical problems, these divergences can also result from the fact that sex differences in cognitive and emotional areas are subject to various influence factors. Besides the biological factors such as sex hormones, social and environmental factors play a part not to be underestimated. The significance of the latter two factors is reflected in the term 'gender', which, in contrast to the biological term 'sex', defines the social or psychological gender, e. g., our role in society as man or woman. In the following, psychological and neuroscientific research results on the modulation of sex differences by sex hormones as well as by experience, training, and gender role stereotypes are described.

Sex hormones not only influence the sexual differentiation of the brain during the prenatal phase, but also modulate cognitive and emotional performance in adult humans. Although current data are still contradictory, they show, however, that the spatial performance of women varies across their menstrual cycle. The performance at the beginning of the cycle with low estradiol and progesterone concentrations is better than towards the middle of the cycle with high concentra- 
tions of both hormones. Conversely, a better verbal performance is found in the middle compared to the beginning of the cycle (60). The results of the few studies which examine the hemodynamic responses across the menstrual cycle of women within one group of subjects are still fairly inconsistent. For a spatial and a verbal task, Dietrich et al. describe a general increase in activated voxels during the follicular phase with high estradiol concentrations compared to the menses with low estradiol concentrations. During a motor test, the increase in the number of voxels was considerably lower (61). In an own work, the expected changes in performance of mental rotation are found across the cycle. These performance changes were combined with a slight activation increase during the follicular phase in parietal and motor brain regions compared to menses (62). Schoening et al. describe a positive relation between the hemodynamic response in frontal as well as parietal brain regions and the estradiol concentration both during the menses and the luteal phase of spontaneously cycling women who were to perform mental rotation tasks (63). These relations seem to exist for verbal functions as well. Fernandez et al. report a positive relation between the activity in superior temporal as well as medial superior frontal brain regions and the concentrations of progesterone and estradiol in spontaneously cycling women (64). Susanne Weis and colleagues examined to what extent functional cerebral asymmetries change in women across their menstrual cycle. For a word matching task, they showed that the inhibition of the right hemisphere by the left hemisphere was lower during the follicular phase with high estradiol levels than during the menses, i. e., the functional asymmetry between the hemispheres was lower (65).

Despite several contradictory results, primarily the perception of negative emotional incidences seems to vary across the menstrual cycle $(66,67)$. Derntl et al. assume that the perception of such stimuli is higher in women during the luteal phase with high progesterone concentrations, similar to that during pregnancy, to avoid any risk in the development of the embryo (67). Several imaging studies examined the changes in perception of erotic pictures, films, or male and female faces across the female cycle. Gizewski et al. showed 22 women during different cycle phases and 22 men erotic and emotionally neutral film sequences (68). Men basically reacted with a higher neuronal activity. Women, in turn, reacted with higher hemodynamic responses during the midluteal phase of their cycle than during their menses. These changes were found particularly in regions involved in the processing of emotional stimuli such as the anterior cingulum, left insular cortex, and orbitofrontal cortex (68). In another study, women's perception of male faces evoked a higher activity in the right medial orbitofrontal cortex during the late follicular phase with highest estradiol concentrations compared to the midluteal phase (69). These studies mentioned as examples show that during phases of high sex hormone concentrations, a higher neuronal response results from emotionally significant stimuli, although no clear statement can yet be made on specific regional changes. 
Hence, both for cognitive and emotional functions, a modulability of behaviour and brain functions by sex hormones can be verified. However, especially the neuronal effects and their regional specificity are still unclear. In addition, several modes of action of sex hormones are discussed. It is known that, besides the modulation of protein synthesis and neurotransmission, estradiol also has cerebrovascular effects (70). The latter can lead to changed hemodynamic responses, which, however, can hardly be separated from the neuronal effects of estradiol using imaging methods. Regarding the neuronal effects, Hausmann and Güntürkün set up the hypothesis of the progesterone-mediated interhemispheric interaction. According to this hypothesis, progesterone inhibits the activity of excitatoric glutamatergic callosal neurons. This results altogether in a missing inhibition of the counterlateral hemisphere and thus a decoupling of the activity of both brain hemispheres (71). Weis et al. were able to confirm this hypothesis in the work mentioned above (65). Concerning the modulation of emotional processes, it is assumed that estradiol boosts the serotonergic activity and thus modulates the serotonin metabolism using estradiol receptors of the ERß type, e. g., in the raphe nucleus of the mid- brain. Serotonin itself is known as a modulator of mood and mental state $(72,73)$.

Not only sex hormones but also environmental factors modulate cognitive performance. Behavioural studies reliably show that experience and training improve the performance, e. g., during tests on spatial thinking (74). For a long time, neuroscientific studies have pointed out the enormous structural and functional plasticity of the brain as a result of learning and experience (75). We performed an extensive cooperation study with more than 3.000 Japanese, Canadian and German students. The results showed that students of the natural and technology-oriented sciences outperform students of the humanities and social sciences in the Mental Rotations Test. (See figure 1) (76). Students of the natural and technology-oriented sciences deal with, e.g., spatial construction tasks much more extensively during their studies than students of humanities and social sciences. Here, good spatial imagination is beneficial, whereas for studies of the humanities and social sciences it is less important. In an summarising analysis of own imaging data of more than 80 subjects, the influence of three factors on the neuronal network of spatial cognitive processes was examined: sex, spatial component, and spatial experience (77). The spatial component factor involved the two spatial cognitive tests known as mental rotation and spatial orientation. Students either of the humanities and social sciences (low spatial experience) or of computer visualisation (high spatial experience) constituted the factor experience. The results showed, that the spatial component factor affected the neuronal activity in defined brain regions specific to each task. The sex factor was associated with changes in the hemodynamic responses in premotor brain regions involved either in response selection or in motor imagination processes. The higher activation in these brain regions in men is considered to be related to a rather motor-oriented problem solving strategy. The spatial experience factor influenced the activity not only in brain regions associated 
with the processing of visual stimuli, but also in areas involved in motor imagination and response control (figure 2). Students with little spatial experience showed a considerably higher activity in these regions than students with high spatial experience. It is therefore assumed that in our studies, individual differences in performance were determined by rather unspecific perception and motor processes than by differences in the specific spatial cognitive processes. Hence, less experienced students possibly had more difficulties to extract the adequate perceptual information from the stimulus material or to choose the correct motor response (77).

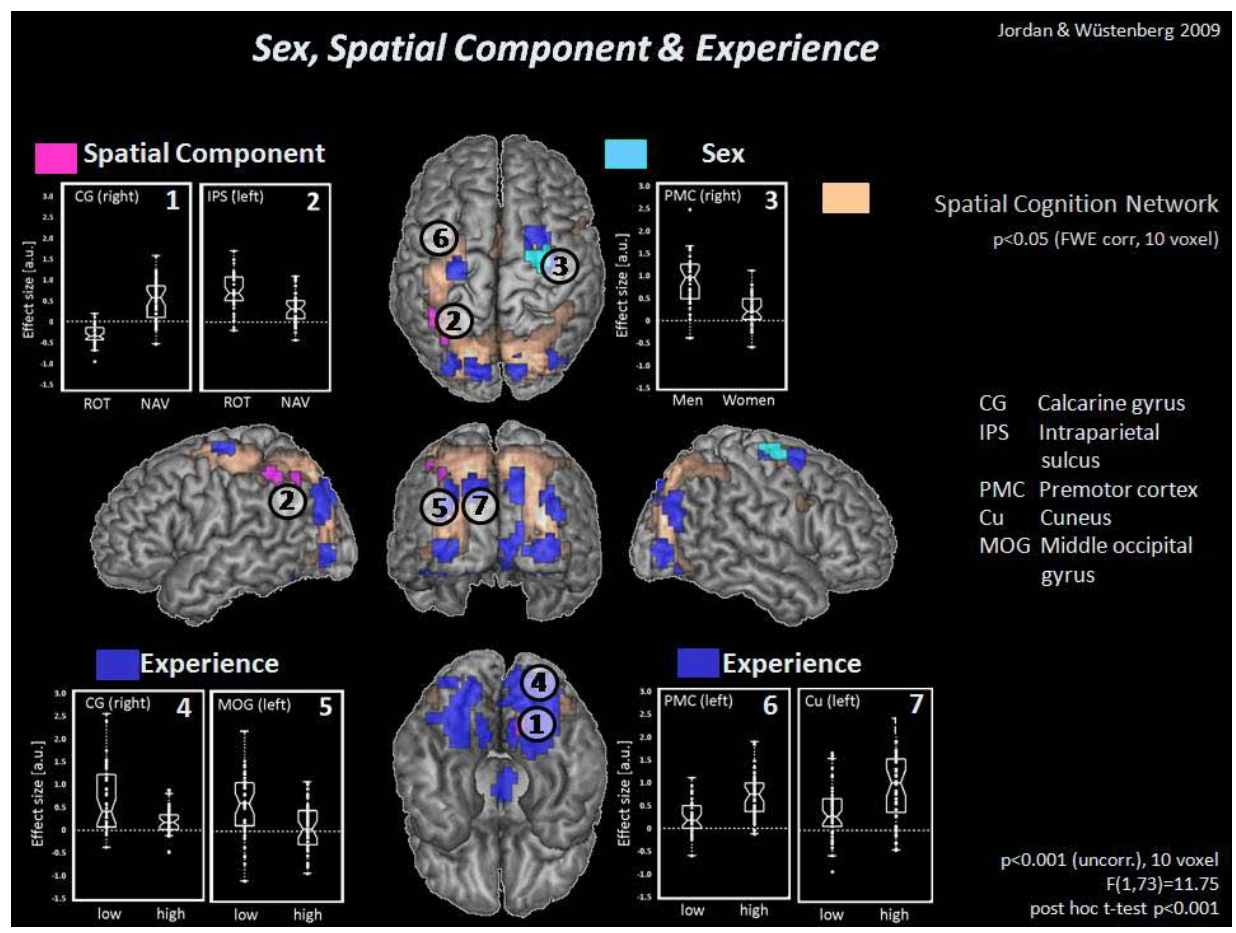

Figure 2: Spatial cognition network and modulating factors. Spatial component: rotation (ROT), navigation (NAV), sex (men, women), experience (low, high)(77).

For a long time it has been known from social psychological research that prejudices, also known as stereotypes, can influence the individual cognitive performance. Already in 1995, Claude M. Steele and Joshua Aronson showed that simply the request to indicate one's race in a questionnaire influenced the performance during an intelligence test (78). In connection with sex differences, it is therefore of particular interest to what extent the initially mentioned stereotypes can have an effect on cognitive performance. Angelica Moe showed that the mental rotation performance of women improved, when they had previously been informed before that women perform better in this test than men (79). In an own study, merely the 
answering of questions on characteristic male or characteristic female performance in a questionnaire resulted in a mental rotation performance that was improved in men and worsened in women. Furthermore, the male experimental group showed significantly higher testosterone concentrations in the saliva compared to the male control group that had completed a stereotype-neutral questionnaire (80). Hence, merely the indirect activation of gender role stereotypes by instructions or questionnaires leads to a changed cognitive performance. So far, only two imaging studies on gender role stereotypes have been published. Wraga and colleagues confronted three groups of women either with a positive, neutral or negative instruction on the ability of women performing spatial thinking. Afterwards, the women were to perform mental rotation tasks (81). Women who had received positive instructions performed best compared to the other two groups and showed a higher but focal activation of visual cortex areas. Women having received negative instructions performed worst and showed a higher activation of especially emotion-relevant brain regions, such as the anterior cingulum or the orbital and medial frontal gyrus, compared to the other two groups (81). Krendl et al. informed their women that complex mathematic tasks can generally either be better or worse performed by women compared to men. This again resulted in the expected changes in performance and in an increased activation of the ventral anterior cingulum in women having received the negative information about their mathematic performance (82). These brain regions are related to the perception of the significance of emotional information and the processing of negative social information. Therefore, it is assumed that the activation of the corresponding stereotype increases test anxiety, i. e., emotional reactions, so that performance worsens. Other explanations assume that cognitive resources are bound by the intense preoccupation with the stereotype and its impact and are therefore not available anymore to solve the task.

\section{Conclusion}

Classic bestsellers. like those by Dr. Paul Julius Moebius On the Physiological FeebleMindedness of Women of the year 1903 (1) or by the married couple Allan and Barbara Pease Why Men Don't Listen and Women Can't Read Maps of 1998 (2, 3), fail when describing differences between men and women in an unbalanced way or as being unchangeable. It is known today that, with regard to sex and gender differences, our brain and our behaviour are subject to the influence of biological factors such as sex hormones as well as of environmental factors such as experience or gender role stereotypes. Although research results are still relatively inconsistent, they often point in one direction and indicate that differences may be relatively small but certainly not negligible. Thus, prenatal organizing effects of sex hormones and sex chromosomes lead to a sexual differentiation of the brain structure. This in turn is related to functional sex differences in the brain. The latter, how- 
ever, are influenced by the current sex hormone level or factors such as experience, training, or gender role stereotypes. Based on today's knowledge about the plasticity of the brain, a continuous neurofunctionally and structurally verifiable interaction can be assumed between biological, psychological and social factors, which permanently modulate our brain and thus our thoughts and behaviour. The ability of lifelong learning is owed to this enormous plasticity.

\section{Acknowledgments}

I wish to express my heartfelt thanks to Sophie Hinrichs and Mathias Brosz for their thorough and discerning review of the manuscript as well as their valuable notes. This article is based on a german book chapter: Gebirn zwischen Sex und Gender - Frauen und Männer aus neurowissenschaftlicher Perspektive. In: Steins G (ed.): Psychologie und Geschlechterforschung. Wiesbaden: VS Verlag; 2009 (in press). I wish to express my heartfelt thanks also to Katja Kleinschmidt for her excellent translation of this text.

\section{References}

1. Möbius PJ: Über den physiologischen Schwachsinn des Weibes. 5. ed., Halle a. S.: Carl Marhold; 1903.

2. Pease A, Pease B: Why men don't listen and women can't read maps. Mona Vale, Australia: Pease Training International; 1998.

3. Pease A, Pease B: Warum Männer nicht zuhören und Frauen schlecht einparken. München: Econ Ullstein List Verlag; 2000.

4. Kimura D: Sex and cognition. Cambridge, Mass./London: MIT Press; 1999.

5. Hines M: Brain Gender. New York: Oxford University Press; 2004.

6. Quaiser-Pohl C, Jordan K: Warum Frauen glauben, sie können nicht einparken und Männer ihnen Recht geben. München: C.H. Beck; 2004.

7. Jost A: Recherches sur la differenciation sexuelle de l'embryon de lapin. Arch Anat Micosc Morphol Exp 26; 1947; 271-315.

8. Phoenix CH, Goy RW, Gerall AA, Young WC: Organizing action of prenatally administered testosterone propionate on the tissures mediating mating behavior in the female guinea pig. Endocrinology 65; 1959; 369-382.

9. Arnold AP, Breedlove SM: Organizational and activational effects of sex steroids on brain and behavior: a reanalysis. Hormones and Behaviour 19(4); 1985; 469-498. 
10. Rupprecht R: Neuroactive steroids: mechanisms of action and neuropsychopharmacological properties. Psychoneuroendocrinology 28(2); 2003; 139-168.

11. Collaer ML, Hines M: Human behavioral sex differences: a role for gonadal hormones during early development? Psychological Bulletin 118(1); 1995; 55107.

12. Hines M: Sexual differentiation of human brain and behavior. In: Donald W, Pfaff A, Arnold P, Fahrbach SE, Etgen AM, Rubin RT (eds): Hormones, Brain and Behavior. Boston: Academic Press; 2002; 425-462.

13. Puts D, McDaniel M, Jordan C, Breedlove S: Spatial ability and prenatal androgens: meta-analyses of congenital adrenal hyperplasia and digit ratio (2D:4D) studies. Archives of Sexual Behavior 37(1); 2008; 100-111.

14. Peters M, Laeng B, Latham K, Jackson M, Zaiyouna R, Richardson C: A redrawn Vandenberg and Kuse Mental Rotations Test: different versions and factors that affect performance. Brain and Cognition 28(1); 1995; 39-58.

15. Schwarz JM, McCarthy MM: Steroid-induced sexual differentiation of the developing brain: multiple pathways, one goal. Journal of Neurochemistry 105(5); 2008; 1561-1572.

16. Zuloaga DG, Puts DA, Jordan CL, Breedlove SM: The role of androgen receptors in the masculinization of brain and behavior: What we've learned from the testicular feminization mutation. Hormones and Behavior 53(5); 2008; 613-626.

17. Arnold AP, Xu J, Grisham W, Chen X, Kim YH, Itoh Y. Minireview: Sex chromosomes and brain sexual differentiation. Endocrinology 145(3); 2004; 1057-1062.

18. Bocklandt S, Vilain E: Sex differences in brain and behavior: hormones versus genes. In: Daisuke Y (ed.): Advances in genetics: genetics of sexual differentiation and sexually dimorphic behaviors. London et al.: Elsevier; 2007; 245-266.

19. Pakkenberg B, Gundersen HJ: Neocortical neuron number in humans: effect of sex and age. Journal of Comparative Neurology 384(2); 1997; 312-320.

20. Zilles K: Architektonik und funktionelle Neuroanatomie der Hirnrinde des Menschen. In: Förstl H, Hautzinger M, Roth G (eds): Neurobiologie psychischer Störungen. Heidelberg: Springer Medizin Verlag; 2006; 76-140.

21. Cosgrove KP, Mazure CM, Staley JK: Evolving Knowledge of Sex Differences in Brain Structure, Function, and Chemistry. Biological Psychiatry 62(8); 2007; 847-855. 
22. Im K, Lee JM, Lee J, Shin YW, Kim IY, Kwon JS, et al.: Gender difference analysis of cortical thickness in healthy young adults with surface-based methods. NeuroImage 31(1); 2006; 31-38.

23. Luders E, Narr KL, Thompson PM, Rex DE, Jancke L, Toga AW:

Hemispheric asymmetries in cortical thickness. Cerebral Cortex 16(8); 2006; 1232-1238.

24. Luders E, Narr KL, Thompson PM, Rex DE, Jancke L, Steinmetz H, et al.: Gender differences in cortical complexity. Nature Neuroscience 7(8); 2004; 799-800.

25. Goldstein JM, Seidman LJ, Horton NJ, Makris N, Kennedy DN, Caviness VS Jr., et al.: Normal sexual dimorphism of the adult human brain assessed by in vivo magnetic resonance imaging. Cerebral Cortex 11(6); 2001; 490-497.

26. Nopoulos P, Flaum M, O'Leary D, Andreasen NC: Sexual dimorphism in the human brain: evaluation of tissue volume, tissue composition and surface anatomy using magnetic resonance imaging. Psychiatry Research 98(1); 2000; $1-13$.

27. Swaab DF, Gooren LJG, Hofman MA: Brain research, gender and sexual orientation. Journal of Homosexuality 28(3); 1995; 283-301.

28. DeLacoste-Utamsing C, Holloway RL: Sexual dimorphism in the human corpus callosum. Science 216(4553); 1982; 1431-1432.

29. Allen LS, Richey MF, Chai YM, Gorski RA: Sex differences in the corpus callosum of the living human being. Journal of Neuroscience 11(4); 1991; 933 942.

30. Steinmetz H, Jancke L, Kleinschmidt A, Schlaug G, Volkmann J, Huang Y: Sex but no hand difference in the isthmus of the corpus callosum. Neurology 42(4); 1992; 749-752.

31. Bishop KM, Wahlsten D: Sex differences in the human corpus callosum: myth or reality? Neuroscience and Biobehavioral Reviews 21(5); 1997; 581-601.

32. Zilles K: Biometrische Analyse der Frischvolumina verschiedener prosencephaler Hirnregionen von 78 menschlichen, adulten Gehirnen. Gegenbaurs Morphologisches Jahrbuch 118; 1972; 234-273.

33. Dorion AA, Capron C, Duyme M: Measurement of the corpus callosum using magnetic resonance imaging: analyses of methods and techniques. Perceptual and Motor Skills 92(3 Pt 2); 2001; 1075-1094. 
34. Welcome SE, Chiarello C, Towler S, Halderman LK, Otto R, Leonard CM: Behavioral correlates of corpus callosum size: Anatomical/behavioral relationships vary across sex/handedness groups. Neuropsychologia 47(12); 2009; 2427-2435.

35. Güntürkün O, Hausmann M: Funktionelle Hirnorganisation und Geschlecht. In: Lautenbacher S, Güntürkün O, Hausmann M (eds): Geschlecht und Gehirn. Heidelberg: Springer Science; 2007; 87-104.

36. Taber KH, Murphy DD, Blurton-Jones MM, Hurley RA: An update on estrogen: higher cognitive function, receptor mapping, neurotrophic effects. Journal of Neuropsychiatry and Clinical Neurosciences 13(3); 2001; 313-317.

37. Woolley CS, Gould E, Frankfurt M, McEwen BS: Naturally occurring fluctuation in dendritic spine density on adult hippocampal pyramidal neurons. Journal of Neuroscience 10(12); 1990; 4035-4039.

38. Amunts K, Armstrong E, Malikovic A, Homke L, Mohlberg H, Schleicher A, et al.: Gender-specific left-right asymmetries in human visual cortex. Journal of Neuroscience 27(6); 2007; 1356-1364.

39. Hammers A, Chen CH, Lemieux L, Allom R, Vossos S, Free SL, et al.: Statistical neuroanatomy of the human inferior frontal gyrus and probabilistic atlas in a standard stereotaxic space. Human Brain Mapping 28(1); 2007; 34 48.

40. Chiarello C, Welcome SE, Halderman LK, Towler S, Julagay J, Otto R, et al.: A Large-Scale Investigation of Lateralization in Cortical Anatomy and Word Reading: Are There Sex Differences? Neuropsychology 23(2); 2009; 210-222.

41. Wallentin M. Putative sex differences in verbal abilities and language cortex: A critical review. Brain and Language 108(3); 2009; 175-183.

42. Casey MB: Understanding individual differences in spatial ability within females: A nature/nurture interactionist framework. Developmental Review 16(3); 1996; 241-260.

43. Thomsen T, Hugdahl K, Ersland L, Barndon R, Lundervold A, Smievoll AI, et al.: Functional magnetic resonance imaging (fMRI) study of sex differences in a mental rotation task. Medical Science Monitor 6(6); 2000; 1186-1196.

44. Jordan K, Wustenberg T, Heinze HJ, Peters M, Jancke L: Women and men exhibit different cortical activation patterns during mental rotation tasks. Neuropsychologia 40(13); 2002; 2397-2408. 
45. Seurinck R, Vingerhoets G, de Lange FP, Achten E: Does egocentric mental rotation elicit sex differences? Neuroimage 23(4); 2004; 1440-1449.

46. Jancke L, Jordan K. Functional Neuroanatomy of mental rotation performance. In: Mast F, Jancke L (eds): Spatial Processing in Navigation, Imagery and Perception. New York: Springer; 2007; 184-207

47. Ragland JD, Coleman AR, Gur RC, Glahn DC, Gur RE: Sex differences in brain-behavior relationships between verbal episodic memory and resting regional cerebral blood flow. Neuropsychologia 38(4); 2000; 451-461.

48. Goldstein JM, Jerram M, Poldrack R, Anagnoson R, Breiter HC, Makris N, et al.: Sex Differences in Prefrontal Cortical Brain Activity During fMRI of Auditory Verbal Working Memory. Neuropsychology 19(4); 2005; 509-519.

49. Bell EC, Willson MC, Wilman AH, Dave S, Silverstone PH: Males and females differ in brain activation during cognitive tasks. Neuroimage 30(2); 2006; 529_ 538.

50. Shaywitz BA, Shaywitz SE, Pugh KR, Constable RT, Skudlarski P, Fulbright RK, et al.: Sex differences in the functional organization of the brain for language. Nature 373(6515); 1995; 607-609.

51. Weiss EM, Siedentopf C, Hofer A, Deisenhammer EA, Hoptman MJ, Kremser $\mathrm{C}$, et al.: Brain activation pattern during a verbal fluency test in healthy male and female volunteers: a functional magnetic resonance imaging study. Neuroscience Letters 352(3); 2003; 191-194.

52. Kaiser A, Kuenzli E, Zappatore D, Nitsch C. On females' lateral and males' bilateral activation during language production: A fMRI study. International Journal of Psychophysiology 63(2); 2007; 192-198.

53. Sommer IEC, Aleman A, Bouma A, Kahn RS: Do women really have more bilateral language representation than men? A meta-analysis of functional imaging studies. Brain 127(8); 2004; 1845-1852.

54. Sommer IE, Aleman A, Somers M, Boks MP, Kahn RS: Sex differences in handedness, asymmetry of the Planum Temporale and functional language lateralization. Brain Research 1206; 2008; 76-88.

55. Kelly C, Foxe JJ, Garavan H: Patterns of normal human brain plasticity after practice and their implications for neurorehabilitation. Archives of Physical Medicine and Rehabilitation 87(12, Supplement 1); 2006; 20-29.

56. Kessler RC: Epidemiology of women and depression. Journal of Affected Disorders 74(1); 2003; 5-13. 
57. Schienle A: Geschlechterdifferenzen in der Emotionalität aus der Sicht des Neuroimaging. In: Lautenbacher S, Güntürkün O, Hausmann M (eds): Gehirn und Geschlecht. Heidelberg: Springer; 2007; 143-160.

58. Cahill L: Why sex matters for neuroscience. Nature Reviews Neuroscience 7(6); 2006; 477-484.

59. Sergerie K, Chochol C, Armony JL: The role of the amygdala in emotional processing: A quantitative meta-analysis of functional neuroimaging studies. Neuroscience \& Biobehavioral Reviews 32(4); 2008; 811-830.

60. Hausmann M: Kognitive Geschlechtsunterschiede. In: Lautenbacher S, Güntürkün O, Hausmann M (eds): Geschlecht und Gehirn. Heidelberg, Berlin: Springer Science; 2007; 105-124.

61. Dietrich T, Krings T, Neulen J, Willmes K, Erberich S, Thron A, et al.: Effects of blood estrogen level on cortical activation patterns during cognitive activation as measured by functional MRI. Neuroimage 13(3); 2001; 425-432.

62. Fellbrich A: Sexualhormone, mentale Rotation und neuronale Korrelate. Diplomarbeit, Institut für Psychologie, Otto-von Guericke Universität Magdeburg; 2004.

63. Schoning S, Engelien A, Kugel H, Schafer S, Schiffbauer H, Zwitserlood P, et al.: Functional anatomy of visuo-spatial working memory during mental rotation is influenced by sex, menstrual cycle, and sex steroid hormones. Neuropsychologia 45(14); 2007; 3203-3214.

64. Fernandez G, Weis S, Stoffel-Wagner B, Tendolkar I, Reuber M, Beyenburg S, et al.: Menstrual cycle-dependent neural plasticity in the adult human brain is hormone, task, and region specific. Journal of Neuroscience 23(9); 2003; 3790_ 3795.

65. Weis S, Hausmann M, Stoffers B, Vohn R, Kellermann T, Sturm W: Estradiol modulates functional brain organization during the menstrual cycle: an analysis of interhemispheric inhibition. Journal of Neuroscience 28(50); 2008; 13401 13410.

66. Pearson R, Lewis MB: Fear recognition across the menstrual cycle. Hormones and Behavior 47(3); 2005; 267-271.

67. Derntl B, Kryspin-Exner I, Fernbach E, Moser E, Habel U: Emotion recognition accuracy in healthy young females is associated with cycle phase. Hormones and Behavior 53(1); 2008; 90-95.

68. Gizewski ER, Krause E, Karama S, Baars A, Senf W, Forsting M: There are differences in cerebral activation between females in distinct menstrual phases during viewing of erotic stimuli: A fMRI study. Experimental Brain Research 174(1); 2006; 101-108. 
69. Rupp HA, James TW, Ketterson ED, Sengelaub DR, Janssen E, Heiman JR: Neural activation in the orbitofrontal cortex in response to male faces increases during the follicular phase. Hormones and Behavior 56(1); 2009; 6672.

70. White RE: Estrogen and vascular function. Vascular Pharmacology 38(2); 2002; 73-80.

71. Hausmann M, Güntürkün O: Steroid fluctuations modify functional cerebral asymmetries: the hypothesis of progesterone-mediated interhemispheric decoupling. Neuropsychologia 38(10); 2000; 1362-1374.

72. Deecher D, Andree TH, Sloan D, Schechter LE: From menarche to menopause: Exploring the underlying biology of depression in women experiencing hormonal changes. Psychoneuroendocrinology 33(1); 2008; 3-17.

73. Lasiuk GC, Hegadoren KM: The effects of estradiol on central serotonergic systems and its relationship to mood in women. Biological Research for Nursing 9(2); 2007; 147-160.

74. Baenninger M, Newcombe N: The role of experience in spatial test performance: A meta-analysis. Sex Roles 20(5/6); 1989; 327-343.

75. Kelly AMC, Garavan H: Human functional neuroimaging of brain changes associated with practice. Cerebral Cortex 15(8); 2005; 1089-1102.

76. Peters M, Lehmann W, Takahira S, Takeuchi Y, Jordan K: Mental Rotation Test Performance in cross-cultural samples $(n=3367)$ : overal sex differences and the role of academic program in performance. Cortex 42; 2006; $1005-$ 1014.

77. Jordan K, Wüstenberg T: The neural network of spatial Cognition and its modulation by biological and environmental factors. Journal of Individual Differences; 2009 (in press).

78. Steele CM, Aronson J. Stereotype threat and the intellectual test performance of African Americans. Journal of Personality and Social Psychology 69(5); 1995; 797-811.

79. Moe A: Are males always better than females in mental rotation? Exploring a gender belief explanation. Learning and Individual Differences 19(1); 2009; 21-27.

80. Hausmann M, Schoofs D, Rosenthal HES, Jordan K: Interactive effects of sex hormones and gender stereotypes on cognitive sex differences. A psychobiosocial approach. Psychoneuroendocrinology 34(3); 2009; 389-401. 
81. Wraga M, Helt M, Jacobs E, Sullivan K. Neural basis of stereotype-induced shifts in women's mental rotation performance. Social Cognitive and Affective Neuroscience 2(1); 2007; 12-19.

82. Krendl AC, Richeson JA, Kelley WM, Heatherton TF: The negative consequences of threat: a functional magnetic resonance imaging investigation of the neural mechanisms underlying women's underperformance.

Psychological Science 19(2); 2008; 168-175. 



\title{
Sex and gender in addiction research and therapy
}

\author{
Verena Metz \& Gabriele Fischer
}

\section{Abstract}

Historically, addiction research has neglected the scientific focus on women, and most studies have been conducted on male patients only, with the concluding results generalised to the female population. The role of sex and gender differences in susceptibility to the development of addictive disorders, and their consequences for prevention and treatment strategies require detailed studies, as do the increasing prevalence rates of addictive disorders among adolescents and the aging population. This literature review synthesises evidence of sex and gender differences in substance-related and substance-unrelated addictions, with particular emphasis on women's health. These differences are described in view to epidemiological and etiological factors, onset and course of illness, symptomatology, comorbidity, as well as treatment. Current research findings on gender aspects referring to specific licit (nicotine, alcobol, prescription drugs) and illicit (cocaine, heroin) substances as well as substance-unrelated conditions (pathological gambling, internet addiction) are presented. However, evidence-based science on differences between men and women in addictive disorders is still underrepresented in that target area, in addition to the fact that currently findings of different types of studies applying varied methods are reported. Finally, a critical discussion highlights common methodological flaws and limitations in research on sex and gender differences, and emphasizes the need for the implementation of a sex and gender-sensitive methodology in evidence-based studies. 


\section{Introduction}

Research in psychiatry focusing on sex and gender differences takes various aspects into account, ranging from the availability of services, epidemiological and etiological considerations, the metabolisation of drugs, to gender-specific stigmatisation or patient satisfaction and retention in treatment. Multiple issues play an important role in clinical practice and deserve special attention, although there are still several topics that have not been thoroughly studied so far, since there is a general lack of addressing sex and gender aspects regarding psychiatric, particularly addictive disorders, in medical research.

The objective of this literature review is to present the clinically most relevant, well-established and current research findings regarding prevalence, epidemiological factors, symptomatology, as well as treatment of substance-related and substance-unrelated addictive disorders. Special consideration is given to substance abuse during pregnancy and its effects on the infant.

The review is based on literature search using PubMed, indicating search terms for the specific addictive disorders and 'sex differences' or 'gender differences' combined with the main issues addressed ('epidemiology', 'treatment', 'onset' etc.), and selecting the most recent publications.

Research on gender issues in medical healthcare revealed that women have to consult a doctor twice as often as men in order to have their symptoms taken seriously, and that diagnoses more often are psycho-somatic conditions than in men who tend to get a somatic diagnosis. Men less frequently fulfil the necessary criteria for a psychiatric illness than women who clearly outweigh the male patients in prevalence rates of anxiety and depressive as well as somatoform disorders; the prevalence of schizophrenia is equally high among both sexes, but regarding addiction, a completely different picture can be observed (1-4).

\subsection{Differences between women and men in prevalence of addictive disorders}

In general, men are two to three times more likely to develop substance abuse or dependence, and are affected four times more often by an alcohol use disorder than women; the prevalence of illicit substance use is also much higher in the male adult population $(10.2 \%$ men versus $6.1 \%$ women reportet illicit substance use in the last month in an national survey in the United States 2005). However, the frequency of non-medical use of prescription drugs is almost equally high among men and women $(2.7 \%$ versus $2.6 \%)$, and generally a trend towards narrowing of maleto-female prevalence ratios can be observed in many Western countries (2-5). 
Special consideration should be given to the increasingly high substance use among the young population in Europe, which is rising particularly among women, and constitutes a major public health issue. Figure 1 presents prevalence rates of lifetime use of different substances among 15- to 16-year-old students from 15 European countries (6). The figure also shows that the gender gap regarding the preponderance of male patients is narrowing. It should be noted that these data were collected in a standardised way via group-administered, anonymous questionnaires, so the calculated prevalences might be biased through self-assessment.

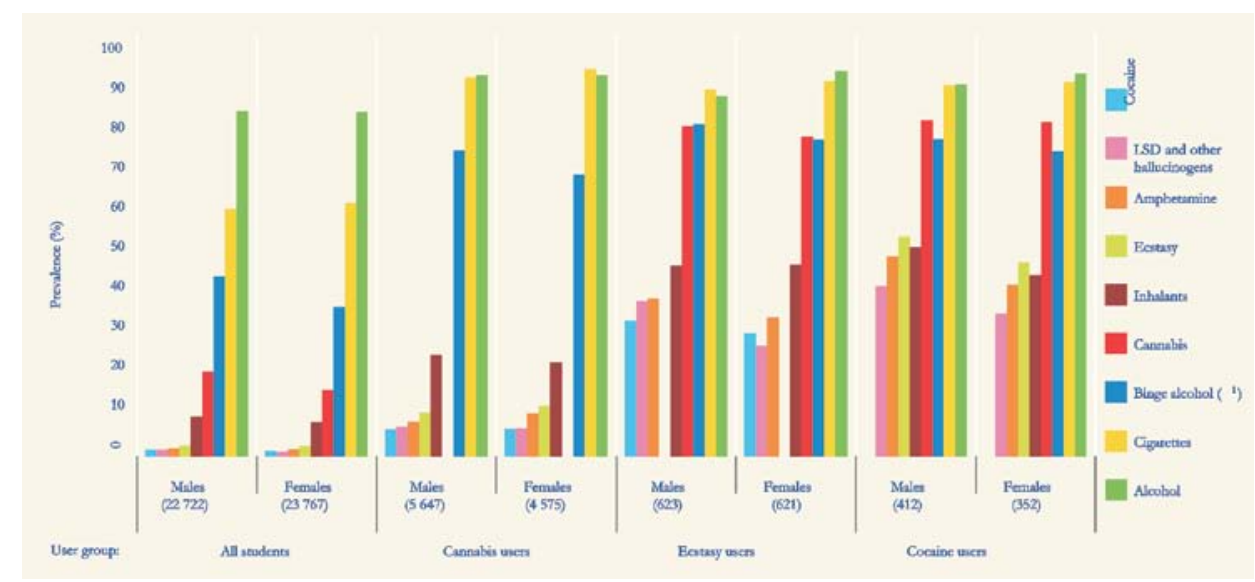

Figure 1: Prevalences of lifetime substance use among different user groups of 15- to 16-year-old students from 15 European countries. User groups are defined as those who have lifetime experience of the substance. Total numbers for the 15 ESPAD countries are given in brackets. Lifetime prevalence rates are the average for 15 countries (Germany, Greece, France, Italy, Lithuania, Hungary, Malta, The Netherlands, Slovenia, Slovakia, Finland, Sweden, UK, Norway, and Croatia) (6). *Binge drinking is defined as consuming 5 or more drinks in a row.

Substance-unrelated addictions reveal an epidemiological picture with men constituting the majority of patients.

In a recent study nearly twice as many adolescent Taiwanese boys than girls were suffering from internet addiction (26.6\% vs. $13.8 \%$ ), which is an addictive disorder particularly affecting the young generation (7). For pathological gambling, which is strongly associated with comorbid substance abuse in both sexes, the odds ratio is also significantly higher for men than for women (e.g. $\mathrm{OR}=4.5$ ) (8); the ratio of adolescent boys to girls with severe gambling-related problems is estimated to be in the range of $3: 1$ to $5: 1$, with girls showing a prevalence of severe gambling problems between 0.5 and $1.8 \%$ (9). 


\subsection{Onset and course of addictive disorders}

Women generally start substance use at a higher age than men (10), but their disease progression is faster as well as the development of medical and social problems associated with the substance abuse ('telescoping effect'), particularly regarding alcohol use disorders. Subsequently, women often have a shorter interval from first use to first treatment episode (11).

Interestingly, these aspects also hold true for gambling problems; in a study conducted by Desai \& Potenza (2008) (12), women with gambling problems were significantly older than their male counterparts; female pathological gamblers start gambling at a later age with gambling problems developing more rapidly compared to male gamblers (13).

In general, women with a diagnosis of substance abuse (305.00-305.90, DSMIV) (14) exhibit a different psychological pattern than men; while men predominantly show externalising psychopathology (e.g. antisocial behaviour, hyperactivity disorder, conduct disorder) in substance abuse, women both develop externalising and internalising symptomatology (e.g. depression, anxiety disorder) $(15,16)$.

The relation of posttraumatic stress disorder (PTSD) to substance abuse has also received special consideration in research due to the frequency of its association (e.g. $45 \%$ in women compared to $24 \%$ in men) (16). While PTSD may be both a result and a predictor of substance use disorders, the higher prevalence in women as well as differences in its genesis (e.g. sexual versus physical abuse) (17), clearly suggest that onset of this disorder differs substantially in male versus female substance abusing patients, and therefore stress the need for discriminative preventive and therapeutic measures. These associations were also found in a study examining differences between male and female pathological gamblers; female adult pathological gamblers were more likely to have a history of physical abuse, unsatisfactory spousal relationships, and problems related to loneliness and depression, whereas males exhibited more impulse control problems and scored higher on measures of antisocial personality and sensation seeking (13).

\section{Gender and sex differences in risk factors, symptomatology, comorbidity, and treatment}

\subsection{Alcohol use disorders}

Men and women show an equally high genetic susceptibility to alcoholism $(18,19)$, although they are affected differently by various risk factors; alcohol use disorders in women are associated with a low household income, widowhood, a lower level of education, and physical or sexual abuse in childhood $(20,21)$. 
Baumann et al. (2007) investigated the relationship between age and 'deprivation' defined by the cumulative number of low educational level, manual worker, unemployed, living alone, nationality other than Western European, low income, nonhome ownership - and substance use for each sex, and found strong associations between deprivation indicators and both alcohol and tobacco use for men and women (see table 1).

Table 1: Associations between age, deprivation, and substance use for each sex (21).

\begin{tabular}{|c|c|c|c|c|c|c|c|c|c|c|c|c|c|c|}
\hline \multirow[b]{2}{*}{ No. of subjects } & \multicolumn{7}{|c|}{ Men (2,959 subjects) } & \multicolumn{7}{|c|}{ Women $(3,257$ subjects) } \\
\hline & $\begin{array}{l}529 \\
637\end{array}$ & $\begin{array}{c}30-39 \\
645\end{array}$ & $\begin{array}{c}40-49 \\
528\end{array}$ & $\begin{array}{c}50-59 \\
373\end{array}$ & $\begin{array}{c}60-69 \\
428\end{array}$ & $\begin{array}{l}\geq 70 \\
348\end{array}$ & p-value & $\begin{array}{l}529 \\
799\end{array}$ & $\begin{array}{c}30-39 \\
655\end{array}$ & $\begin{array}{c}40-49 \\
491\end{array}$ & $\begin{array}{c}50-59 \\
391\end{array}$ & $\begin{array}{c}60-69 \\
487\end{array}$ & $\begin{array}{l}\geq 70 \\
434\end{array}$ & p-value \\
\hline \multicolumn{15}{|l|}{ Deprivation } \\
\hline Low educational level & 10.1 & 15.2 & 22.7 & 29.0 & 44.2 & 58.0 & $<0.001$ & 8.8 & 16.5 & 30.5 & 44.5 & 56.5 & 61.7 & $<0.001$ \\
\hline Manual worker & 20.4 & 35.6 & 29.4 & 28.2 & 25.2 & 20.1 & $<0.001$ & 6.4 & 9.9 & 12.4 & 9.0 & 12.3 & 8.8 & 0.002 \\
\hline Low perceived income & 11.9 & 9.6 & 11.2 & 9.9 & 3.7 & 2.6 & $<0.001$ & 10.9 & 9.3 & 13.9 & 8.4 & 4.3 & 5.3 & $<0.001$ \\
\hline Living alone & 10.1 & 7.9 & 5.9 & 5.1 & 6.5 & 10.1 & 0.012 & 9.4 & 7.0 & 4.1 & 13.0 & 22.6 & 42.6 & $<0.001$ \\
\hline Unemployed & 5.0 & 3.4 & 2.5 & 5.9 & 0.2 & - & $<0.001$ & 7.3 & 5.5 & 5.3 & 5.9 & 1.4 & - & $<0.001$ \\
\hline Foreign nationality & 2.4 & 2.0 & 2.1 & 2.7 & 2.6 & 3.4 & 0.79 & 1.8 & 1.7 & 0.8 & 3.1 & 1.9 & 2.3 & 0.24 \\
\hline Not home-owner & 56.4 & 48.7 & 31.2 & 22.8 & 18.0 & 26.2 & $<0.001$ & 61.2 & 46.7 & 31.0 & 28.4 & 24.2 & 36.2 & $<0.001$ \\
\hline D score & & & & & & & $<0.001$ & & & & & & & $<0.001$ \\
\hline$D=1$ & 39.3 & 37.0 & 31.2 & 32.7 & 31.3 & 42.0 & & 42.5 & 38.9 & 31.4 & 37.6 & 42.7 & 38.7 & \\
\hline$D=2$ & 23.7 & 22.0 & 18.0 & 15.3 & 21.0 & 23.8 & & 21.3 & 16.3 & 18.5 & 18.9 & 24.8 & 32.0 & \\
\hline$D \geq 3$ & 9.1 & 12.6 & 11.4 & 11.3 & 8.6 & 9.8 & & 6.4 & 7.9 & 9.0 & 11.3 & 9.9 & 16.4 & \\
\hline Tobacco use & 37.1 & 41.2 & 38.1 & 23.6 & 15.0 & 11.2 & $<0.001$ & 34.7 & 36.0 & 21.4 & 12.0 & 7.2 & 3.0 & $<0.001$ \\
\hline Aicohol abuse & 11.0 & 11.8 & 15.9 & 16.6 & 10.8 & 8.9 & 0.003 & 3.9 & 4.0 & 5.1 & 3.1 & 1.4 & 1.4 & 0.004 \\
\hline Frequent use of psychotropic drugs & 21.5 & 23.7 & 25.2 & 23.3 & 22.0 & 28.4 & 0.19 & 42.2 & 36.0 & 41.3 & 43.2 & 41.1 & 43.5 & 0.10 \\
\hline
\end{tabular}

Age was related to $D$ with $p<0.001$.

Alcoholism shows a strong association with comorbid depression and anxiety disorder in both sexes; interestingly, relapses caused by negative affects like anger or grief are predicted by depression severity in men, whereas in women alcohol dependence severity seems to be the crucial factor $(22,23)$. However, opposite findings in that regard have been reported by other groups, alcoholic women under 40 have a 5 times higher probability of attempting suicide than non-alcoholic women (24).

In women, alcoholism has been linked to infertility, impairment of reproductive function, miscarriage, premature delivery and early hysterectomy, breast cancer, and hip fractures (25-28). During pregnancy, alcohol poses various health risks for mother and child, including a higher rate of spontaneous abortions, low birth weight in infants, a shorter gestation period, increased perinatal mortality, as well as the 'Fetal Alcohol Syndrome', comprising physical changes and abnormalities in the central nervous system, and mental retardation (29). Other effects of prenatal alcohol consumption are congenital malformations, abnormalities of eye and ear, genito-urinary defects, and learning disabilities (30).

Usually, women consume less alcohol than men, but in women who drink equally high amounts of alcohol as men, both immediate (blood alcohol concentration) and chronic effects (e.g. hepatic cirrhosis) are amplified $(31,32)$. 
Alcoholic women start abusing alcohol later in life than men, but seek treatment at the same age; female patients are underrepresented in alcohol treatment programs due to financial limitations, lack of childcare facilities, ineffective screening by health care providers, limited availability of gender-specific services, fear of losing their children, and internal barriers like feelings of shame, guilt, and denial (33-35). Factors predictive for entering treatment in men originate in alcohol-related problems at work or alcohol-related legal problems (e.g. driving under influence and temporarily losing their driving licence), whereas women are more likely to seek help if they face medical and social problems (33).

\subsection{Nicotine abuse and dependence}

In the past decades there has been a rapid increase in the number of smoking women, particularly young women, and the World Health Organization estimates that tobacco-related mortality will have doubled among women by the year 2020 (36).

Besides the well-known health damages caused by nicotine abuse like pulmonary and cardio-vascular as well as neoplastic diseases, fertility and the female hormone system are particularly affected $(37,38)$. Additionally, cataracts and eye problems, loss of hearing and teeth, a higher rate of osteoporosis, as well as cerebrovascular and thromboembolic complications, especially among women taking oral contraceptives, have been observed (39-41).

Generally, women show less physical dependence on nicotine than men, while greater importance of psycho-social factors can be found, e.g., women tend to relapse in negatively commotated situations like stress and frustrations and men in positively commutated situations $(42,43)$.

The relationship of diet to smoking is also noteworthy; it has been shown that smoking women have a lower average body weight compared to non-smoking females, probably due to an accelerated metabolism caused by nicotine intake. As this effect is reversible, fear of gaining weight during smoking cessation prevents women from entering treatment or constitutes a major factor for therapy drop-out. Optimised treatment for weight-concerned female smokers should therefore include dietary counselling (44).

Smoking during pregnancy is associated with a higher risk of placenta praevia, premature birth, spontaneous abortion, sudden infant death syndrome (SIDS), as well as 'fetal tobacco syndrome' in children of heavy smokers $(45,46)$. The vasoconstrictive effects of tobacco smoke reduce the blood flow between mother and fetus (47), and hemodynamic disturbances during pregnancy may contribute to an elevated risk of developing diabetes and obesity in later life (48). Moreover, nicotine causes neurotoxic effects that may enhance abnormalities in synaptic activity (49), and manipulate the central nervous system of the child (50). Withdrawal symptoms such as tremors and pathological motor reflexes have been observed in neonates, too $(49,51)$. 
Regarding long-term consequences, prenatal nicotine exposure has been linked to a range of developmental problems, including lower scores on orientation, consolability items, and IQ rates, poorer performance at school, altered auditory functioning $(52,53)$, the development of attention-deficit/hyper-activity disorders in later years (49), and inferior selective attention in preschool children (54).

\subsection{Cocaine abuse and dependence}

Cocaine is the only illicit substance to which women are exposed at a significantly earlier age than men; as they also enter treatment earlier, it has to be questioned whether this can be explained by the earlier acquisition of the disorder, the telescoping effect, a conjunction of these two factors, or by another reason not yet detected within research (55).

While antisocial personality disorder is linked to cocaine abuse in males, it does not seem to be an important risk factor for women, who are more likely to abuse cocaine when suffering from post-traumatic stress disorder, particularly after rape (56-59).

Regarding neuropsychological reactions to cocaine use, women experience less euphoria and more nervousness than men, as well as more psychopathology in early abstinence, and mental distress (55, 60-63).

Cocaine-induced vasoconstriction differs in men and women who experience a particularly high degree of cerebral vasoconstriction during their luteal menstrual cycle phase (64). Moreover, women face a higher risk of acquiring HIV infection or other STDs compared to men, not only due to intravenous consumption, but also because of high-risk sexual behaviour, particularly a higher number of sexual partners and less consistent condom use (65).

Cocaine consumption during pregnancy is associated with earlier delivery, lower birth weight, higher susceptibility to respiratory distress syndrome, congenital syphilis, congenital malformations and neonatal withdrawal syndrome (66). Ogunyemi and Hernández-Loera (2004) found a positive correlation between neonatal withdrawal and maternal urine toxicology (67). Regarding cognitive long-term effects, different results were found so far, ranging from no effects to impaired motor and mental development; however, these findings are frequently correlated with other factors, including prenatal exposure to tobacco, marijuana, or alcohol, and the quality of the child's environment. Further research is needed to address this topic adequately (68).

\subsection{Abuse and dependence on heroin/opioids}

Predisposing factors for women abusing opioids are similar to those in alcohol and cocaine abusers, and include sexual abuse during childhood (20). For female patients, sex partners and spouses exert great influence and play a major role in the initiation and progression of opiate abuse, while male patients are rather influenced 
by their peers (69). Regarding differences how heroin addicted subjects conduct their lives and finance their drugs, men are more likely to be actively employed, to sell drugs or to be incarcerated, while female addicts tend to depend on welfare or prostitution (70).

Regarding medical consequences of heroin abuse, no major sex differences have been reported; however, heroin interferes with the menstrual cycle, and female injection drug users face a higher risk of $\operatorname{HIV}$ infections $(71,72)$. This increased risk may be explained by a variety of contributing factors such as the greater likelihood of prostitution in order to finance the addictive behaviour, and the finding that women may also have to resort to used injection equipment more frequently than men $(73,74)$, which implicates that women may obtain greater benefits from harm reduction programs than men.

Concerning treatment, opioid dependent women generally show poorer treatment responses than opioid dependent men and are more likely to terminate their therapy early, mainly due to an increased social stigma and child-care matters (75, 76). In a study by Ortner et al. (2001), three factors proved to be predictive for a positive treatment outcome in a subgroup of pregnant women, namely early treatment intervention, longer duration of maintenance therapy, and a high frequency of attendance to group therapy (77).

Opioid dependent pregnant women need specially tailored care integrating medical and psychosocial aspects because their children are at high risk of prematurity, lower birth weight, and severe neonatal abstinence syndrome that requires pharmacological treatment (78). It is already accepted in Western countries that opioid maintenance therapy should be seen as the standard therapy for pregnant women addicted to heroin, as it has been shown that women in methadone programs will take more check-ups during pregnancy, and the children born to adequately maintained women are healthier than those of untreated women (79). More confirmative studies are needed to prove safety and effectiveness of slow-release preparations of morphine, which have also been used in opioid maintenance treatment for pregnant patients (80); research results regarding buprenorphine were promising because they revealed a less severe neonatal abstinence syndrome compared to the other maintenance substances (79). Another important finding for treatment during pregnancy is that twice-a-day doses of methadone may be needed in the last trimester due to hormonal enzyme induction and there generally exists some evidence about a higher $\mu$-opioid-receptor-binding in women $(81,82)$, a fact necessitating special consideration if these women are not to be undertreated. It also seems likely that, besides the effects of hormonal regulation during pregnancy on metabolism, other biological differences exist, and may have important effects. 


\subsection{Prescription drug use disorders}

Prescription drug use refers mainly to the use of prescribed pain medication, stimulant medication, sleeping medication, and sedative/anxiety medication due to the high inherent abuse potential of these medications. Regarding differences between men and women, age seems to be an important mediating factor as well as the distinction between the abuse of prescribed medications and non-medical prescription drug misuse.

Young women are significantly more likely to report medically prescribed use of any abusable medication than men (31\% vs. $24 \%$ ), pain medication ( $27 \%$ vs. $21 \%$ ), sleep medication ( $4 \%$ vs. $2 \%$ ) and sedative or anxiety medication (4\% vs. $3 \%$, whereas male students are more likely to use medically prescribed stimulants for $\mathrm{ADHD}(3 \%$ vs. $2 \%$ ) (83). McCabe et al. (2009) found that lifetime illicit use of prescription drugs is generally higher among young men than women and depends on the motive for drug consumption; female students are more likely to report illicit use of prescription drugs for self-treatment, while male students tend to take medications recreationally. (See table 2). Additionally, a logistic regression analysis revealed that the odds of binge drinking, illicit drug use, positive alcohol, and drug abuse results in screening examinations were significantly more frequent for recreational and mixed subtypes than for the self-treatment subtype (84).

Table 2: Differences between men and women in lifetime prevalence (in percent) of non-medical prescription drug misuse subtypes among college students in the United States (84). ${ }^{*} \mathrm{p}<0.05$ based on Chi-square tests; ${ }^{* * *} \mathrm{p}<0.001$ based on Chisquare tests; n.s. non-significant.

\begin{tabular}{|c|c|c|c|c|c|c|}
\hline & \multicolumn{3}{|c|}{ Pain medication $(n=3535)$} & \multicolumn{3}{|c|}{$\begin{array}{l}\text { Stimulant medication } \\
\qquad(n=3550)\end{array}$} \\
\hline & $\begin{array}{l}\text { Self- } \\
\text { treatment }\end{array}$ & Recreational & Mixed & $\begin{array}{c}\text { Self- } \\
\text { treatment }\end{array}$ & $\begin{array}{c}\text { Recrea- } \\
\text { tional }\end{array}$ & Mixed \\
\hline Gender & $* * *$ & $* * *$ & $* * *$ & $* * *$ & $* * *$ & $* * *$ \\
\hline Female & 7.2 & 2.6 & 4.3 & 2.0 & 0.8 & 4.3 \\
\hline \multirow[t]{3}{*}{ Male } & 4.3 & 4.2 & 5.1 & 2.4 & 2.5 & 4.8 \\
\hline & \multicolumn{3}{|c|}{ Sleeping medication $(n=3553)$} & \multicolumn{3}{|c|}{$\begin{array}{l}\text { Sedative/ anxiety medication } \\
\qquad(\mathrm{n}=3550)\end{array}$} \\
\hline & $\begin{array}{c}\text { Self- } \\
\text { treatment }\end{array}$ & Recreational & Mixed & $\begin{array}{c}\text { Self- } \\
\text { treatment }\end{array}$ & $\begin{array}{l}\text { Recrea- } \\
\text { tional }\end{array}$ & Mixed \\
\hline Gender & n.s. & n.s. & n.s. & $*$ & $*$ & $*$ \\
\hline Female & 2.9 & 0.6 & 1.3 & 1.0 & 1.6 & 1.5 \\
\hline Male & 2.1 & 0.4 & 1.4 & 0.2 & 2.3 & 1.8 \\
\hline
\end{tabular}


Simoni-Wastila (2004) analysed data from the 1991 National Household Survey on Drug Abuse (NHSDA) based on a sample of 3185 adults and found that women were significantly more likely than men to use any prescription drug, mainly due to their increased risk for narcotic analgesic and minor non-medical tranquilizer use (85). Another study by Simoni-Wastila (2000) revealed that female sex, the age group of 25-34 years, being Caucasian, employed, insured, having a regular source of care, and reporting poor or fair health, were significant predictors of abusive prescription drug use; a physical diagnosis of cardiovascular disease, arthritis, back pain, gastrointestinal disorders, cancer, insomnia, fatigue and obesity elevated the risk of prescription drug use $(\mathrm{OR}=2.84)$, as well as any mental medical condition $(\mathrm{OR}=5.26)$. Younger age (18-24 years), urbanicity, marital status, and educational attainment did not significantly predict abusive drug use (86). Huang et al. (2006) found that the odds for non-medical prescription drug use and drug use disorders in the United States were higher among men, Native Americans, young and middle-aged persons who were widowed/separated/divorced or never married, as well as residents of the Western states, with the highest abuse/dependence liability for amphetamines; non-medical prescription drug use disorders were highly comorbid with Axis I (clinical disorders, including major mental disorders, as well as developmental and learning disorders) and Axis II (underlying pervasive or personality conditions, as well as mental retardation) disorders (87).

Among older adults, there is a growing problem of misuse and abuse of prescription drugs, with at least one in four older adults using psychotropic medications, although illegal drug use is relatively rare compared to younger adults (88). Inappropriate drug use, particularly psychotropic drug use, is more common in women than in men $(24.6 \%$ vs. $19.3 \%$ according to a Swedish study with 600.000 subjects aged 75-89 years); neither socioeconomic status nor comorbidities seemed to explain these sex differences (89). The prevalence of prescription drug abuse is estimated to be as high as $11 \%$ among female older adults, and associated with social isolation, depression, a history of substance abuse, and medical exposure to prescription drugs with abuse potential, especially benzodiazepines, opiate analgesics, and skeletal muscle relaxants. However, tolerance, withdrawal syndrome, and dose escalation are less common in the older patients $(88,90)$. The increasing prescription drug use among the elderly poses a major public health problem as the population is growing older and specific screening and assessment instruments for the older adults are missing.

It has to be noted that the majority of presented results on prescription drug use are US-based, as so far only limited data are available from Europe.

\subsection{Substance-unrelated addictions}

The field of substance-unrelated addictions, comprising addictions like shopping addiction, internet addiction, pathological gambling, and sex addiction, is rather new in research and, subsequently, many issues have not profoundly been scientifi- 
cally examined yet. In this article, gender and sex differences of pathological gambling as well as internet addiction will be addressed. Pathological gambling (312.31, DSM-IV) (14), whose categorisation in international classifications is still under discussion due to both facets of the disorder counted among impulse control disorders as well as aspects rather referring to characteristics of addiction. However, research has addressed several sex and gender differences relevant for clinical practice so far: pathological gamblers seem to exhibit gender-specific motives for their problem behaviour; two recent studies found that the competitive nature of winning and losing particularly attracted the male patients, whereas women used gambling as an escape from their problems $(13,91)$.

Regarding comorbidities, typical patterns can be observed; besides a general 'dose-response' association between increasing gambling problems and the odds of psychiatric comorbidity in both sexes, the co-occurrence of gambling problems and several Axis I psychiatric disorders, namely major depression, dysthymia, panic disorder, social phobia, and generalised anxiety disorder, are stronger in women than in men.

Other Axis I disorders like mania, hypomania, phobia, alcohol and drug abuse/dependence, as well as Axis II disorders co-occur equally frequent in both sexes (12). Table 3 displays rates of psychiatric disorders from a large study conducted in the United States $(92,93)$, by sex and problem severity.

Table 3: Psychiatric disorders by sex and gambling severity - results from the NESARC study $(\mathrm{N}=43.093)(12)$.

\begin{tabular}{|c|c|c|c|c|c|c|c|c|c|c|c|c|}
\hline \multirow[b]{2}{*}{ Diagnosis } & \multicolumn{4}{|l|}{ Males } & \multirow[b]{2}{*}{$\chi^{2}$} & \multirow[b]{2}{*}{$p$} & \multicolumn{4}{|l|}{ Females } & \multirow[b]{2}{*}{$\chi^{2}$} & \multirow[b]{2}{*}{$p$} \\
\hline & $\begin{array}{l}\text { Non/LF- } \\
\text { gamblers }^{c}\end{array}$ & $\begin{array}{l}\text { Low-risk } \\
\text { gamblers }\end{array}$ & $\begin{array}{l}\text { At-risk } \\
\text { gamblers }\end{array}$ & $\begin{array}{l}\text { Problem/ } \\
\text { pathological } \\
\text { gamblers }\end{array}$ & & & $\begin{array}{l}\text { Non/LF- } \\
\text { gamblers }^{c}\end{array}$ & $\begin{array}{l}\text { Low-risk } \\
\text { gamblers }\end{array}$ & $\begin{array}{l}\text { At-risk } \\
\text { gamblers }\end{array}$ & $\begin{array}{l}\text { Problem/ } \\
\text { pathological } \\
\text { gamblers }\end{array}$ & & \\
\hline Major depression & 4.96 & 4.68 & 6.75 & 7.18 & 4.59 & 0.21 & 8.85 & 9.59 & 18.5 & 30.92 & 22.7 & 0.002 \\
\hline Dysthymia & 1.17 & 1.26 & 1.18 & 4.19 & 2.3 & 0.52 & 2.25 & 2.62 & 6.07 & 8.80 & 12.9 & 0.008 \\
\hline Panic disorder ${ }^{a}$ & 1.22 & 1.27 & 2.28 & 3.75 & 3.6 & 031 & 2.60 & 3.41 & 12.28 & 13.34 & 20.8 & 0.0004 \\
\hline Social phobia & 1.96 & 2.31 & 3.16 & 10.14 & 7.8 & 0.06 & 3.13 & 4.16 & 6.85 & 8.60 & 11.9 & 0.01 \\
\hline Simple phobia & 4.01 & 5.33 & 8.79 & 19.2 & 26.2 & 0.0001 & 8.64 & 12.76 & 19.88 & 25.27 & 45.4 & $<.0001$ \\
\hline Generalized anxiety & 1.15 & 1.45 & 2.21 & 3.94 & 4.7 & 0.21 & 2.56 & 3.69 & 4.03 & 14.53 & 14.9 & 0.004 \\
\hline Alcohol ab/dep ${ }^{6}$ & 9.95 & 15.31 & 27.25 & 36.60 & 72 & $<.0001$ & 4.25 & 6.41 & 14.31 & 19.60 & 38.1 & $<.0001$ \\
\hline Nicotine dep & 11.52 & 18.27 & 26.07 & 43.96 & 85 & $<.0001$ & 9.87 & 16.02 & 31.99 & 42.50 & 81.6 & $<.0001$ \\
\hline Drug ab/dep & 2.41 & 3.28 & 7.06 & 6.25 & 15.4 & 0.003 & 1.06 & 1.65 & 4.94 & 5.27 & 15.2 & 0.003 \\
\hline Antisocial & 4.45 & 7.12 & 12.67 & 25.2 & 44.9 & $<.0001$ & 1.58 & 2.70 & 6.27 & 12.32 & 30.8 & $<.0001$ \\
\hline Obsessive-compulsive & 7.04 & 9.35 & 13.85 & 23.42 & 30.5 & $<.0001$ & 7.25 & 9.91 & 19.72 & 26.74 & 39.9 & $<.0001$ \\
\hline Paranoid & 3.35 & 4.19 & 7.68 & 28.03 & 30.7 & $<.0001$ & 4.61 & 5.69 & 14.08 & 21.91 & 25.3 & 0.0001 \\
\hline Schizoid & 2.78 & 3.95 & 3.95 & 15.59 & 14.9 & 0.004 & 2.92 & 3.23 & 9.20 & 16.09 & 21.9 & 0.0003 \\
\hline Histrionic & 1.59 & 1.97 & 5.58 & 15.78 & 23.8 & $<.0001$ & 1.71 & 1.95 & 5.21 & 8.83 & 9.9 & 0.03 \\
\hline
\end{tabular}

With or without agoraphobia

$\mathrm{b} \mathrm{ab} / \mathrm{dep}=$ abuse or dependence

${ }^{c} \mathrm{Non} / \mathrm{L} F=$ non or low-frequency gamblers 
A recent study investigating sex differences in adolescent problem gamblers (94), revealed that male social gamblers (low level of gambling severity) were 2.67 times more likely than females to use hard drugs and alcohol $(\mathrm{OR}=1.59)$ on a weekly basis, whereas boys with high gambling severity were less likely to use hard drugs compared to their female counterparts $(\mathrm{OR}=0.88)$. Regarding depression, the opposite trend was observed; boys with low gambling severity were less likely than girls to meet clinical criteria for depression, whereas the prevalence rates among adolescents with high gambling severity did not differ significantly; boys and girls with high gambling severity also showed a similar pattern of self-reported weekly drug use, and low school grade average.

Another noteworthy finding is that an age-by-gender interaction regarding treatment seeking may be observed among pathological gamblers where males exhibit a more pronounced age-related shortening in the duration between problem onset and treatment seeking (95). Crisp et al. (2004) characterised the help seeking female patients ( $46 \%$ of all help seeking pathological gamblers) in Australia as being slightly older than the male patients (39.6 vs. 36.1 years), more likely to be married $(42.8 \%$ vs. $30.2 \%)$ and living with their families $(78.9 \%$ vs. $61.5 \%)$ and having dependent children ( $48.4 \%$ vs. $35.7 \%)$. Women reported average gambling debts $(A \$ 7,342)$ of less than half of that owed by men $(A \$ 19,091)$. These differences between male and female patients should be taken into account while developing and implementing problem gambling counselling services (96).

A specific form of pathological gambling refers to online gambling, whose prevalence rates range between 0.3 and $5.3 \%$ in the adult population of Western countries; the typical online gambler is male, 34 years or younger, single, and has a higher employee status or is working independently $(97,98)$. A study of LaBrie et al. (2008) investigating the gambling behaviour of more than 4000 online casino gamblers, reported 93\% male participants with a mean age of 30 years from 46 countries, with Germany (19\%) ranking first, followed by Austria (11\%) (99). A scientifically based analysis of online gambling markets in Germany, Austria and Switzerland in 2005, revealed that Germany is the country with the highest turnover (3.3 billion $€$ per year) reflecting the highest amount of wagers, followed by Austria ( 1.4 billion $€$ per year), and Switzerland ( 0.3 billion $€$ per year); however, the 'per capita wager' was highest in Austria with $177.49 €$, leaving Germany and Switzerland far behind, with $39.74 €$ and $36.08 €$, respectively (100). Only few studies have been conducted yet to examine this new form of gambling with addiction potential, but it may become increasingly important in the near future.

Research in the field of internet addiction in general is rather new and focusing on the young generation. Little is known yet of specific gender and sex differences in this disorder, inter alia because internet use of both sexes is still not explored thoroughly. Generally, women prefer using the internet for communication and personal information and thus cultivate social support, whereas men typically look for information regarding weather, sports, and games (101). 
Depression and low family monitoring were found to be discriminative factors for both sexes in adolescent internet addiction (7). Moreover, less actual social support and higher virtual social support turned out to be linked to higher depressive symptoms in both genders; maybe support perceived as insufficient promotes online social activity which worsens personal problems in reality and, subsequently, depressive symptoms (102). The same study revealed that internet addiction in male students was predicted by virtual social support, directly or indirectly mediated through depressive symptoms; the association with actual social support was only mediated through depressive symptoms. In female students, both actual and virtual social support directly predicted internet addiction or were mediated through depressive symptoms (102). More profound investigation of these and other possible confounding factors in internet addiction is needed in order to derive causal relations.

\section{Discussion}

This literature review summarises the most important findings regarding sex and gender differences in addictive disorders, aiming at encouraging further research in this area which needs improvement in order to allow a clear interpretation of results; often addicted women are compared to addicted men, or to non-addicted women, and rarely to both, which causes problems when trying to disentangle the influence of gender on the illness from potential differences to be found among subgroups at risk compared to those considered to be normal.

Moreover, gender research often fails to take into account that men and women - having different specific needs and differing regarding their health status - never constitute homogeneous groups, and lacks inclusion of various relevant confounding variables. A gender-comparing approach should always consider potentially interacting factors like age, educational and socio-economic level as well as marital status, and aim to find gender or sex differences yielding an improvement in the development of gender-specific measures in the domains of health promotion, prevention, treatment, after-care, and service provision, by applying research instruments that have been validated for both sexes.

Finally, frequent lack of evidence-based research often prohibits exact evaluation of research findings, and, therefore, a stronger orientation towards this scientific standard must be established in the scientific community studying sex and gender differences in addiction.

Limitations of the presented research findings refer to the restricted validity due to this biased choice of comparison groups, as well as a selection bias regarding participant recruitment, which can hardly be excluded; addicted patients represent a special population characterised by especially low compliance rates. Subsequently, the probability of recruiting more compliant and consequently more stable patients for scientific research is high, and, therefore, results from the most 
unstable patients are hardly ever included. Furthermore, participant recruitment frequently does not reach clients living in outlying, particularly rural areas due to limited availability of service and research institutions.

Regarding substance use research in special patient populations like pregnant women, high ethical restrictions, e. g. in psychopharmacological medication use, and imposed restrictions frequently impede the implementation of research projects. It would be important to encourage the realisation of research with special patient populations because only these findings are clinically applicable to those clients.

Furthermore, studies systematically investigating biological differences in pharmacokinetics and pharmacodynamics of abused licit/illicit substances as well as in medications administered are needed.

Concerning substance-unrelated addictions, many aspects of these disorders have not been studied yet, and, therefore, only a special choice of research results available so far, has been presented. Regarding internet addiction, the availability of findings is even more restricted as most research has been conducted with an adolescent population only; scientific research investigating substance-unrelated conditions has to be extended to get an insight into these disorders in order to pose relevant research questions relating to sex and gender.

\section{References}

1. Klose M, Jacobi F: Can gender differences in the prevalence of mental disorders be explained by sociodemographic factors? Archives of Women's Mental Health 7(2); 2004; 133-148.

2. Meyer C, Rumpf HJ, Hapke U, DIlling H, John U: Lebenszeitprävalenz psychischer Störungen in der erwachsenen Allgemeinbevölkerung. Ergebnisse der TACOS-Studie. Nervenarzt 71; 2000; 535-542.

3. Jacobi F, Wittchen HU, Hölting C, Höfler M, Pfister H, Müller N, Lieb R: Prevalence, co-morbidity and correlates of mental disorders in the general population: results from the German Health Interview and Examination Survey (GHS). Psychological Medicine 34; 2004; 1-15.

4. Jacobi F, Wittchen HU, Hölting C, Sommer S, Lieb R, Höfler M, Pfister H:

Estimating the prevalence of mental and somatic disorders in the community; Aims and methods of the German National Health Interview and Examination Survey. International Journal of Methods in Psychiatric Research 11; 2002; 1 19. 
5. SAMHSA: 2005 National Survey on Drug Use and Health: Detailed Tables http://www.oas.samhsa.gov/nsduh/2k5nsduh/tabs/Sect1peTabs1 to18.pdf $<10$ September 2009>

6. EMCDDA: Annual Report 2006. Selected issues 2: A gender perspective on drug use and responding to drug problems. 2006. http://issues06.emcdda.eur opa. eu <15 September 2009>

7. Yen CF, Ko CH, Yen JY, Chang YP, Cheng CP: Multi-dimensional discriminative factors for Internet addiction among adolescents regarding gender and age. Psychiatry and Clinical Neurosciences 63(3); 2009; 357-364.

8. Kessler RC, Hwang I, LaBrie R, Petukhova M, Sampson NA, Winters KC, Shaffer HJ: DSM-IV pathological gambling in the National Comorbidity Survey Replication. Psychological Medicine 38(9); 2008; 1351-1360.

9. Jacobs DF: Youth gambling in North America: Long term trends, future prospects. In: Derevensky J, Gupta R (eds.): Gambling problems in youth: Developmental and applied perspectives. New York: Kluwer; 2004; 1-26.

10. Van Etten ML, Anthony JC: Comparative epidemiology of initial drug opportunities and transitions to first use: marijuana, cocaine, hallucinogens and heroin. Drug and Alcohol Dependence 54; 1999; 117-125.

11. Zilberman M, Tavares H, el-Guebaly N: Gender similarities and differences: the prevalence and course of alcohol- and other substance-related disorders. Journal of Addictive Diseases 22(4); 2003; 61-74.

12. Desai RA, Potenza MN. Gender differences in the associations between pastyear gambling problems and psychiatric disorders. Social Psychiatry and Psychiatric Epidemiology 2008; 43(3); 173-183.

13. Ibanez A, Blanco C, Moreryra P, Saiz-Ruiz J: Gender differences in pathological gambling. Journal of Clinical Psychiatry 64(3); 2003; 295-301.

14. Diagnostic and Statistical Manual (Version IV). http://psych.org/MainMenu/ Research/DSMIV.aspx. <17 September 2009>

15. Dakof GA: Understanding gender differences in adolescent drug abuse: issues of comorbidity and family functioning. Journal of Psychoactive Drugs 32; 2000; 25-32.

16. Lipschitz DS, Grilo CM, Fehon D, McGlashan TM, Southwick SM: Gender differences in the associations between posttraumatic stress symptoms and problematic substance use in psychiatric inpatient adolescents. Journal of Nervous and Mental Disease 188; 2000; 349-356. 
17. Deykin EY, Buka SL: Prevalence and risk factors for posttraumatic stress disorder among chemically dependent adolescents. American Journal of Psychiatry 154; 1997; 752-757.

18. Prescott CA, Aggen SH, Kendler KS: Sex differences in the sources of genetic liability to alcohol abuse and dependence in a population-based sample of U.S. twins. Alcoholism: Clinical and Experimental Research 23(7); 1999; 11361144.

19. McGue M, Elkins I, Iacono WG. Genetic and environmental influences on adolescent substance use and abuse. American Journal of Medical Genetics 96; 2000; 671-677.

20. Simpson TL, Miller WR. Concomitance between childhood sexual and physical abuse and substance use problems. A review. Clinical Psychology Review 22(1); 2002; 27-77.

21. Baumann M, Spitz E, Guillemin F, Ravaud JF, Choquet M, Falissard B, Chau $\mathrm{N}$, Lorhandicap group. Associations of social and material deprivation with tobacco, alcohol, and psychotropic drug use, and gender: a population-based study. International Journal of Health Geographics 6; 2007; 50.

22. Zywiak WH, Stout RL, Trefry WB, Glasser I, Connors GJ, Maisto SA, Westerberg VS: Alcohol relapse repetition, gender, and predictive validity. Journal of Substance Abuse Treatment 30(4); 2006; 349-353.

23. Fischer EH, Goethe JW. Anxiety and alcohol abuse in patients in treatment for depression. The American Journal of Drug and Alcohol Abuse 24(3); 1998; 453-463.

24. Conner KR, Hesselbrock VM, Schuckit MA, Hirsch JK, Knox KL, Meldrum S, Bucholz KK, Kramer J, Kuperman S, Preuss U, Soyka M: Precontemplated and impulsive suicide attempts among individuals with alcohol dependence. Journal of Studies on Alcohol 67(1); 2006; 95-101.

25. O'Leary CM, Nassar N, Kurinczuk JJ, Bower C: The effect of maternal alcohol consumption on fetal growth and preterm birth. British Journal of Obstetrics and Gynaecology 116(3); 2009; 390-400.

26. Settnes A, Jorgensen T, Lange AP: Hysterectomy in Danish women: weightrelated factors, psychologic factors, and life-style variables. Obstetrics and Gynecology 88; 1996; 99-105.

27. Clark MK, Sowers MF, Dekordi F, Nichols S. Bone mineral density and fractures among alcohol-dependent women in treatment and in recovery. Osteoporosis International 14(5); 2003; 396-403. 
28. Seitz HK, Maurer B. The relationship between alcohol metabolism, estrogen levels, and breast cancer risk. Alcohol Research \& Health 30(1); 2007; 42-43.

29. May PA, Gossage JP, Kalberg WO, Robinson LK, Buckley D, Manning M, Hoyme HE: Prevalence and epidemiologic characteristics of FASD from various research methods with an emphasis on recent in-school studies. Developmental Disabilities Research Reviews 15(3); 2009; 176-192.

30. Ryan DM, Bonnett DM, Gass CB. Sobering thoughts: town Hall meetings on fetal alcohol spectrum disorders. American Journal of Public Health 96(12); 2006; 2098-2101.

31. Ammon E, Schafer C, Hofmann U, Klotz U: Disposition and first-pass metabolism of ethanol in humans: is it gastric or hepatic and does it depend on gender? Clinical Pharmacology and Therapeutics 59; 1996; 503-513.

32. Stokkeland K, Hilm G, Spak F, Franck J, Hultcrantz R: Different drinking patterns for women and men with alcohol dependence with and without alcoholic cirrhosis. Alcohol 43(1); 2008; 39-45.

33. Limosin F: Clinical and biological specificities of female alcoholism. Le Encéphale: Journal de Neurologie, de Psychiatrie et de Médecine Psychosomatique 28(6 Pt 1); 2002; 503-509.

34. Zilberman ML, Tavares H, Andrade AG: Discriminating drug-dependent women from alcoholic women and drug-dependent men. Addictive Behaviors 28(7); 2003; 1343-1349.

35. Green CA. Gender and use of substance abuse treatment services. Alcohol Research and Health 29(1); 2006; 55-62.

36. WHO: WHO-International Conference on Tobacco and Health; 1999; Kobe, Japan.

37. Bridgewood A, Lilly R, Thomas M, Al E: Living in Britain: Results from the General Household Survey; 2000; London: The Stationary Office, Office for National Statistics, Social Survey Division.

38. Windsor RA, Boyd NR, Orleans CT: A meta-evaluation of smoking cessation intervention research among pregnant women: improving the science and art. Health Education Research 13; 1998; 419-438.

39. Prescott E, Osler M, Andersen PK, Hein HO, Borch-Johnsen K, Lange P, Schnohr P, Vestbo J: Mortality in women and men in relation to smoking. International Journal of Epidemiology 27(1); 1998; 27-32. 
40. Ben-Zaken Cohen S, Paré PD, Man SF, Sin DD: The growing burden of chronic obstructive pulmonary disease and lung cancer in women: examining sex differences in cigarette smoke metabolism. American Journal of Respiratory and Critical Care Medicine 176(2)2007; 113-120.

41. Action on Smoking and Health: Smoking statistics: illness \& death. ASH Factsheet No. 2. London: Action on Smoking and Health; 1999.

42. Heatherton TF, Kozlowski LT, Frecker RC, Fagerstrom KO: The Fagerstrom Test for Nicotine Dependence: a revision of the Fagerstrom Tolerance Questionnaire. British Journal of Addiction 86; 1991; 1119-1127.

43. Mitchell SL, Perkins KA: Interaction of stress, smoking, and dietary restraint in women. Physiology and Behavior 64; 1998; 103-109.

44. Sallit J, Ciccazzo M, Dixon Z: A cognitive-behavioral weight control program improves eating and smoking behaviors in weight-concerned female smokers. Journal American Dietetic Association 109(8); 2009; 1398-1405.

45. Tuthill DP, Stewart JH, Coles EC, Andrews J, Cartlidge PH: Maternal cigarette smoking and pregnancy outcome. Paediatric and Perinatal Epidemiology 13; 1999; 245-253.

46. DiFranza JR, Aligne CA, Weitzman M. Prenatal and postnatal environmental tobacco smoke exposure and children's health. Pediatrics 113(4 Suppl); 2004; 1007-1015.

47. Ates U, Ata B, Armagan F, Has R, Sidal B: Acute effects of maternal smoking on fetal hemodynamics. International Journal of Obstetrics and Gynaecology 87; 2004; 14-18.

48. Somm E, Schwitzgebel VM, Vauthay DM, Camm EJ, Chen CY, Giacobino JP, Sizonenko SV, Aubert ML, Hüppi PS: Prenatal nicotine exposure alters early pancreatic islet and adipose tissue development with consequences on the control of body weight and glucose metabolism later in life. Endocrinology 149; 2008; 6289-6299.

49. Law KL, Stroud LR, LaGasse LL, Niaura R, Lui J, Lester BM: Smoking during pregnancy and newborn neurobehaviour. Pediatrics 111; 2003; 1318-1323.

50. Levin ED, Slotkin TA: Developmental neurotoxicity of nicotine. In: Slikker W, Chang LW (eds): Handbook of Developmental Neurotoxicity. New York: Academic Press; 1998; 587-615.

51. Garcia-Algar O, Puig C, Mendez C, Vall O, Pacifici R, Pichini S: Neonatal nicotine withdrawal syndrome. Journal of Epidemiology and Community Health 55; 2001; 687-688. 
52. Jacobsen LK, Slotkin TA, Mencel WE, Frost SJ, Pugh KR: Gender-specific effects of prenatal and adolescent exposure to tobacco smoke on auditory and visual attention. Neuropharmacology 32; 2007; 2453-2464.

53. McCartney JS, Fried PA, Watkinson B: Central auditory processing in schoolage children prenatally exposed to cigarette smoke. Neurotoxicology and Teratology 16; 1994; 269-276.

54. Noland JS, Singer LT, Short EJ, Minnes S, Arendt RE, Kirchner HL, Bearer C: Prenatal drug exposure and selective attention in preschoolers.

Neurotoxicology and Teratology 27; 2005; 429-438.

55. Najavits LM, Lester KM. Gender differences in cocaine dependence. Drug and Alcohol Dependence 97(1-2); 2008; 190-194.

56. Weiss RD, Martinez-Raga J, Griffin ML, Greenfield SF, Hufford C: Gender differences in cocaine dependent patients: a 6 month follow-up study. Drug and Alcohol Dependence 44; 1997; 35-40.

57. Hyman SM, Paliwal P, Chaplin TM, Mazure CM, Rounsaville BJ, Sinha R: Severity of childhood trauma is predictive of cocaine relapse outcomes in women but not men. Drug and Alcohol Dependence 92(1-3); 2008; 208-216.

58. Wasserman DA, Havassy BE, Boles SM: Traumatic events and post-traumatic stress disorder in cocaine users entering private treatment. Drug and Alcohol Dependence 46; 1997; 1-8.

59. Hyman SM, Garcia M, Sinha R: Gender specific associations between types of childhood maltreatment and the onset, escalation and severity of substance use in cocaine dependent adults. The American Journal of Drug and Alcohol Abuse 32(4); 2006; 655-664.

60. Kosten TR, Kosten TA, McDougle CJ, Hameedi FA, McCance EF, Rosen MI, Oliveto AH, Price LH: Gender differences in response to intranasal cocaine administration to humans. Biological Psychiatry 39; 1996; 147-148.

61. Lukas SE, Sholar M, Lundahl LH, Lamas X, Kouri E, Wines JD, Kragie L, Mendelson JH: Sex differences in plasma cocaine levels and subjective effects after acute cocaine administration in human volunteers. Psychopharmacology 125; 1996; 346-54.

62. Wong CJ, Badger GJ, Sigmon SC, Higgins ST: Examining possible gender differences among cocaine-dependent outpatients. Experimental and Clinical Psychopharmacology 10(3); 2002; 316-323.

63. Marlowe DB, Husband SD, Lamb RJ, Iguchi MY, Bux DA, Kirby KC, Platt JJ: Psychiatric comorbidity in cocaine dependence. Diverging trends, Axis II spectrum, and gender differentials. American Journal on Addictions 9(1); 1995; 70-81. 
64. Kaufman MJ, Levin JM, Maas LC, Kukes TJ, Villafuerte RA, Dostal K, Lukas SE, Mendelson JH, Cohen BM, Renshaw PF: Cocaine-induced cerebral vasoconstriction differs as a function of sex and menstrual cycle phase, Biological Psychiatry 49; 2001; 774-81.

65. Wilson TE, Minkoff H, DeHovitz J, Feldman J, Landesman S: The relationship of cocaine use and human immunodeficiency virus serostatus to incident sexually transmitted diseases among women. Sexually Transmitted Diseases 25(2); 1998; 70-75.

66. National Toxicology Program: NTP-CERHR monograph on the potential human reproductive and developmental effects of amphetamines. NTP CERHR MON 16; 2005; vii-III1.

67. Ogunyemi D, Hernández-Loera GE: The impact of antenatal cocaine use on maternal characteristics and neonatal outcomes. The Journal of Maternal-Fetal \& Neonatal Medicine 15(4); 2004; 253-259.

68. Frank DA, Augustyn M, Knight WG, Pell T, Zuckerman B: Growth, development, and behavior in early childhood following prenatal cocaine exposure: a systematic review. Journal of the American Medical Association 285(12); 2001; 1613-1625.

69. Miller M, Neaigus A: Sex partner support, drug use and sex risk among HIVnegative non-injecting heroin users. AIDS Care 14(6); 2002; 801-813.

70. Kelly SM, Schwartz RP, O'Grady KE, Mitchell SG, Reisinger HS, Peterson JA, Agar MH, Brown BS: Gender differences among in- and out-of-treatment opioid-addicted individuals. The American Journal of Drug and Alcohol Abuse 35(1); 2009; 38-42.

71. Evans JL, Hahn JA, Page-Shafer K, Lum PJ, Stein ES, Davidson PJ, Moss AR. Gender differences in sexual and injection risk behavior among active young injection drug users in San Francisco (the UFO Study). Journal of Urban Health 80(1); 2003; 137-146.

72. Latkin CA, Mandell W, Knowlton AR, Doherty MC, Vlahov D, Suh T, Celentano DD: Gender differences in injection-related behaviors among injection drug users in Baltimore, Maryland. AIDS Education and Prevention 10(3); 1998; 257-263.

73. Bennett GA, Velleman RD, Barter G, Bradbury C: Gender differences in sharing injecting equipment by drug users in England. AIDS Care 12; 2000; 77-87.

74. Miller M, Eskild A, Mella I, Moi H, Magnus P: Gender differences in syringe exchange program use in Oslo, Norway. Addiction 96; 2001; 1639-1651. 
75. Jones HE, Fitzgerald H, Johnson RE: Males and females differ in response to opioid agonist medications. American Journal on Addictions 14(3); 2005; 223 233.

76. Green CA, Polen MR, Dickinson DM, Lynch FL, Bennett MD: Gender differences in predictors of initiation, retention, and completion in an HMObased substance abuse treatment program. Journal of Substance Abuse Treatment 23(4); 2002; 285-295.

77. Ortner R, Schuster A, Rohrmeister K, Fischer G: Prädiktoren zur Stabilisierung opioidabhängiger gravider Frauen mit Ausblick auf die elterliche Sorge. Suchttherapie 2; 2001; 152-158.

78. Fajemirokun-Odudeyi O, Sinha C, Tutty S, Pairaudeau P, Armstrong D, Phillips T, Lindow SW: Pregnancy outcome in women who use opiates. European Journal of Obstetrics \& Gynecology and Reproductive Biology 126(2); 2006; 170-175.

79. Fischer G, Johnson RE, Eder H, Jagsch R, Peternell A, Weninger M, Langer M, Aschauer HN: Treatment of opioid-dependent pregnant women with buprenorphine. Addiction 95; 2000; 239-44.

80. Fischer G, Jagsch R, Eder H, Gombas W, Etzersdorfer P, Schmidl-Mohl K, Schatten C, Weninger M, Aschauer HN: Comparison of methadone and slowrelease morphine maintenance in pregnant addicts. Addiction 94(2); 1999; 231-239.

81. Jarvis M A, Wu-Pong S, Kniseley J S, Schnoll SH: Alterations in methadone metabolism during late pregnancy. Journal of Addictive Diseases 18; 1999; 5161.

82. Zubieta JK, Dannals RF, Frost JJ: Gender and age influences on human brain mu-opioid receptor binding measured by PET. American Journal of Psychiatry 156(6); 1999; 842-848.

83. McCabe SE, Teter CJ, Boyd CJ. Medical use, illicit use, and diversion of abusable prescription drugs. Journal of American College Health 54(5); 2006; 269-278.

84. McCabe SE, Boyd CJ, Teter CJ. Subtypes of nonmedical prescription drug misuse. Drug and Alcohol Dependence 102(1-3); 2009; 63-70.

85. Simoni-Wastila L, Ritter G, Strickler G: Gender and other factors associated with the nonmedical use of abusable prescription drugs. Substance Use and Misuse 39(1); 2004; 1-23.

86. Simoni-Wastila L: The use of abusable prescription drugs: the role of gender. Journal of Women's Health and Gender-Based Medicine 9(3); 2000; 289-297. 
87. Huang B, Dawson DA, Stinson FS, Hasin DS, Ruan WJ, Saha TD, Smith SM, Goldstein RB, Grant BF: Prevalence, correlates, and comorbidity of nonmedical prescription drug use and drug use disorders in the United States: Results of the National Epidemiologic Survey on Alcohol and Related Conditions. Journal of Clinical Psychiatry 67(7); 2006; 1062-1073.

88. Simoni-Wastila L, Yang HK: Psychoactive drug abuse in older adults. The American Journal of Geriatric Pharmacotherapy 4(4); 2006; 380-94.

89. Johnell K, Weitoft GR, Fastbom J: Sex differences in inappropriate drug use: a register-based study of over 600,000 older people. The Annals of Pharmacotherapy 43(7); 2009; 1233-1238.

90. Culberson JW, Ziska M: Prescription drug misuse/abuse in the elderly. Geriatrics 63(9); 2008; 22-31.

91. Grant JE, Kim SW: Gender differences in pathological gamblers seeking medication treatment. Comprehensive Psychiatry 43(1); 2002; 56-62.

92. Grant BF, Stinson FS, Dawson DA, Chou SP, Dufour MC, Compton W, Pickering RP, Kaplan K: Prevalence and co-occurrence of substance use disorders and independent mood and anxiety disorders: results from the National Epidemiologic Survey on Alcohol and Related Conditions. Archives of General Psychiatry 61(8); 2004; 807-816.

93. Grant BF, Kaplan K, Shepard J, Moore T: Source and accuracy statement for wave 1 of the 2001-2002 national epidemiologic survey on alcohol and related conditions. Bethesda: National Institute on Alcohol Abuse and Alcoholism; 2003.

94. Ellenbogen S, Derevensky J, Gupta R: Gender differences among adolescents with gambling-related problems. Journal of Gambling Studies 23(2); 2007; 133-143.

95. Grant JE, Kim SW, Odlaug BL, Buchanan SN, Potenza MN. Late-onset pathological gambling: clinical correlates and gender differences. Journal of Psychiatric Research 43(4); 2009; 380-387.

96. Crisp BR, Thomas SA, Jackson AC, Smith S, Borrell J, Ho WY, Holt TA, Thomason N: Not the same: a comparison of female and male clients seeking treatment from problem gambling counselling services. Journal of Gambling Studies 20(3); 2004; 283-299.

97. Griffiths MD, Wood RT, Parke J: Social responsibility tools in online gambling: A survey of attitudes and behavior among internet gamblers. Cyberpsychology \& Behavior; 2009 Jul 13 (Epub ahead of print). 
98. Griffiths M, Wardle H, Orford J, Sproston K, Erens B: Sociodemographic correlates of internet gambling: findings from the 2007 British gambling prevalence survey. Cyberpsychology \& Behavior 12(2); 2009; 199-202.

99. LaBrie RA, Kaplan SA, LaPlante Da, Nelson SE, Shaffer HJ: Inside the virtual casino: a prospective longitudinal study of actual Internet casino gambling. European Journal of Public Health 18(4); 2008; 410-416.

100. Goldmedia. Online Betting \& Gambling 2010. Marktpotenziale für OnlineGlücksspiele in Deutschland, Österreich und der Schweiz. http://www.goldmedia.com/aktuelles/info/ article/online-betting-gambling2010.html. <10 September 2009>

101. Boneva B, Kraut R, Frohlich D: Using email for personal relationships: the difference gender makes. American Behavioral Scientist 45; 2001; 530-549.

102. Yeh YC, Ko HC, Wu JY, Cheng CP: Gender differences in relationships of actual and virtual social support to Internet addiction mediated through depressive symptoms among college students in Taiwan. Cyberpsychology \& Behavior 11(4); 2008; 485-487. 



\section{Contributors}

Gabriele Fischer Prof. Dr. Gabriele Fischer is Medical Director of the Addiction Clinic, Medical University Vienna; Chair of the University Board of Medical University Innsbruck, Austria; Member of the Scientific Board for Quality Control \& Quality Management in Medicine, Austria; Member of the General Medical Council, Austria; Senior Editor of 'Addiction' and board member of other peerreviewed journals; Active Member of the European Academy of Sciences and Arts; Founding (board) member: 'Women for women: health policy in focus'; Consultant: WHO, UNO, EU, European Parliament, OSI; National and International research Grants as well as Member of National and International Societies including chair positions. Her recent publications are: Fischer G, Ortner R, Rohrmeister K, Jagsch R, Baewert A, Langer M, Aschauer H: Methadone versus Buprenorphine in Pregnant Addicts: A Double-blind, Double-dummy Comparison Study. Addiction 101; 2006; 275-281. Winklbaur B, Kopf N, Ebner N, Jung E, Thau K, Fischer G: Treating pregnant women dependent on opioids is not the same as treating pregnancy and opioid dependence: a knowledge synthesis for better treatment for women and neonates. Addiction 103; 2008; 1429-1440. Winklbaur B, Baewert A, Jagsch R, Rohrmeister K, Aeschbach Jachman C, Thau $\mathrm{K}$, Fischer G: Association between prenatal tobacco exposure and neonatal outcomes of opioid maintained pregnant women and how to handle it. European Addiction Research 15; 2009; 150-156.

Kirsten Jordan Dr. rer. nat. Kirsten Jordan is working as research assistant at the department for Forensic Psychiatry and Psychotherapy of the Georg-AugustUniversity Göttingen. Her research focuses on functional neuroanatomy of spatial cognitive and verbal processes, sex differences as well as on neurobiological and endocrinological aspects of forensic relevant disorders. Key publications are: Hausmann M, Schoofs D, Rosenthal HE, Jordan K: Interactive effects of sex 
hormones and gender stereotypes on cognitive sex differences. A psychobiosocial approach. Psychoneuroendocrinology 34; 2009; 389-401. Jordan K., Wüstenberg T: The Neural Network of Spatial Cognition and it's Modulation by Biological and Environmental Factors. Journal of Individual Differences; 2009 (in press). Jordan K., Wüstenberg T, Heinze HJ, Peters M, Jancke L: Women and men exhibit different cortical activation patterns during mental rotation tasks. Neuropsychologia 40; 2002; 2397-2408.

Ineke Klinge Dr. Ineke Klinge is associated professor of Gender Medicine at the Caphri School for Public Health and Primary Care of the Faculty of Health, Medicine and Life Sciences of Maastricht University. Her research focuses on the integration of sex and gender issues in biomedical and health related research from basic to societal level and on mainstreaming diversity and patients' perspective in health care research policies. Her empirical work contributes to theories of difference and intersectionality. Key publications are: Klinge I: Gender perspectives in European research. Pharmacological research 58(3); 2008; 183-189. Klinge I: Bringing Gender Expertise to Biomedical and Health-Related Research. Gender Medicine 4(2); 2007; 59-63. Klinge I, Bosch M: Transforming Research Methodologies in EU Life Sciences and Biomedicine. Gender-Sensitive ways of Doing Research. State of the Art. European Journal of Women's Studies 12(3); 2005; 377-395. Klinge I, Bosch M: Gender in Research. Gender Impact Assessment of the specific programmes of the Fifth Framework Programme. Quality of Life and Management of Living Resources (EUR 20017). Brussels: European Commission; 2001.

Verena Metz Verena Metz is a clinical psychologist, and working as a research assistant in the team of Prof. Gabriele Fischer at the Addiction Clinic at the Medical University of Vienna, Austria. She is currently writing her doctoral thesis on outcome parameters and neonatal abstinence syndrome in infants born to opioidmaintained mothers. Her research topics are gender medicine, particularly women's health. Her recent publications is: Metz V, Radler D, Fischer G: Sex differences in psychopharmacology: gender medicine in psychiatry. Psychiatr Psychother 2(4); 2009; 64-69.

Silke Schicktanz Prof. Dr. Silke Schicktanz is Juniorprofessor of History, Theory, and Ethics in Medicine at the University Medical School Göttingen, Germany. She teaches ethics and history in medicine as well as gender studies. Her research focuses on the relationship between ethical and socio-cultural aspects of modern medicine. Recent topics are the normative role of body and identity including gender and age, cross-cultural similarities and differences in public attitudes towards biomedicine, and normative concepts of responsibility and autonomy. Recent key publications are: Schicktanz S, Pethes N (eds): Sexuality as Experiment? Identity, Morality and Reproduction between Science and Fiction. Frankfurt/Main: Cam- 
pus; 2008 (in German). Schicktanz S, Ehm S (eds): Body as measure? Biomedicine and its impact on the meaning of body and identity. Stuttgart: Hirzel; 2006 (in German). Schicktanz S, Schweda M: "One man's trash is another man's treasure" Exploring economic and moral subtexts of the 'organ shortage' problem in public views on organ donation. Journal of Medical Ethics 35; 2009; 473-476. Raz A, Schicktanz S: Diversity and Uniformity in Genetic Responsibility: Moral Attitudes of Patients, Relatives and Lay People in Germany and Israel. Medicine, Health Care and Philosophy; 2009 (online first).

Sigrid Schmitz. Dr. habil. Sigrid Schmitz is university lecturer at the University of Freiburg/Germany (until June 2009) and at the University of Oldenburg/Gemany (from October 2009). With a study in biology her main research is on gender aspects at the intersection between computer and brain sciences within the broader scope of Gender and Science \& Technology Studies. She contributes to the development of didactic concepts for gender studies in SET-disciplines based on approaches on gender and e-learning. Since 2002 she is leading the Forum of Competence 'Gender Studies in Computer and Natural Sciences' [gin] together with Prof. Britta Schinzel. She was visiting professor at the University of Graz/Austria (2003) and at the Humboldt University of Berlin (2008). Key publications are: Kaiser A, Schmitz S. et al.: On sex/gender related similarities and differences in fMRI language research. Brain Research Reviews: doi:10.1016/j.brainresrev.2009. 03.005; 2009. Nikoleyczik K, Schmitz S: Transdisciplinary Gender-sensitive Teaching: Didactical Concepts and Technical Support. Intern. Journals of Innovation in Education (IJIIE), Special Issue: Innovation in Education: Diversity in Teaching and Learning; 2009 (in press). Ebeling S, Schmitz S: Gender Research and Sciences: Introduction to a complex interplay. Wiesbaden: VS; 2006 (in German).

Mark Schweda Mark Schweda, M.A. (philosophy), is research associate at the University of Göttingen, Department of Medical Ethics and History of Medicine. His research focuses on socio-cultural contexts of biomedicine and bioethics and on philosophical, socio-cultural and bioethical aspects of ageing. Recent publications are: Schweda M, Wöhlke S, Schicktanz S.: Understanding Public Skepticism Toward Organ Donation and Its Commercialization: The Important Role of Reciprocity. Transplantation Proceedings 41(6); 2009; 2509-2511. Schicktanz S, Schweda M: "One man's trash is another man's treasure": exploring economic and moral subtexts of the "organ shortage" problem in public views on organ donation. Journal of Medical Ethics 35; 2009; 473-476. Schweda M, Schicktanz S: Public Moralities concerning Donation and Disposition of Organs. Results from a Cross-European Study. Cambridge Quarterly of Healthcare Ethics 17(3); 2008; 5772. 
Claudia Wiesemann Claudia Wiesemann is Director of the Institute of Medical Ethics and History of Medicine at Göttingen University, Germany. She is president of the German Academy for Ethics in Medicine - an academic society devoted to the advancement of research, education and public debate in bioethics with members in Germany, Austria and Switzerland -, a member of the Central Ethics Committee for Stem Cell Research at the German Federal Ministry of Health and of the Commission for Ethics of Research With Minors of the German Academy of Pediatrics and Adolescent Medicine. She has coordinated several European research projects. Claudia Wiesemann was trained as a physician and has studied history and philosophy. Within the German Network Intersexuality, she chairs the Ethics Working Group that has currently published guidelines for the ethical management of intersexuality/DSD. Her focus of research lies on medical ethics from a cultural perspective, research ethics, gender and bioethics, and the ethics of reproductive medicine and the family. Recent publications are: Conradi E, BillerAndorno N, Boos M, Sommer C, Wiesemann C: Gender in medical ethics: Reexamining the conceptual basis of empirical research. Medicine, Health Care and Philosophy 6; 2003; 51-58. Thyen U, Richter-Appelt H, Wiesemann C, Holterhus, PM, Hiort O: Deciding on Gender in Children with Intersex Conditions. Considerations and Controversies. Treatments in Endocrinology 4/1; 2005; 1-8. Wiesemann C, Ude-Koeller C, Sinnecker GHG, Thyen U: Ethical principles and recommendations for the medical management of differences of sex development (DSD)/intersex in children and adolescents. European Journal of Pediatrics; 2009. (in print/online access)

Sabine Wöhlke Sabine Wöhlke, M.A., has studied Cultural Anthropology/European Ethnology; Gender studies, and Media Research at Georg-August-University Göttingen. Her main research topics are group-specific forms of every-day life and processes of cultural transmission in family, age-groups, community and class and gender research and women's role (feminist studies). Moreover, she is interested in qualitative methodology (relationship between theory, empirical studies and practical work experience, field research and documentation methods), with a special regard on 'focus-groups' and the mass media (television, radio, film, mass literature). Recent publications are: Wöhlke S: Theoretical considerations on donation, gift, and reciprocity in the context of living kidney transplantation. In: Potthast $\mathrm{T}$, Herrmann B, Müller B (eds): Ethical, legal, and social aspects of the commercialisation of the human body and its parts. Paderborn: Mentis; 2009; 201219. Schweda M, Wöhlke S, Schicktanz S.: Understanding Public Skepticism Toward Organ Donation and Its Commercialization: The Important Role of Reciprocity. Transplantation Proceedings 41(6); 2009; 2509-2511. 
ex and gender in biomedicine are innovative research concepts of theoretical and clinical medicine that enable a better understanding of health and disease, evidence-based knowledge, effective therapies, and better health outcomes for women and men. Gender Medicine stimulates new ways of doing research: that is to consider sex and gender at all levels of research, from basic research into gene polymorphisms to health behaviour. New research questions have been put forward that focus not on differences per se but on the development of differences. In this book, contributions from the field of neuroscience, addiction research, and organ transplantation exemplify concepts, approaches, methods and results in the field. 